Universidade de São Paulo

Faculdade de Filosofia, Ciências e Letras de Ribeirão Preto

\author{
Natália Destefano
}

Psicofísica de percepção em tomadas de decisão: a propriedade aditiva do grau de inconsistência intertemporal e uma nova proposta para a função peso de probabilidades 



\section{Natália Destefano}

Psicofísica de percepção em tomadas de decisão: a propriedade aditiva do grau de inconsistência intertemporal e uma nova proposta para a função peso de probabilidades

Tese apresentada à Faculdade de Filosofia, Ciências e Letras de Ribeirão Preto da Universidade de São Paulo como parte das exigências para a obtenção do título de Doutor em Ciências.

Área de Concentração:

Física Aplicada a Medicina e Biologia.

Orientador:

Alexandre Souto Martinez.

Ribeirão Preto 
Autorizo a reprodução e divulgação total ou parcial deste trabalho, por qualquer meio convencional ou eletrônico, para fins de estudo e pesquisa, desde que citada a fonte.

\section{FICHA CATALOGRÁFICA}

Destefano, Natália

Psicofísica de percepção em tomadas de decisão: a propriedade aditiva do grau de inconsistência intertemporal e uma nova proposta para a função peso de probabilidades / Natália Destefano; orientador: Alexandre Souto Martinez. - - Ribeirão Preto, 2013.

89 f. : il.

Tese (Doutorado) - - Faculdade de Filosofia, Ciências e Letras de Ribeirão Preto, Universidade de São Paulo, 2013.

Inclui Bibliografia.

1. tomadas de decisão. 2. efeitos psicofísicos. 3. inconsistência intertemporal. 4. função peso. 
Nome: Destefano, Natália

Título: Psicofísica de percepção em tomadas de decisão: a propriedade aditiva do grau de inconsistência intertemporal e uma nova proposta para a função peso de probabilidades

Tese apresentada à Faculdade de Filosofia, Ciências e Letras de Ribeirão Preto da Universidade de São Paulo como parte das exigências para a obtenção do título de Doutor em Ciências.

Aprovado em:

\section{Banca Examinadora}

$\operatorname{Prof}(\mathrm{a}) \cdot \operatorname{Dr}(\mathrm{a})$.

Instituição:

Julgamento:

Assinatura:

Prof(a). Dr(a). :

Instituição:

Julgamento:

Assinatura:

Prof(a). Dr(a). :

Instituição:

Julgamento:

Assinatura:

$\operatorname{Prof}(\mathrm{a}) \cdot \operatorname{Dr}(\mathrm{a})$.

Instituição:

Julgamento:

Assinatura:

$\operatorname{Prof}(\mathrm{a}) \cdot \operatorname{Dr}(\mathrm{a})$.

Instituição:

Julgamento:

Assinatura: 
Dedico este trabalho aos meus pais, Ademir e Maria. 


\section{Agradecimentos}

Ao prof. Alexandre Souto Martinez, pela orientação, amizade e confiança, fundamentais para o desenvolvimento deste trabalho, e pelo apoio e incentivo dedicados às minhas decisões profissionais. Sua experiência, conhecimentos e caráter foram essenciais para a minha formação e meu crescimento pessoal e profissional.

Ao prof. Marcelo Mulato pelo apoio durante a coordenação do programa de Física Aplicada a Medicina e Biologia e pelo incentivo à busca de minhas realizações. Seus conselhos e indicações na fase final do Mestrado foram determinantes na definição dos caminhos que me levaram a integrar o Laboratório de Modelagem em Sistemas Complexos, onde pude desenvolver este trabalho.

Aos demais professores que contribuíram para minha formação acadêmica, através da orientação em disciplinas e monitorias.

Às secretárias Nilza Marina Leone e Sônia Aparecida Nali de Paula, pela disposição e atenção proporcionadas ao longo de todo o processo de pós graduação.

Aos amigos do laboratório: Brenno Caetano Troca Cabella, Cristiano Roberto Fabri Granzotti, Enock de Almeida Andrade Neto, Fabiano Lemes Ribeiro, Fernanda Miranda de Oliveira, Juliana Militão da Silva Berbert, Lindomar Soares dos Santos, Marcelo Alves Pereira, Olavo Henrique Menin, Rodrigo Silva González e Tiago José Arruda, pelas inúmeras discussões que enriqueceram meu trabalho, pelo companheirismo diário e pelas alegrias que pude vivenciar ao lado de cada um.

À minha família, em especial aos meus pais Ademir e Maria e à minha irmã Patrícia, pelo amor, carinho e incentivo incondicionais. Vocês são a base da minha vida e a inspiração que motiva todas as minhas conquistas.

Aos amigos incríveis que fizeram parte da minha vida por todos estes anos em Ribeirão Preto. Muito obrigada por todo carinho, atenção e companheirismo que me proporcionaram momentos inesquecíveis.

Aos meus gestores Lívia Maria C. Rocha e Douglas B. Pinheiro, por permitirem a minha ausência nos momentos finais de desenvolvimento deste trabalho.

À $\operatorname{FAPESP}(09 / 17733-5)$ pelo apoio financeiro. 
"Entendi que a vida não tece apenas uma teia de perdas mas nos proporciona uma sucessão de ganhos. O equilíbrio da balança depende muito do que soubermos e quisermos enxergar."

Lya Luft 


\section{Resumo}

DESTEFANO, N. Psicofísica de percepção em tomadas de decisão: a propriedade aditiva do grau de inconsistência intertemporal e uma nova proposta para a função peso de probabilidades . 2013. 89 f. Tese (Doutorado - Programa de Pós-Graduação em Física Aplicada a Medicina e Biologia) - Faculdade de Filosofia, Ciências e Letras de Ribeirão Preto, Universidade de São Paulo, Ribeirão Preto, 2013.

Tomadas de decisão intertemporais são influenciadas não somente pelo efeito de desconto do valor em diferentes instantes, como também pelo efeito de percepção temporal. Uma das principais dificuldades que afetam experimentos padrões envolvendo estas escolhas é a simultaneidade de ambos os efeitos no processo de desconto. Através da unificação das leis da psicofísica de percepção do atraso e da associação destas às funções de desconto de valor, propusemos uma forma generalizada para o processo de desconto intertemporal envolvendo ambos os domínios. Mostramos também que a propriedade aditiva do grau de inconsistência, grandeza obtida a partir das funções de desconto, permite discriminar a influência de cada efeito no processo de tomada de decisão. De forma similar ao proposto para escolhas intertemporais, estendemos a teoria psicofísica de percepção ao domínio das probabilidades. Adotando a perspectiva de que o atraso médio para recebimento de uma recompensa está relacionado à sua probabilidade de recebimento, obtivemos uma função de desconto probabilística que abrange os efeitos de desconto de valor e de percepção de probabilidades. Em paralelo ao desenvolvimento no domínio experimental, exploramos também os modelos teóricos (axiomáticos) que fundamentam as tomadas de decisão probabilísticas. Propusemos que a forma da função peso de probabilidades, exploradas em modelos como a teoria da utilidade esperada dependente da ordenação e a teoria do prospecto acumulado, seja representada pela função de desconto generalizada que obtivemos a partir dos modelos comportamentais. Neste caso, a função peso é amparada por modelos comportamentais de decisão e deriva da suposição de que indivíduos se comportam de forma similar frente a probabilidades e atrasos.

Palavras-chave: 1. tomadas de decisão. 2. efeitos psicofísicos. 3. inconsistência intertemporal. 4. função peso. 


\section{Abstract}

DESTEFANO, N. Psychophysics of perception in decision making: the additive property of the intertemporal degree of inconsistency and a new proposal for the probability weighting function. 2013. $89 \mathrm{f}$. Thesis (Ph.D. Postgraduate program in Physics Applied to Medicine and Biology) - Faculty of Philosophy, Sciences and Letters, University of São Paulo, Ribeirão Preto, 2013.

Intertemporal decision making are influenced not only by the effect of the reward value discount at different moments, but also by the time perception effect. One of the main difficulties that affects standard experiments involving intertemporal choices is the simultaneity of both effects on the discount. Through the unification of the psychophysical laws of delay perception and their association to the value discounting functions, we proposed a generalized process for the intertemporal discount involving both domains. We also showed that the additive property of the inconsistency degree, quantity obtained from the discount functions, allowed us to distinguish between both effects in decision making. As proposed for intertemporal choices, we extended the psychophysical perception theory to the probabilities domain. Adopting the perspective that the average delay for receiving a reward is related to the probability of receiving it, we obtained a probabilistic discount function covering value discounting and probability perception. Parallel to the experimental development, we also explored theoretical models that underlie probabilistic decision making. We proposed that the shape of the probability weighting function, explored in models such as rank-dependent expected utility theory and cumulative prospect theory, should be described by the generalized probabilistic function that we obtained from the behavioral models. Therefore, the weighting function is supported by behavioral models and derives from the assumption that subjects behave similarly in front of probabilities and delays.

Key-words: 1. decision making. 2. psychophysical effects. 3. intertemporal inconsistency. 4. weighting function. 


\section{Lista de Figuras}

1.1 Esquema ilustrando as interações entre as grandezas valor, tempo e probabilidade em tomadas de decisão. . . . . . . . . . . . . . . . 2

2.1 Esquema ilustrando as interações entre as grandezas valor, tempo e probabilidade em tomadas de decisão. Exploramos inicialmente modelos comportamentais sobre tomadas de decisão envolvendo valor e tempo........................... 6

2.2 Curva de desconto hipotética para uma recompensa de $V_{0}=\mathrm{R} \$ 10$. Os pontos indicados no gráfico correspondem a valores subjetivos (ou pontos de indiferença) da recompensa para cada atraso especificado. Neste caso, receber $\mathrm{R} \$ 6$ imediatamente é equivalente a receber $\mathrm{R} \$ 10$ em um mês, ou seja, $\mathrm{R} \$ 6$ é o valor subjetivo da recompensa de $\mathrm{R} \$ 10$ para o atraso de um mês. . . . . . . . . . . . . . . . . . . . . 7

2.3 Preferência ao longo do tempo em escolhas intertemporais. O parâmetro $S$ representa o instante de recebimento de uma recompensa menor, entregue com menor atraso, enquanto $L$ representa o instante do recebimento de uma recompensa maior, porém tardia. No modelo exponencial (a), as curvas de desconto de ambas as recompensas não se cruzam e a preferência do indivíduo não depende do instante da escolha. No modelo hiperbólico (b), as curvas de decaimento se cruzam em $A$ : se a escolha é feita em algum instante posterior a $A$, a recompensa menor e mais imediata será preferida; se a escolha for realizada em algum instante anterior a $A$, a recompensa maior e tardia será preferida, caracterizando escolhas inconsistentes. . . . . . . . . . 14 
3.1 Esquema ilustrando as interações entre as grandezas valor, tempo e probabilidade em tomadas de decisão. Adotamos a perspectiva de que o atraso médio para recebimento de uma recompensa está relacionado à sua probabilidade de recebimento e exploramos modelos comportamentais sobre tomadas de decisão envolvendo valor e probabilidade. 26

3.2 Esquema ilustrando o lançamento consecutivo de um dado. Após $n$ lançamentos, a face 6 é obtida e uma recompensa é entregue. Nesta configuração, $c$ representa a duração de cada lançamento, $d$ o tempo entre dois lançamentos consecutivos e $t$ o intervalo de tempo médio entre o primeiro e o $n$-ésimo lançamento. . . . . . . . . . . . . . . 27

3.3 Desconto generalizado em função de $\Theta$ para diferentes valores de $\tilde{q}$ e $s$ : (a) Modelos sem percepção psicofísica $(s=1)$; (b) Desconto exponencial $(\tilde{q}=0)$ associado a diferentes funções de percepção $(s$ variável); (c) Descontos exponencial $(\tilde{q}=0)$ e hiperbólico $(\tilde{q}=1)$ associados a diferentes funções de percepção. Para todos os casos foram mantidos $k=1, a=5$ e $b=0,001 \ldots \ldots 34$

4.1 Esquema ilustrando as interações entre as grandezas valor, tempo e probabilidade em tomadas de decisão. Exploramos modelos teóricos sobre tomadas de decisão envolvendo valor e probabilidade. . . . . . . 36

4.2 Função utilidade hipotética para tomadores de decisão (estritamente)

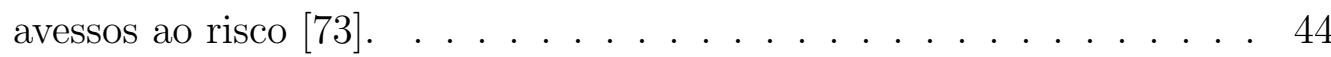

4.3 Função utilidade hipotética para tomadores de decisão (estritamente) propensos ao risco $[73] \ldots \ldots \ldots \ldots$. . . . . . . . . . . . . 45

4.4 Função utilidade hipotética para tomadores de decisão neutros ao $\operatorname{risco}[73] . \ldots \ldots \ldots \ldots$

5.1 Domínios da teoria da utilidade não-esperada. O domínio convencional consiste primariamente de críticas ao axioma da independência. $\mathrm{O}$ domínio não-convencional explora críticas à suposição de que escolhas podem ser representadas por funções de preferência bem definidas. . . 51 
5.2 Forma hipotética da função de ponderação de probabilidades. $\pi(p)=$ $p$ somente para $p=p^{*}$, sendo côncava para $p<p^{*}$ e convexa para $p>p^{*}$. Quiggin [81] propôs $p^{*}=0,5 \ldots \ldots \ldots$. . . . . . 56

5.3 Representação esquemática das teorias convencionais da NEUT, as quais consistem primariamente de críticas às violações do axioma da independência da EUT.

5.4 Formulações (a) sequencial e (b) final de um jogo de duas etapas envolvendo prospectos. . . . . . . . . . . . . . . . . . 59

5.5 Função de valor hipotética proposta por Kahneman e Tversk [64]. . . 61

5.6 Função peso hipotética proposta por Kahneman e Tversky [64]. . . . 63

5.7 Representação esquemática dos domínios convencionais e nãoconvencionais da NEUT. . . . . . . . . . . . . . . . . . . . . . 64

5.8 Funções peso para ganhos $\left(\pi^{+}\right)$e perdas $\left(\pi^{-}\right)$obtidas por Kahneman e Tversky no desenvolvimento da CPT [83] . . . . . . . . . . . . . 66

6.1 Formas paramétricas para a função peso: Linear: $\pi(p)=p$; Tversky e Kahneman [Eq. (6.1)]: $\gamma=0,61$; Wu e Gonzalez [Eq. 6.2]: $\delta=0,84$ e $\gamma=0,68$; Prelec [Eq. 6.3]: $\alpha=0,74 \ldots \ldots 72$

6.2 Função generalizada da forma de $\pi(p)$ proposta por Wu e Gonzalez [Eq. (6.9)]: $k_{\tilde{q}}=1,19$ e $b=0,68$, para $\tilde{q}$ variando de 0 a $2 \ldots 73$

6.3 Função generalizada da forma proposta por Prelec [Eq. (6.11)]: $k_{\tilde{q}} a=$ 1 e $b=0,74$, para $\tilde{q}$ variando de 0 a $1 \ldots \ldots 75$

6.4 Formas paramétricas para a função peso: Linear: $\pi(p)=p$; Tversky e Kahneman [Eq. (6.1)]: $\gamma=0,61$; Wu e Gonzalez [Eq. (6.2)]: $\delta=0,84$ e $\gamma=0,68$; Prelec [Eq. (6.3)]: $\alpha=0,74$; Forma proposta [Eq. (6.13)]: $s=2, \tilde{q}=4, k_{\tilde{q}}=100, a=1.7$ e $b=0.05$. 
xviii 


\section{Lista de Tabelas}

2.1 Modelos de desconto em escolhas intertemporais. Os subíndices 0,1 e $\tilde{q}$ representam os modelos de desconto exponencial, hiperbólico e $\tilde{q}$-generalizado, respectivamente. Os subíndices $f, s$ e $u$ representam as percepções do atraso tipo Weber-Fechner, Stevens e a unificação destas leis, respectivamente. Note que, de todas as associações, somente cinco casos já foram considerados na literatura: os três modelos sem efeito de percepção temporal (exponencial, hiperbólico e $\tilde{q}$-generalizado) e a associação do desconto exponencial às percepções de Weber-Fechner e Stevens. . . . . . . . . . . . . . . . . . . . . 22

3.1 Modelos de desconto em escolhas probabilísticas. Os subíndices 0, 1 e $\tilde{q}$ representam os modelos de desconto exponencial, hiperbólico e q-generalizado, respectivamente. Os subíndices $f, s$ e $u$ representam as percepções de $\Theta$ seguindo as leis de Weber-Fechner, Stevens e a unificação destas, respectivamente. . . . . . . . . . . . . . . . 33

4.1 Exemplo de dominância estocástica. Um par de loterias é descrito pelo percentual de bolinhas de gude de diferentes cores e pelo valor de perda ou ganho associado à cor da bolinha a ser sorteada aleatoriamente $[75] \ldots \ldots \ldots \ldots$. . . . . . . . . . . . . . . . . . . . . 41

4.2 Verificação da dominância estocástica da loteria $\vec{L}_{B}$ sobre a loteria $\vec{L}_{A} \cdot 42$

5.1 Problema da doença asiática proposto por Tversky e Kahneman: para o grupo I, o cenário é apresentado em termos de vidas salvas; para o

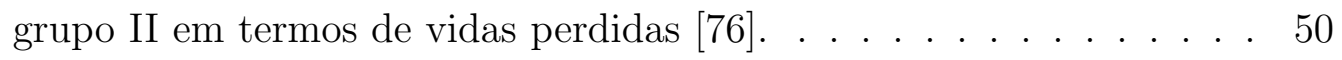


6.1 Formas funcionais e parâmetros empiricamente estimados para a função peso de probabilidades [84]. . . . . . . . . . . . . . . . . . 71 


\section{Sumário}

$\begin{array}{ll}\text { Lista de Figuras } & \text { Xv }\end{array}$

Lista de Tabelas $\quad$ xix

1 Introdução 1

2 Decisões intertemporais 5

2.1 Funções de desconto . . . . . . . . . . . . . . . . 6

2.1.1 Experimentos .................... 7

2.1.2 Funções exponencial e hiperbólica . . . . . . . . . . . 10

2.2 Impulsividade e grau de inconsistência . . . . . . . . . . . . . . . 12

2.2.1 Modelos exponencial e hiperbólico . . . . . . . . . . . . 13

2.2 .2 Outros modelos . . . . . . . . . . . . . . . . . . . . 14

2.3 Efeitos psicofísicos de percepção do atraso . . . . . . . . . . . . . . . 16

2.3.1 Weber-Fechner . . . . . . . . . . . . . . 17

2.3 .2 Stevens . . . . . . . . . . . . . . . . . . 18

2.4 Resultados . . . . . . . . . . . . . . . . . . 19

2.4.1 Unificação das funções de percepção . . . . . . . . . . . . . . 20

2.4.2 Propriedade aditiva da inconsistência . . . . . . . . . . . 23

3 Decisões probabilísticas $\quad 25$

3.1 Funções de desconto . . . . . . . . . . . . . . . . . . . . . 25

3.2 Resultados . . . . . . . . . . . . . . . . . . . 31

4 Teoria da utilidade esperada 35

4.1 Primórdios e proposição . . . . . . . . . . . . . . . . 35 
xxii

4.2 Bases axiomáticas . . . . . . . . . . . . . . . . . . . . 39

$\begin{array}{lll}5 & \text { Teorias da utilidade não-esperada } & 47\end{array}$

5.1 Anomalias da utilidade esperada . . . . . . . . . . . . . . . 48

5.2 Teorias convencionais . . . . . . . . . . . . . . 51

5.3 Teorias não-convencionais . . . . . . . . . . . . . . 55

5.4 Teoria do prospecto acumulado . . . . . . . . . . . . . . 64

6 Formas funcionais da função peso: uma nova proposta 69

$\begin{array}{lll}7 & \text { Conclusões } & 77\end{array}$

$\begin{array}{ll}\text { Referências } & 79\end{array}$ 


\section{Capítulo}

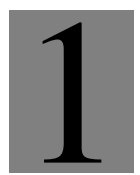

\section{Introdução}

Em contraste com os princípios da Física, a Economia é baseada em uma série de axiomas que somente nas últimas décadas têm sido explorados por experimentos. Isto leva ao surgimento de uma série de limitações e desvios quando modelos econômicos padrões são testados empiricamente [1]. Em sua maioria, a revisão destes problemas e a formulação de novos modelos envolvem um contexto interdisciplinar, onde se torna importante a conexão entre diferentes áreas tais como a economia, a física, a psicologia, dentre outras.

Escolhas são relativamente predizíveis quando as alternativas diferem somente em uma dimensão [2]. Por exemplo, indivíduos sujeitos a uma escolha entre duas recompensas que diferem somente em quantidade geralmente optam pela alternativa de maior valor. Se as recompensas diferem apenas em probabilidade, indivíduos, em geral, optam pela recompensa mais provável. Ou ainda, indivíduos sujeitos a escolhas em que as recompensas diferem apenas no intervalo de tempo a ser esperado até o seu recebimento (atraso) tendem a escolher a recompensa mais imediata. Entretanto, problemas cotidianos frequentemente envolvem escolhas que diferem em mais de uma dimensão. As preferências de indivíduos em relação a estas escolhas multidimensionais, em geral, não são facilmente predizíveis. Em áreas como a neuroeconomia, a econofísica e a sociofísica, um dos problemas centrais a serem explorados é entender como indivíduos tomam suas decisões frente a estas questões multidimensionais. Neste trabalho, exploramos escolhas envolvendo três dimensões: valor, tempo e probabilidade (Fig. 1.1).

Tomadas de decisão intertemporais envolvem escolhas entre opções cujas con- 


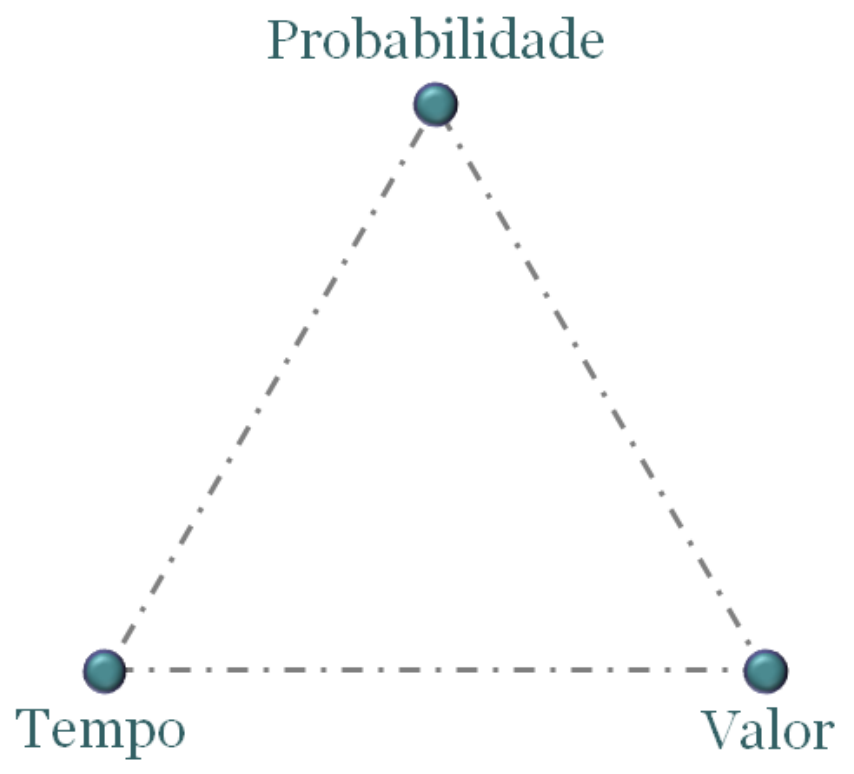

Figura 1.1 - Esquema ilustrando as interações entre as grandezas valor, tempo e probabilidade em tomadas de decisão.

sequências ocorrem em diferentes instantes. Nestas escolhas, recompensas tardias são descontadas (ou desvalorizadas) em relação às imediatas. Exemplos típicos de tomadas de decisão intertemporais bidimensionais, que envolvem as grandezas valor e tempo, são questões em que indivíduos devem escolher entre uma recompensa menor, porém mais imediata, e outra maior, entregue posteriormente.

De forma semelhante, tomadas de decisão probabilísticas envolvem escolhas entre opções cujas consequências diferem em relação a suas probabilidades de recebimento. Do ponto de vista do desconto, recompensas incertas são descontadas em relação às certas. Em escolhas probabilísticas, em geral, indivíduos devem escolher entre uma recompensa menor, a ser recebida com maior probabilidade, e outra maior, porém menos provável. Nestes casos tem-se problemas bidimensionais, envolvendo as grandezas valor e probabilidade.

Em economia, a teoria da utilidade esperada (EUT) [3], proposta por Bernoulli em 1738, e a teoria da utilidade descontada (DUT) [4], proposta por Samuelson em 1937, são modelos normativos tradicionalmente aceitos, respectivamente, para a descrição de tomadas de decisão probabilísticas e intertemporais. Paralelas em estrutura, ambas as teorias surgiram inicialmente devido à simplicidade 
de suas formulações e à similaridade destas aos cálculos financeiros tradicionais de valor atuarial e valor presente [5]. A posterior axiomatização da EUT e da DUT, respectivamente, por Von Neumann e Morgenstern [6] e por Koopmans [7], forneceram uma série de suposições plausíveis que fundamentaram ambas as teorias, incentivando a dominância destas como modelos padrões de tomada de decisão. Entretanto, paralelamente ao desenvolvimento axiomático, pesquisadores propuseram um número crescente de problemas de escolha que violaram sistematicamente as suposições da EUT. Estas evidências levaram ao desenvolvimento de novos modelos teóricos, chamados teorias da utilidade não-esperada (NEUT), que procuraram incorporar as anomalias apresentadas pelo modelo padrão. Em paralelo ao desenvolvimento teórico envolvendo escolhas intertemporais e probabilísticas, inúmeros trabalhos experimentais também foram desenvolvidos em ambos os domínios. Estes estudos levaram à proposição de modelos comportamentais que, baseados em experimentos, buscam descrever o comportamento dos indivíduos frente a tomadas de decisão multidimensionais.

Embora o início do desenvolvimento dos modelos teóricos seja anterior aos modelos comportamentais, na apresentação deste trabalho exploramos inicialmente o domínio dos modelos comportamentais. Esta abordagem (não cronológica) facilita a compreensão e interpretação dos resultados apresentados. No Capítulo 2, descrevemos conceitos e resultados da literatura experimental (modelos comportamentais) envolvendo tomadas de decisão intertemporais. Mostramos também os resultados relacionados ao tema obtidos durante o desenvolvimento deste trabalho, os quais foram publicados no periódico Physica A: Statistical Mechanics and its Applications, intitulado The additive property of the inconsistency degree in intertemporal decision making through the generalization of psychophysical laws [8]. No Capítulo 3, a literatura experimental envolvendo tomadas de decisão entre recompensas probabilísticas é apresentada. Revisamos que as mesmas formas matemáticas descrevem adequadamente os resultados empíricos relacionados ao desconto intertemporal (em função do atraso) e ao desconto probabilístico, o que levanta a hipótese de um processo único envolvendo preferências intertemporais e probabilísticas. Propomos, então, a extensão de nossos resultados referentes a escolhas intertemporais ao domínio das probabilidades. A partir do domínio experimental envolvendo tomadas de 
decisão intertemporais é possível obter formas analíticas que representem o comportamento de indivíduos frente a escolhas probabilísticas. No Capítulo 4, passamos ao domínio dos modelos teóricos envolvendo tomadas de decisão probabilísticas. Uma revisão bibliográfica dos primórdios da teoria da utilidade esperada, sua proposição e posterior axiomatização são apresentados. Esta teoria tornou-se popular entre os economistas e passou a ser tradicionalmente aceita como um modelo normativo para descrição de tomadas de decisão sob incerteza. No Capítulo 5, descrevemos alguns problemas de escolha que mostraram que a EUT é sistematicamente violada e introduzimos as teorias da utilidade não-esperada. No Capítulo 6, mostramos que a forma analítica que propusemos para descontos probabilísticas pode também ser explorada no domínio teórico da utilidade não-esperada. O Capítulo 7 apresenta as conclusões deste trabalho. 


\section{Capítulo}

\section{Decisões intertemporais}

Neste capítulo exploramos modelos comportamentais sobre tomadas de decisão envolvendo valor e tempo (Fig. 2.1). Iniciamos pela descrição das funções de desconto e de experimentos padrões envolvendo a determinação destas funções em escolhas intertemporais. Apresentamos dois modelos que objetivam descrever o processo de desconto em função do atraso de uma recompensa observado experimentalmente: o exponencial e o hiperbólico. Em seguida, introduzimos a impulsividade e a inconsistência, dois conceitos importantes no contexto das escolhas intertemporais, que fornecem ferramentas básicas para comparação entre os modelos. Além disso, descrevemos as leis da psicofísica e a associação dos chamados efeitos psicofísicos de percepção aos modelos de desconto intertemporal. Por fim, apresentamos os resultados relacionados ao tema que obtivemos durante o desenvolvimento deste trabalho: (i) a unificação das leis da psicofísica de Weber-Fechner e de Stevens para o atraso, utilizando a função logarítmica da mecânica estatística não-extensiva e, (ii) a proposição de uma solução para o problema da dependência entre os efeitos de desconto de valor e de percepção do atraso nas funções de desconto, a partir da propriedade aditiva do grau de inconsistência. 


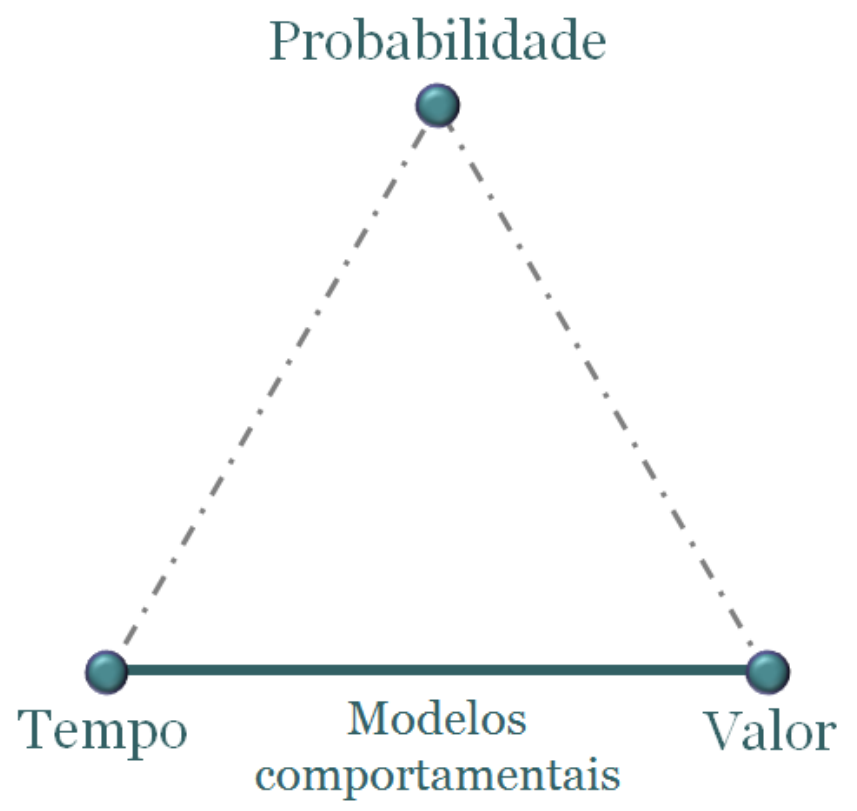

Figura 2.1 - Esquema ilustrando as interações entre as grandezas valor, tempo e probabilidade em tomadas de decisão. Exploramos inicialmente modelos comportamentais sobre tomadas de decisão envolvendo valor e tempo.

\subsection{Funções de desconto}

Indivíduos sujeitos a escolhas intertemporais enfrentam um conflito entre a utilidade (ou valor) de uma recompensa imediata e a de uma tardia. Por exemplo, escolher entre $R \$ 10$ hoje ou $R \$ 15$ daqui a um mês. Em tomadas de decisão intertemporais, o intervalo temporal entre o instante presente e o instante de entrega da recompensa é chamado de atraso [9]. No exemplo acima, $\mathrm{R} \$ 10$ hoje corresponde à recompensa imediata (com atraso nulo) e $\mathrm{R} \$ 15$ daqui a um mês corresponde à recompensa tardia, entregue com um atraso de um mês.

Estudos levaram a um forte consenso de que recompensas tardias $(V)$ são descontadas (ou desvalorizadas) em relação a recompensas imediatas $\left(V_{0}\right)$ [2]. O valor (ou utilidade) de uma recompensa $V$ diminui à medida que o tempo até o seu recebimento (atraso) aumenta. A Fig. 2.2 mostra um exemplo hipotético do desconto do valor de uma recompensa de $\mathrm{R} \$ 10$ em função do atraso. O valor não descontado (real) de uma dada recompensa é chamado valor objetivo. No exemplo da Fig. 2.2, a recompensa imediata vale $V_{0}=\mathrm{R} \$ 10$. O valor a ser recebido imediatamente que é 
equivalente ao recebimento de $V_{0}$ no atraso especificado é chamado valor subjetivo da recompensa ou ponto de indiferença.

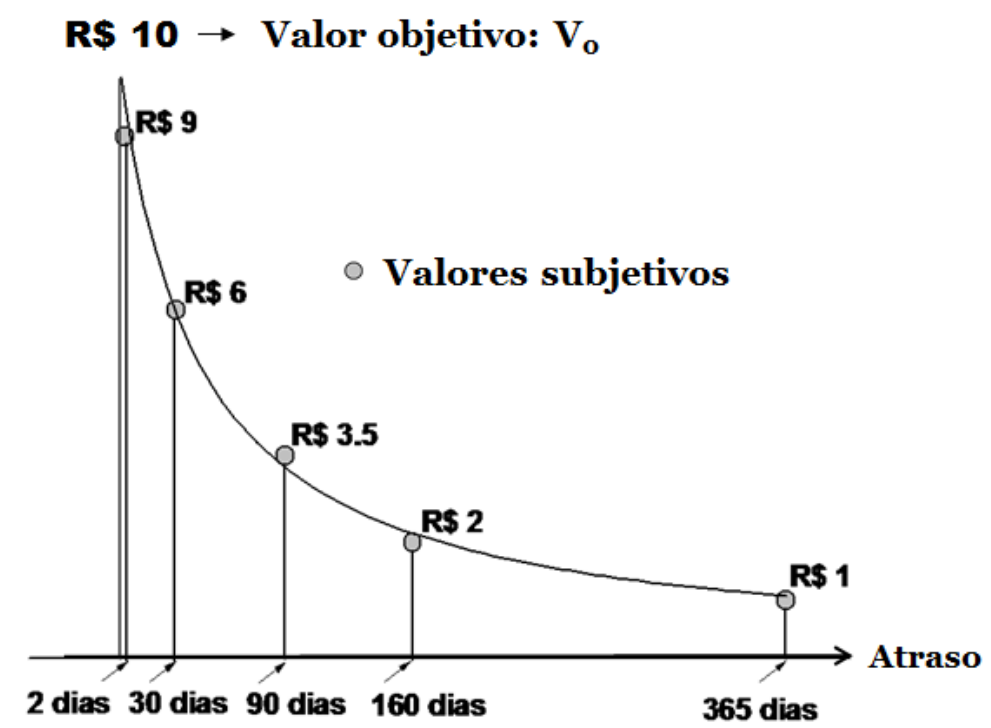

Figura 2.2 - Curva de desconto hipotética para uma recompensa de $V_{0}=\mathrm{R} \$ 10$. Os pontos indicados no gráfico correspondem a valores subjetivos (ou pontos de indiferença) da recompensa para cada atraso especificado. Neste caso, receber $\mathrm{R} \$ 6$ imediatamente é equivalente a receber $\mathrm{R} \$ 10$ em um mês, ou seja, $\mathrm{R} \$ 6$ é o valor subjetivo da recompensa de $\mathrm{R} \$ 10$ para o atraso de um mês.

O comportamento do valor subjetivo de uma recompensa em função do atraso, $V(t)$, é analisado por modelos de decaimento chamados funções de desconto. A curva de desconto é caracterizada por uma função monotônica decrescente cujo valor assintótico é nulo.

\subsubsection{Experimentos}

Experimentos com seres humanos e animais têm sido realizados para a determinação dos pontos de indiferença $[10,11,12,13,14,15,16]$. Em geral, em experimentos envolvendo o desconto intertemporal com humanos, os participantes 
escolhem entre duas recompensas monetárias: uma de menor valor porém entregue imediatamente e outra de maior valor entregue com um determinado atraso. Para cada atraso estudado, o experimento inicia-se com o mesmo valor para ambas as recompensas, de modo que o participante opte pela recompensa imediata. O valor da recompensa tardia é mantido constante enquanto a recompensa imediata tem seu valor diminuído. O participante realiza, então, uma nova tomada de decisão entre as recompensas imediata e tardia. Esse procedimento é repetido até que a recompensa tardia seja preferida à recompensa imediata. O último valor de recompensa imediata escolhido, $V_{d}$, é então descrito como o ponto de indiferença para o atraso analisado. Em alguns experimentos, a fim de evitar uma possível influência da ordem de apresentação das recompensas, o procedimento inverso também é analisado: inicia-se o experimento a partir do menor valor para a recompensa imediata, de modo que a recompensa tardia seja preferida à imediata. A recompensa imediata é, então, incrementada até que seu primeiro valor, $V_{s}$, seja escolhido. O ponto de indiferença, nestes casos, é obtido a partir da média entre $V_{d}$ e $V_{s}$. Vários pontos de indiferença obtidos para diferentes atrasos são ajustados e descritos por funções de desconto, como mostrado na Fig. 2.2.

$\mathrm{Na}$ maior parte dos experimentos envolvendo escolhas intertemporais utilizam-se recompensas hipotéticas. Além disso, os atrasos não são vivenciados pelo indivíduo no decorrer do experimento. Esse tipo de procedimento tem a vantagem de ser barato e eficiente do ponto de vista temporal.

Para verificar a validade dos resultados obtidos, entretanto, alguns estudos têm comparado dados experimentais de procedimentos envolvendo recompensas hipotéticas e reais. Neste último caso, uma resposta é selecionada aleatoriamente entre todas as escolhas realizadas por um determinado indivíduo, de modo que este possa receber uma recompensa real de acordo com o valor e o atraso escolhidos [17]. Até um trabalho recente desenvolvido por Johnson e Bickel [18], nenhum experimento havia analisado os mesmos indivíduos em ambas as condições (real e hipotética). Neste estudo, não foram observadas diferenças significativas entre procedimentos reais e hipotéticos. Entretanto, deve-se considerar que os valores de recompensa e os atrasos utilizados nos procedimentos reais foram menores que os utilizados em experimentos hipotéticos. Madden et al. [19] analisaram os mesmos valores de re- 
compensa e atraso para ambos os procedimentos. Em todos os casos o valor objetivo da recompensa foi de $\$ 10$. Novamente, não foram observadas diferenças significativas entre ambos os procedimentos.

Apesar dos resultados encontrados, ainda não pode-se afirmar que os experimentos hipotéticos possam substituir experimentos reais em estudos envolvendo tomadas de decisão intertemporais. Devido à utilização de recompensas e atrasos muito pequenos em experimentos reais, novos trabalhos são necessários para a extensão deste resultado para maiores valores de recompensa e atrasos mais longos. Além disso, deve-se considerar a possível influência da repetição sequencial do experimento: para que ambas as condições (real e imaginária) sejam avaliadas para o mesmo indivíduo, é necessária a realização do mesmo procedimento por no mínimo duas vezes (sequenciais) para cada participante. Neste caso, a independência entre as respostas de ambos os questionários não é garantida.

Existe ainda uma terceira categoria de experimentos sobre desconto que consiste de medidas em tempo real. Essas medidas diferem de ambos os experimentos descritos até então porque os participantes vivenciam as consequências associadas a suas escolhas (isto é, atraso e recompensa) em tempo real, enquanto completam a avaliação [20, 21, 22]. Esse tipo de experimento envolve menores atrasos (<90 s) e menores recompensas $(<\$ 0.50)$ em comparação com os demais testes [23]. Medidas em tempo real podem auxiliar melhor os pesquisadores na determinação de variações de curto prazo no desconto temporal como, por exemplo, o tempo de percurso da droga ou os efeitos decorrentes dela em dependentes químicos [24, 25, 26]. Além disso medidas em tempo real são ferramentas mais adequadas para a análise de desconto em crianças, pois a abstração necessária para avaliar atrasos e recompensas neste caso é menor quando comparado aos experimentos descritos anteriormente. Apesar das possíveis vantagens deste método, seu uso é menos comum quando comparado ao dos outros dois experimentos, em parte pelo aumento do gasto e do tempo necessários para realização do procedimento [23].

Além da variação associada ao tipo de recompensa (real ou hipotética), o procedimento padrão para estudo de escolhas intertemporais permite o surgimento de outras possíveis fontes de variabilidade, tais como:

1. efeito da ordem de apresentação (ascendente ou descendente) das recompensas 
imediatas [27];

2. efeito da ordem de apresentação (ascendente ou descendente) dos atrasos [28];

3. efeito do sinal, que sugere diferentes graus de desconto para perdas e ganhos [29];

4. efeito da magnitude da recompensa, que sugere diferentes graus de desconto para diferentes valores de recompensa [30].

Um aspecto ainda não tão bem explorado nestes experimentos é a extensão à qual participantes podem automaticamente julgar as recompensas tardias como incertas. Em geral, a incerteza sobre a entrega dessas recompensas não é especificada nas questões de desconto propostas. Patak e Reynolds em [31] utilizaram um procedimento em que imediatamente após as medidas convencionais de desconto em relação ao atraso, os participantes receberam um formulário em que foram indagados sobre suas noções de incerteza relacionadas às recompensas tardias avaliadas. Como resultado, foi encontrada uma boa correlação $(r=0.55)$ entre a incerteza e o grau de desconto de recompensas tardias.

As medidas de desconto são projetadas para indexar a desvalorização de recompensas tardias especificamente como função do atraso até a sua entrega. Entretanto, como descrito anteriormente, os experimentos padrões para medidas de $V(t)$ são influenciados por uma série de fatores de variabilidade. Estes fatores dificultam a análise dos resultados obtidos, e consequente elaboração de modelos comportamentais, visto que não é possível isolar o atraso como única variável no processo de desconto. Portanto, estes experimentos precisam ser revistos e reformulados para facilitar a interpretação dos processos envolvidos nas tomadas de decisão intertemporais.

\subsubsection{Funções exponencial e hiperbólica}

Apesar da dificuldade de se medir $V(t)$, diversos modelos comportamentais têm sido estudados na tentativa de estabelecer uma função matemática (função de desconto) que descreva adequadamente o processo de desconto em função do 
atraso observado experimentalmente. A princípio serão descritas duas das principais funções propostas na literatura: a exponencial e a hiperbólica.

Na teoria econômica padrão, assim como uma conta bancária aumenta a partir de uma taxa de juros fixa ao longo do tempo, o valor presente de uma recompensa futura decresce a uma proporção fixa por unidade de atraso. Neste caso, o desconto do valor real (objetivo) de uma recompensa no tempo é caracterizado por um modelo de decaimento exponencial [4]:

$$
V_{0 n}(t)=V_{0} e^{-k_{0} t}
$$

sendo $t, V_{0 n}(t)$ e $V_{0}$, respectivamente, o atraso, o valor subjetivo e o valor objetivo (real) da recompensa. A grandeza $k_{0}$ é a taxa com que um indivíduo desconta recompensas tardias e tem como unidade o inverso do tempo. Maiores valores de $k_{0}$ correspondem a curvas de desconto com decaimento mais acentuado. Neste modelo, a preferência entre duas recompensas intertemporais não depende de quando a escolha é realizada. Se as recompensas forem deslocadas de um mesmo intervalo de tempo, a preferência entre estas não sofre alteração.

Entretanto, resultados experimentais $[17,19,22,32,33,34]$ mostram que o desconto do valor de uma recompensa em função do atraso é melhor descrito por uma função hiperbólica [14]:

$$
V_{1 n}(t)=\frac{V_{0}}{1+k_{1} t}
$$

sendo $t, V_{1 n}(t)$ e $V_{0}$, respectivamente, o atraso, o valor subjetivo e o valor objetivo (real) da recompensa, e $k_{1}$ um parâmetro livre, que também tem o inverso do tempo como unidade.

A seguir introduziremos alguns conceitos utilizados no contexto das escolhas intertemporais. Estes conceitos são fundamentais para entender algumas características do desconto intertemporal que levam à sua melhor descrição por uma função hiperbólica (e não exponencial). 


\subsection{Impulsividade e grau de inconsistência}

A impulsividade em escolhas intertemporais é definida como a grande preferência por recompensas menores e imediatas a recompensas maiores e tardias [11]. Por exemplo, suponha a seguinte questão: "Você prefere $\mathrm{R} \$ 10$ daqui a um ano ou $\mathrm{R} \$ 15$ daqui a um ano e uma semana?". Se um indivíduo A preferir a primeira opção $(\mathrm{R} \$ 10$ daqui a um ano) enquanto um indivíduo B preferir a segunda opção ( $\mathrm{R} \$ 15$ daqui a um ano e uma semana), diz-se que o indivíduo A é mais impulsivo que o indivíduo B, pois A prefere uma recompensa menor porém mais imediata, enquanto B prefere esperar um intervalo de tempo maior a fim de receber uma recompensa maior. Para evitar as diferentes conotações atribuídas ao termo "impulsividade", será utilizada a definição de "taxa de desconto" como uma medida de impulsividade no contexto das tomadas de decisão intertemporais. A taxa de desconto em escolhas intertemporais é definida por [11]:

$$
I=-\frac{d(\ln V)}{d t}=-\frac{1}{V} \frac{d V}{d t}
$$

a variação relativa da função de desconto $V$. O comportamento contrário à impulsividade é definido como auto controle.

Retomando o exemplo anterior (em que o indivíduo A é mais impulsivo que o indivíduo B), considere agora a seguinte questão: "Você prefere $\mathrm{R} \$ 10$ hoje ou $\mathrm{R} \$$ 15 daqui uma semana?". Se o indivíduo B (que escolheu a segunda opção na questão anterior) agora preferir a primeira opção ( $\mathrm{R} \$ 10$ hoje), sua escolha intertemporal é dita dinamicamente inconsistente, visto que, nas duas situações questionadas, o mesmo ganho ( $\mathrm{R} \$ 5)$ é obtido em intervalos de tempo iguais (uma semana).

Experimentos envolvendo seres humanos e animais [12, 30, 35, 36, 37, 38, 39] têm demonstrado que indivíduos tendem a preferir recompensas menores e imediatas num futuro próximo porém tendem a preferir recompensas maiores e tardias no futuro distante. Essa preferência reversa ao longo do tempo é referida como inconsistência dinâmica em escolhas intertemporais [11]. O parâmetro que mede o grau de inconsistência foi definido por Prelec em 2004 [40] e interpretado por Takahashi, 
em 2010, como a variação temporal de $I$ :

$$
\mathbb{I}=\frac{d I}{d t},
$$

sendo $I$ a taxa de desconto relativa definida pela Eq. (2.3).

\subsubsection{Modelos exponencial e hiperbólico}

Definidos a taxa de desconto e o grau de inconsistência no contexto das escolhas intertemporais, voltemos à análise das funções de desconto exponencial e hiperbólica. Para o modelo de desconto exponencial, a taxa de desconto é constante em função do atraso:

$$
I_{0 n}(t)=k_{0}
$$

e, portanto, o grau de inconsistência é nulo:

$$
\mathbb{I}_{0 n}(t)=0
$$

Para o modelo de desconto hiperbólico, a taxa de desconto é uma função decrescente de $t$ :

$$
I_{1 n}(t)=\frac{k_{1}}{\left(1+k_{1} t\right)} .
$$

O valor de uma recompensa é fortemente descontado em atrasos relativamente pequenos, mas é descontado de forma mais moderada com o aumento do atraso. Para este modelo, o grau de inconsistência é não-nulo e pode ser escrito como função da taxa de desconto $\left(I_{1 n}\right)$ :

$$
\mathbb{I}_{1 n}(t)=-\left[\frac{k_{1}}{1+k_{1} t}\right]^{2}=-\left[I_{1 n}(t)\right]^{2}=\mathbb{H}\left[I_{1 n}(t)\right] .
$$

sendo $\mathbb{H}(I)=-I^{2}$.

Considere o desconto de duas recompensas: uma recompensa menor, entregue com menor atraso, e uma maior, porém tardia (maior atraso). No modelo exponencial, em que a taxa de desconto é constante, as curvas de desconto de ambas as recompensas não se cruzam, de modo que a preferência entre elas não se altera, 
independente do instante em que a tomada de decisão é realizada [Fig. 2.3(a)]. Portanto, o modelo exponencial não é capaz de descrever a inconsistência observada experimentalmente em decisões intertemporais. Para o caso da função hiperbólica, a taxa de desconto é inversamente proporcional ao atraso e resulta em curvas de desconto que se cruzam [Fig. 2.3(b)]. Neste caso, a preferência entre as recompensas depende do momento em que a decisão é tomada. Assim, ao contrário do modelo exponencial, o modelo hiperbólico é capaz de descrever a inconsistência intertemporal.

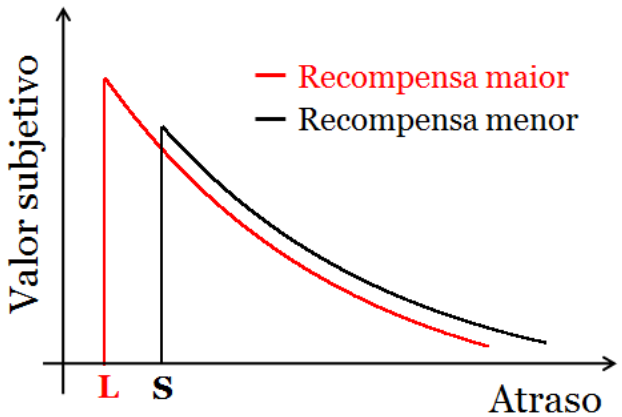

(a) Modelo exponencial

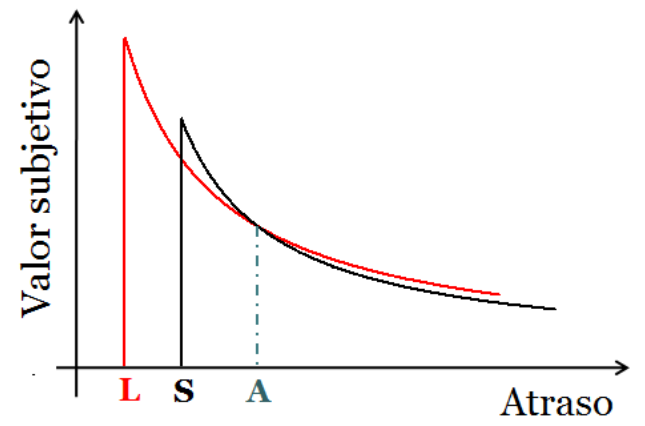

(b) Modelo hiperbólico

Figura 2.3 - Preferência ao longo do tempo em escolhas intertemporais. O parâmetro $S$ representa o instante de recebimento de uma recompensa menor, entregue com menor atraso, enquanto $L$ representa o instante do recebimento de uma recompensa maior, porém tardia. No modelo exponencial (a), as curvas de desconto de ambas as recompensas não se cruzam e a preferência do indivíduo não depende do instante da escolha. No modelo hiperbólico (b), as curvas de decaimento se cruzam em $A$ : se a escolha é feita em algum instante posterior a $A$, a recompensa menor e mais imediata será preferida; se a escolha for realizada em algum instante anterior a $A$, a recompensa maior e tardia será preferida, caracterizando escolhas inconsistentes.

\subsubsection{Outros modelos}

Embora o modelo hiperbólico descreva melhor o desconto intertemporal que o exponencial, os dados obtidos experimentalmente ainda não são ajustados adequadamente pelo modelo. Ele superestima o valor subjetivo de uma recompensa para pequenos atrasos, enquanto o subestima para grandes atrasos [2]. Rachlin [41] 
sugeriu uma função de desconto em que o valor do atraso é elevado a uma potência $g: V(t)=V_{0} /\left(1+k_{1} t^{g}\right)$. Esta função é um caso particular do modelo hiperbólico de Mazur, pois $V_{1 n}\left(t^{g}\right)=V_{0} /\left(1+k_{1} t^{g}\right)$. Myerson e Green [42] sugeriram uma equação hiperbólica mais geral, em que o denominador é elevado a uma potência dada $g$ :

$$
V(t)=\frac{V_{0}}{\left(1+k_{1} t\right)^{g}} .
$$

Mckerchar et al. [34] ajustaram estas funções aos dados de um experimento envolvendo tomadas de decisão intertemporais e mostraram que os modelos de Rachlin e Myerson-Green fornecem um ajuste mais adequado aos resultados experimentais que os modelos exponencial e hiperbólico.

Baseado em argumentos da termodinâmica não-extensiva [43], Tsallis, em 1994, propôs uma generalização das funções logarítmica e exponencial usuais [44]. A função q̃-exponencial é descrita por:

$$
\exp _{\tilde{q}}(x)=\left\{\begin{array}{lr}
\lim _{\tilde{q}^{\prime} \rightarrow \tilde{q}}\left(1+\tilde{q}^{\prime} x\right)^{1 / \tilde{q}^{\prime}}, & \text { se } \tilde{q} x \geq-1 \\
0, & \text { caso contrário }
\end{array}\right.
$$

sendo $\tilde{q}$ um parâmetro livre, $\exp _{\tilde{q}}(x)=e^{x}$ quando $\tilde{q}=0$ e $\exp _{\tilde{q}}(0)=1$, para todos os valores de $\tilde{q}$. O inverso da função $\tilde{q}$-exponencial, chamada função $\tilde{q}$-logaritmo, é definida como:

$$
\ln _{\tilde{q}}(x)=\lim _{\tilde{q}^{\prime} \rightarrow \tilde{q}} \frac{x^{\tilde{q}^{\prime}}-1}{\tilde{q}^{\prime}}
$$

sendo $\tilde{q}$ um parâmetro livre, $\ln _{\tilde{q}}(x)=\ln (x)$ quando $\tilde{q}=0$ e $\ln _{\tilde{q}}(1)=0$. As funções generalizadas representadas pelas Eqs.(2.10) e (2.11) já foram interpretadas geometricamente [45] e podem ser aplicadas, por exemplo, em dinâmica de populações [46, 47, 48] e em distribuições usuais de sistemas complexos [49, 50, 51, 52, 53].

Em 2006, a partir da Eq. (2.10), Cajueiro [54] propôs uma função de desconto q-generalizada, definida como:

$$
V_{\tilde{q} n}(t)=\frac{V_{0}}{\exp _{\tilde{q}}\left(k_{\tilde{q}} t\right)}=\frac{V_{0}}{\left(1+\tilde{q} k_{\tilde{q}} t\right)^{1 / \tilde{q}}},
$$

sendo $V_{0}$ o valor objetivo da recompensa e $k_{\tilde{q}}$ um parâmetro de impulsividade em $t=0$. Para $\tilde{q}=0$, a Eq. (2.12) é equivalente à função de desconto exponencial 
[Eq. (2.1)]. Para $\tilde{q}=1$, ela é equivalente à função de desconto hiperbólica [Eq. (2.2)]. Escrevendo $\tilde{q}=1 / g$ e $k_{\tilde{q}}=g k_{1}$, obtém-se o modelo de Myerson e Green [Eq. (2.9)].

Para o modelo $\tilde{q}$-generalizado, a taxa de desconto relativa é escrita como:

$$
I_{\tilde{q} n}(t)=\frac{k_{\tilde{q}}}{\left[\exp _{\tilde{q}}\left(k_{\tilde{q}} t\right)\right]^{\tilde{q}}},
$$

e o grau de inconsistência pode então ser expresso por:

$$
\mathbb{I}_{\tilde{q} n}(t)=\frac{-k_{\tilde{q}}^{2} \tilde{q}}{\left(1+k_{\tilde{q}} \tilde{q} t\right)^{2}}=\tilde{q} \mathbb{H}\left[I_{\tilde{q} n}(t)\right] .
$$

A Eq.(2.14) pode ser separada em três casos distintos [52]:

(a) $\mathbb{I}_{\tilde{q} n}<0$ para $\tilde{q}>0$ (impulsividade decrescente);

(b) $\mathbb{I}_{\tilde{q} n}=0$ para $\tilde{q}=0$ (desconto exponencial, escolhas intertemporais consistentes);

(c) $\mathbb{I}_{\tilde{q} n}>0$ para $\tilde{q}<0$ (impulsividade crescente).

O modelo de Cajueiro unifica os modelos acima descritos, mas não fornece uma interpretação fundamental para o parâmetro $\tilde{q}$. Uma interpretação psicofísica para os parâmetros $\tilde{q}$ e $k_{\tilde{q}}$ foi descrita por Takahashi [11] e será explorada na seção a seguir.

\subsection{Efeitos psicofísicos de percepção do atraso}

Diversas linhas teóricas atribuem o processo de desconto observado em tomadas de decisão intertemporais a mudanças na avaliação do valor de uma recompensa em diferentes instantes. Entretanto, trabalhos recentes $[55,56,57,58]$ analisam o processo de desconto sob uma nova perspectiva que foca também no efeito da percepção do atraso. Essa nova perspectiva enfatiza que indivíduos, ao formarem suas preferências intertemporais, estimam intervalos de tempo de forma não-objetiva. Assim, o processo de desconto envolvendo escolhas intertemporais engloba não somente o desconto do valor das recompensas em diferentes instantes, como também o efeito da percepção do atraso. 


\subsubsection{Weber-Fechner}

Apesar de sugeridas empiricamente, a Eq. (2.12) somente foi melhor explorada por Takahashi et al. [55]. Os autores incluíram os chamados efeitos psicofísicos de percepção do atraso ao processo de desconto em tomadas de decisão intertemporais.

A razão (invariante) entre estímulos que alcançam a possibilidade de serem discriminados - chamados estímulos supraliminares - foi medida por Weber em 1834. Posteriormente, Fechner (1860) expressou formalmente essa invariância na fração de Weber $(w)$, conhecida como a primeira lei da psicofísica: $w=\Delta \phi / \phi_{p}=$ $\left(\phi_{c}-\phi_{p}\right) / \phi_{p}$, sendo $\phi_{c}$ e $\phi_{p}$ estímulos perceptíveis de uma dada modalidade sensorial, havendo entre eles um limiar $\Delta \phi \neq 0$ [59]. A fração de Weber é adimensional e pode ser expressa como um percentual do estímulo padrão, o qual é específico para cada modalidade sensorial [59].

Possivelmente, há uma dependência entre a capacidade de uma espécie discriminar estímulos de uma dada modalidade sensorial e a constância no processo de expansão ou contração da sensação em relação à realidade física [59]. Segundo Fechner, a relação entre percepção e estímulo é descrita como sendo logarítmica. Essa relação é conhecida como segunda lei da psicofísica ou lei de Weber-Fechner. A lei de Weber-Fechner pode ser aplicada a diversos estímulos sensoriais, tais como as percepções auditiva, visual, térmica, tátil, gustativa ou olfativa.

Takahashi et al. [10] propuseram a percepção logarítmica do atraso a partir da relação:

$$
\tau(t)=a \ln (1+b t)
$$

sendo $\tau$ o intervalo de tempo subjetivo e as grandezas $a$ e $b$ parâmetros psicofísicos.

Se um indivíduo desconta recompensas tardias exponencialmente, mas com uma percepção subjetiva do atraso seguindo a lei de Weber-Fechner, seu desconto temporal é descrito por [55]:

$$
V_{0 f}(t)=V_{0} e^{-k_{0} \tau}=V_{0} e^{-k_{0} a \ln (1+b t)}=\frac{V_{0}}{(1+b t)^{g}},
$$

sendo $b$ e $g=k_{0} a$ parâmetros livres. A taxa de desconto para este caso pode ser 
escrita como:

$$
I_{0 f}(t)=\frac{b g}{1+b t} .
$$

Note que $I_{0 f}$ é uma função decrescente de $t$ quando $b$ e $g$ forem positivos, resultando em preferência reversa ao longo do tempo. O grau de desconto neste caso é dado por:

$$
\mathbb{I}_{0 f}(t)=-\frac{b I_{0 f}(t)}{1+b t}=\mathbb{F}\left[I_{0 f}(t)\right] .
$$

sendo $\mathbb{F}(I)=(-b I) /(1+b t)$.

A generalização de modelos a partir das funções $\tilde{q}$-logaritmo e $\tilde{q}$-exponencial tem atraído a atenção de pesquisadores em diversos contextos [46, 47, 49, 51, 52, 53]. Uma das dificuldades que acompanham estas generalizações, entretanto, é a interpretação do parâmetro q̃ em relação aos parâmetros que descrevem os fenômenos estudados. Na Eq. (2.12), utilizando as relações $\tilde{q}=1 /\left(k_{0} a\right)$ e $k_{\tilde{q}}=k_{0} a b$, verifica-se que este modelo é matematicamente equivalente ao modelo de desconto exponencial com a percepção temporal do tipo Weber-Fechner. Essa equivalência permite uma interpretação para $\tilde{q}$ e $k_{\tilde{q}}$ a partir dos parâmetros psicofísicos $b$ e $k_{0} a$ [11].

Takahashi et al. [10] realizaram experimentos envolvendo escolhas intertemporais e os seus parâmetros foram estimados. O modelo descrito pela Eq. (2.16) foi o que melhor descreveu os valores experimentais quando comparado aos modelos exponencial e hiperbólico. Esse resultado está de acordo com o obtido em trabalhos similares [2].

\subsubsection{Stevens}

A relação entre percepção e estímulo em psicofísica foi também analisada por Stevens [60]. Para Stevens, a relação entre percepção e estímulo é dada por uma lei de potência, conhecida como a terceira lei da psicofísica ou lei de Stevens.

A percepção do atraso segundo uma lei de potência pode ser expressa por:

$$
\tau(t)=c(1+b t)^{s}-c,
$$

sendo $c$ e $s>0$ parâmetros psicofísicos. 
Takahashi et al. [10] foram os primeiros autores a proporem um modelo de desconto temporal incorporando a lei de potência para percepção do atraso: $\tau_{s}(t)=$ $c t^{s}$. A forma proposta pelos autores, entretanto, ao contrário da Eq. (2.19), não permite uma abordagem da propriedade aditiva do grau de inconsistência, a qual será discutida na Seção 2.4.2.

Se um indivíduo desconta recompensas tardias exponencialmente, mas com uma percepção subjetiva do atraso seguindo a lei de Stevens, seu desconto intertemporal é descrito por:

$$
V_{0 s}(t)=V_{0} e^{-k_{p}(1+b t)^{s}-k_{p}},
$$

sendo $k_{p}=k_{0} c$ e $s$ parâmetros livres. Para este caso, a taxa de desconto é função decrescente de $t$ quando $s<1$ e $k_{p}>0$ :

$$
I_{0 s}(t)=k_{p} b s(1+b t)^{s-1} .
$$

O grau de inconsistência para este modelo é:

$$
\mathbb{I}_{0 s}(t)=k_{p} s b^{2}(s-1)(1+b t)^{s-2}=\frac{b(s-1) I_{0 s}}{1+b t}=(1-s) \mathbb{F}\left[I_{0 s}(t)\right] .
$$

\subsection{Resultados}

Uma das principais dificuldades encontradas experimentalmente na determinação das funções de desconto é a simultaneidade com que os efeitos de desconto do valor e de percepção do atraso agem sobre o processo de desconto em tomadas de decisão intertemporais. A análise independente da influência de cada efeito não é permitida pelos experimentos padrões utilizados para medir diretamente estas funções. A seguir descreveremos dois resultados obtidos durante o desenvolvimento deste trabalho. O primeiro resultado consiste em uma abordagem particular e inédita de unificação das leis de Weber-Fechner e de Stevens aplicadas à percepção do atraso, obtida mediante o uso da função q̃-logaritmo. Em seguida, mostraremos que o grau de inconsistência (I) permite uma independência entre os efeitos de desconto do valor e de percepção do atraso. 


\subsubsection{Unificação das funções de percepção}

Uma bem sucedida tentativa de unificação das leis de Weber-Fechner e de Stevens foi feita por Wong e Norwich em 1997 [61]. É apresentada aqui uma abordagem particular e inédita desta unificação para a percepção do atraso, realizada mediante o uso da função $\tilde{q}$-logaritmo. A partir da Eq. (2.19) pode-se escrever: $(\tau) / s=\left[c(1+b t)^{s}-c\right] / s=c\left[(1+b t)^{s}-1\right] / s$. Utilizando-se essa relação e a definição da função logaritmo generalizada [Eq. (2.11)], pode-se reescrever a Eq. (2.19) como:

$$
\tau(t)=a \ln _{s}(1+b t)
$$

sendo $a=c s$. Tomemos a constante $a$ como uma grandeza independente de $s$ e $c$. Esta equação corresponde a uma unificação das Eqs. (2.15) e (2.19), em que para o caso particular $s=0$ obtém-se a lei de percepção de Weber-Fechner para o atraso e para os demais casos obtém-se a forma da lei de Stevens.

A forma unificada das funções de percepção do atraso [Eq. (2.23)] pode ser utilizada em associação com os modelos de desconto exponencial e hiperbólico. As funções:

$$
\begin{aligned}
V_{0 u}(t) & =\frac{V_{0}}{\exp \left[k_{0} a \ln _{s}(1+b t)\right]} \\
I_{0 u}(t) & =\frac{-d \ln V_{0 u}}{d t}=\frac{I_{0}^{(0)}\left[s \ln _{s}(1+b t)+1\right]}{1+b t} \\
\mathbb{I}_{0 u}(t) & =\frac{d I_{0 u}}{d t}=\frac{b(s-1)}{1+b t} I_{0 u}(t)=(1-s) \mathbb{F}\left[I_{0 u}(t)\right],
\end{aligned}
$$

sendo $I_{0}^{(0)}=k_{0} a b$, correspondem ao desconto exponencial. Para o desconto hiperbólico:

$$
\begin{aligned}
V_{1 u}(t) & =\frac{V_{0}}{1+k_{1} a \ln _{s}(1+b t)} \\
I_{1 u}(t) & =\frac{-d \ln V_{0 u}}{d t}=\frac{I_{0}^{(1)}\left[s \ln _{s}(1+b t)+1\right]}{\left[1+k_{1} a \ln _{s}(1+b t)\right](1+b t)} \\
\mathbb{I}_{1 u}(t) & =\frac{d I_{0 u}}{d t}=-I_{1 u}^{2}-\frac{b}{1+b t} I_{1 u}(t)=\mathbb{H}\left(I_{1 u}\right)+(1-s) \mathbb{F}\left[I_{1 u}(t)\right]
\end{aligned}
$$

sendo $I_{0}^{(1)}=k_{1} a b$.

Além disso, a partir das Eqs. (2.23) e (2.12) pode-se obter uma função generalizada para o processo de desconto envolvendo a psicofísica da percepção do 
atraso:

$$
V_{\tilde{q} u}(t)=\frac{V_{0}}{\exp _{\tilde{q}}\left[k_{\tilde{q}} a \ln _{s}(1+b t)\right]}
$$

As expressões para impulsividade e inconsistência para este modelo generalizado são:

$$
I_{\tilde{q} u}(t)=\frac{I_{0}^{(\tilde{q})}\left[s \ln _{s}(1+b t)+1\right]}{\left\{\exp _{\tilde{q}}\left[k_{\tilde{q}} a \ln _{s}(1+b t)\right]\right\} \tilde{q}(1+b t)},
$$

sendo $I_{0}^{(\tilde{q})}=I_{\tilde{q} u}(0)=k_{\tilde{q}} a b, \mathrm{e}$

$$
\mathbb{I}_{\tilde{q} u}(t)=-\tilde{q} I_{\tilde{q} u}^{2}(t)+\frac{(s-1) b}{1+b t} I_{\tilde{q} u}(t)=\tilde{q} \mathbb{H}\left[I_{\tilde{q} u}(t)\right]+(1-s) \mathbb{F}\left[I_{\tilde{q} u}(t)\right] .
$$

A partir da Eq. (2.30) pode-se obter modelos particulares através da variação dos parâmetros $\tilde{q}$ e $s$. A Tabela 2.1 sumariza as possíveis combinações entre os modelos de desconto sem percepção (exponencial, hiperbólico e $\tilde{q}$-generalizado) e as funções de percepção do atraso (tipo Weber-Fechner e Stevens), incluindo a equação de unificação das leis proposta neste trabalho. 
Tabela 2.1 - Modelos de desconto em escolhas intertemporais. Os subíndices 0, 1 e $\tilde{q}$ representam os modelos de desconto exponencial, hiperbólico e $\tilde{q}$ generalizado, respectivamente. Os subíndices $f, s$ e $u$ representam as percepções do atraso tipo Weber-Fechner, Stevens e a unificação destas leis, respectivamente. Note que, de todas as associações, somente cinco casos já foram considerados na literatura: os três modelos sem efeito de percepção temporal (exponencial, hiperbólico e $\tilde{q}$-generalizado) e a associação do desconto exponencial às percepções de Weber-Fechner e Stevens.

$$
\mathbb{H}(I)=-I^{2} ; \mathbb{F}(I)=-b I /(1+b t)
$$

\begin{tabular}{|c|c|c|c|c|}
\hline & & Desconto exponencial (0) & Desconto hiperbólico (1) & Desconto $\tilde{q}$-generalizado $(\tilde{q})$ \\
\hline \multirow{4}{*}{ 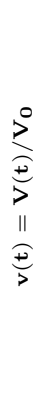 } & Sem percepção (n) & $v_{0 n}=\exp \left(-k_{0} t\right)$ & $v_{1 n}=\frac{1}{1+k_{1} t}$ & $v_{\tilde{q} n}=\frac{1}{\exp _{\tilde{q}}\left(k_{\tilde{q}} t\right)}$ \\
\hline & Weber-Fechner $(f)$ & $v_{0 f}=\frac{1}{(1+b t)^{g}}$ & $v_{1 f}=\frac{1}{1+k_{1} a \ln (1+b t)}$ & $v_{\tilde{q} f}=\frac{1}{\exp _{\tilde{q}}\left[k_{\tilde{q}} a \ln (1+b t)\right]}$ \\
\hline & Stevens $(s)$ & $v_{0 s}=\frac{1}{\exp \left[k_{0} a \ln _{s}(1+b t)\right]}$ & $v_{1 s}=\frac{1}{1+k_{1} a \ln _{s}(1+b t)}$ & $v_{\tilde{q} s}=\frac{1}{\exp _{\tilde{q}}\left[k_{\tilde{q}} a \ln _{s}(1+b t)\right]}$ \\
\hline & Forma unificada $(u)$ & $v_{0 u}=\frac{1}{\exp \left[k_{0} a \ln _{s}(1+b t)\right]}$ & $v_{1 u}=\frac{1}{1+k_{1} a \ln _{s}(1+b t)}$ & $v_{\tilde{q} u}=\frac{1}{\exp _{\tilde{q}}\left[k_{\tilde{q}}^{a} \ln _{s}(1+b t)\right]}$ \\
\hline \multirow{4}{*}{ 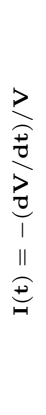 } & Sem percepção (n) & $I_{0 n}=k_{0}$ & $I_{1 n}=\frac{k_{1}}{1+k_{1} t}$ & $I_{\tilde{q} n}=\frac{k_{\tilde{q}}}{\left[\exp _{\tilde{q}}\left(k_{\tilde{q}} t\right)\right]^{\tilde{q}}}$ \\
\hline & Weber-Fechner $(f)$ & $I_{0 f}=\frac{k_{0} a b}{1+b t}$ & $I_{1 f}=\frac{k_{1} a b}{(1+b t)\left[1+k_{1} a \ln (1+b t)\right]}$ & $I_{\tilde{q} f}=\frac{k_{\tilde{q}} a b}{\left\{\exp _{\tilde{q}}\left[k_{\tilde{q}^{a}} \ln (1+b t)\right]\right\}^{\tilde{q}}(1+b t)}$ \\
\hline & Stevens $(s)$ & $I_{0 s}=\frac{I_{0}^{(0)}\left[s \ln _{s}(1+b t)+1\right]}{1+b t}$ & $I_{1 s}=\frac{I_{0}^{(1)}\left[s \ln _{s}(1+b t)+1\right]}{\left[1+k_{1} a \ln _{s}(1+b t)\right](1+b t)}$ & $I_{\tilde{q} s}=\frac{I_{0}^{(\tilde{q})}\left[s \ln _{s}(1+b t)+1\right]}{\left\{\exp _{\tilde{q}}\left[k_{\tilde{q}} a \ln _{s}(1+b t)\right]\right\} \tilde{q}(1+b t)}$ \\
\hline & Forma unificada $(u)$ & $I_{0 u}=\frac{I_{0}^{(0)}\left[s \ln _{s}(1+b t)+1\right]}{1+b t}$ & $I_{1 u}=\frac{I_{0}^{(1)}\left[s \ln _{s}(1+b t)+1\right]}{\left[1+k_{1} a \ln _{s}(1+b t)\right](1+b t)}$ & $I_{\tilde{q} u}=\frac{I_{0}^{(\tilde{q})}\left[s \ln _{s}(1+b t)+1\right]}{\left\{\exp _{\tilde{q}}\left[k_{\tilde{q}} a \ln _{s}(1+b t)\right]\right\}^{\tilde{q}}(1+b t)}$ \\
\hline \multirow{4}{*}{ 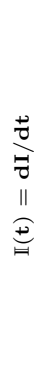 } & Sem percepção (n) & $\mathbb{I}_{0 n}=0$ & $\mathbb{I}_{1 n}=\mathbb{H}\left(I_{1 n}\right)$ & $\mathbb{I}_{\tilde{q} n}=\tilde{q} \mathbb{H}\left(I_{\tilde{q} n}\right)$ \\
\hline & Weber-Fechner $(f)$ & $\mathbb{I}_{0 f}=\mathbb{F}\left(I_{0 f}\right)$ & $\mathbb{I}_{1 f}=\mathbb{H}\left(I_{1 f}\right)+\mathbb{F}\left(I_{1 f}\right)$ & $\mathbb{I}_{\tilde{q} f}=\tilde{q} \mathbb{H}\left(I_{\tilde{q} f}\right)+\mathbb{F}\left(I_{\tilde{q} f}\right)$ \\
\hline & Stevens $(s)$ & $\mathbb{I}_{0 s}=(1-s) \mathbb{F}\left(I_{0 s}\right)$ & $\mathrm{I}_{1 s}=\mathbb{H}\left(I_{1 s}\right)+(1-s) \mathbb{F}\left(I_{1 s}\right)$ & $\mathrm{I}_{\tilde{q} s}=\tilde{q} \mathrm{H}\left(I_{\tilde{q} s}\right)+(1-s) \mathbb{F}\left(I_{\tilde{q} s}\right)$ \\
\hline & Forma unificada $(u)$ & $\mathbb{I}_{0 u}=(1-s) \mathbb{F}\left(I_{0 u}\right)$ & $\mathbb{I}_{1 u}=\mathbb{H}\left(I_{1 u}\right)+(1-s) \mathbb{F}\left(I_{1 u}\right)$ & $\mathbb{I}_{\tilde{q} u}=\tilde{q} \mathbb{H}\left(I_{\tilde{q} u}\right)+(1-s) \mathbb{F}\left(I_{\tilde{q} u}\right)$ \\
\hline
\end{tabular}




\subsubsection{Propriedade aditiva da inconsistência}

A partir da associação dos modelos de desconto de valor e de percepção do atraso, encontramos que, para cada combinação, é possível separar as funções que descrevem a inconsistência em duas partes: uma descrevendo o efeito do desconto de valor e a outra o efeito de percepção do atraso. Além disso, a medida total do grau de inconsistência é obtida a partir da soma destas duas parcelas. Para uma melhor compreensão, considere a Tabela 2.1. Sua primeira coluna relaciona o modelo de desconto exponencial aos efeitos psicofísicos da percepção do atraso. Para estes casos, o grau de inconsistência reflete somente a contribuição do efeito de percepção temporal, uma vez que o grau de inconsistência para o modelo exponencial é nulo. Similarmente, a primeira linha das expressões referentes ao grau de inconsistência reflete somente o efeito do desconto de valor. Para as demais associações, o grau de inconsistência total é composto pela soma das componentes de cada efeito. Por exemplo, o modelo de desconto hiperbólico em associação com a percepção do atraso tipo Weber-Fechner tem como resultante um grau de inconsistência total $\left(\mathbb{I}_{1 f}\right)$ composto pela soma dos termos referentes ao desconto hiperbólico $\left[\mathbb{H}\left(I_{1 f}\right)\right]$ e à percepção de Weber-Fechner $\left[\mathbb{F}\left(I_{1 f}\right)\right]$. Ambas as componentes podem ser escritas em função da taxa de desconto $\left(I_{1 f}\right)$, sendo $\mathbb{H}(I)=-I^{2}$ e $\mathbb{F}(I)=-b I /(1+b t)$.

Esse resultado mostra que, uma vez que a grandeza que permite a independência entre ambos os efeitos é a inconsistência, a determinação direta desta é que favorecerá o entendimento dos fatores que estão envolvidos no processo de desconto e suas respectivas contribuições. As expressões para $V$ e $I$ podem, então, ser obtidas a partir da integração sucessiva de II. 


\section{Capítulo}

\section{Decisões probabilísticas}

No capítulo anterior nos preocupamos em descrever escolhas intertemporais, nas quais tomadores de decisão enfrentam um conflito entre uma recompensa menor, mais imediata, e uma recompensa maior, porém tardia. Na próxima seção focamos em tomadas de decisão envolvendo valor e probabilidade, como mostrado na Fig. 3.1, adotando a perspectiva de que o atraso médio $(t)$ para recebimento de uma recompensa está relacionado à sua probabilidade de recebimento $(p)$. Apresentamos alguns modelos que têm sido propostos e analisados na tentativa de estabelecer uma função matemática que represente o processo de desconto probabilístico. Revisamos que são as mesmas formas matemáticas que descrevem adequadamente o desconto intertemporal e o probabilístico. Propomos, então, a extensão das leis da psicofísica à percepção de probabilidades, estendendo nossos resultados referentes às escolhas intertemporais ao domínio das tomadas de decisão probabilísticas.

\subsection{Funções de desconto}

A idéia de que pessoas se comportam de forma similar frente a probabilidades e atrasos foi inicialmente proposta por Rotter em 1954 [33]. Segundo Rotter, as pessoas escolhem uma recompensa menor mais imediata a uma recompensa maior porém tardia porque atrasos agem como probabilidades. Em 1986, Rachlin et al. [62] notaram que, em eventos probabilísticos repetidos, o atraso médio para recebimento de uma recompensa está relacionado à probabilidade dessa recompensa da forma:

$$
t=\frac{d+c}{p}-d
$$




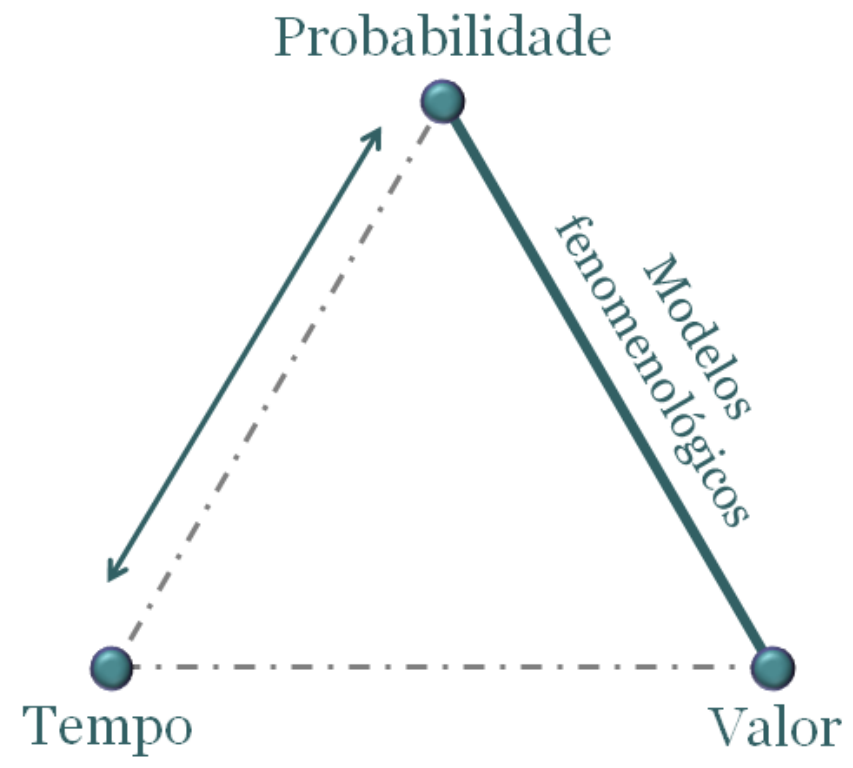

Figura 3.1 - Esquema ilustrando as interações entre as grandezas valor, tempo e probabilidade em tomadas de decisão. Adotamos a perspectiva de que o atraso médio para recebimento de uma recompensa está relacionado à sua probabilidade de recebimento e exploramos modelos comportamentais sobre tomadas de decisão envolvendo valor e probabilidade.

sendo $t$ o intervalo de tempo médio de espera entre a escolha (início da primeira jogada) e a ocorrência do evento (recebimento da recompensa), $p$ a probabilidade do evento, $d$ o intervalo de tempo entre diferentes jogadas, e $c$ a duração de cada jogada. Considere, por exemplo, $n$ lançamentos consecutivos de um dado não viciado $(p=1 / 6)$ em que uma recompensa é entregue quando a face 6 for obtida (Fig. 3.2). Neste caso, $c$ representa a duração de cada lançamento, $d$ o intervalo de tempo entre dois lançamentos consecutivos e $t$ o intervalo de tempo médio entre o primeiro e o $n$-ésimo lançamento (face 6 para cima), onde a recompensa é entregue. '

Se $c$ é pequeno em relação a $t, t=d / p-d=d[(1 / p)-1]=d \Theta$, sendo:

$$
\Theta=\frac{1-p}{p}=\frac{1}{p}-1=-\ln _{-1}(p)
$$

A forma $\ln _{-1}(p)$ representa o logaritmo generalizado [Eq. (2.11)] de $p$, para $\tilde{q}=-1$. Em jogos de repetição, $\Theta$ representa o número médio de perdas esperadas antes que uma vitória ocorra. Observe que, para $p=1, \Theta=0$, para $p=1 / 2, \Theta=1$ e para 


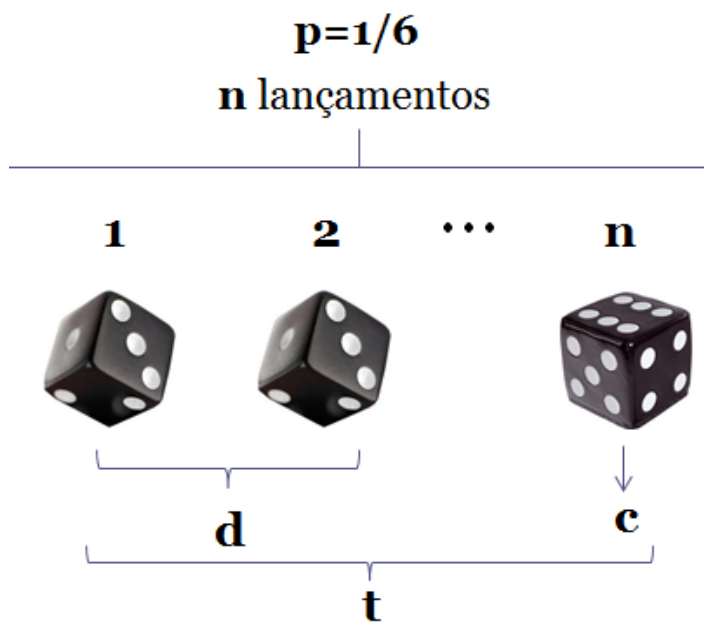

Figura 3.2 - Esquema ilustrando o lançamento consecutivo de um dado. Após $n$ lançamentos, a face 6 é obtida e uma recompensa é entregue. Nesta configuração, $c$ representa a duração de cada lançamento, $d$ o tempo entre dois lançamentos consecutivos e $t$ o intervalo de tempo médio entre o primeiro e o $n$-ésimo lançamento.

$p=0, \Theta \rightarrow \infty$. A grandeza $\Theta$ não é simétrica em relação a $p=1 / 2$.

A substituição do atraso $(t)$ pela expressão acima nas funções exponencial e hiperbólica, descritas anteriormente para o desconto temporal, resulta em [33]:

$$
\begin{aligned}
& V_{0 n p}(\Theta)=V_{0} e^{-h_{0} \Theta}, \\
& V_{1 n p}(\Theta)=\frac{V_{0}}{1+h_{1} \Theta},
\end{aligned}
$$

sendo $V_{0}$ o valor objetivo da recompensa, $V_{0 n p}(\Theta)$ e $V_{1 n p}(\Theta)$ valores subjetivos, e $h_{0}$ e $h_{1}$ parâmetros de aversão ao risco. Estas equações representam as funções de desconto exponencial e hiperbólica para o caso de tomadas de decisão envolvendo recompensas probabilísticas. De forma semelhante ao descrito para escolhas intertemporais, no modelo de desconto exponencial, a preferência entre duas recompensas probabilísticas não depende da faixa de probabilidade em que a escolha é realizada. O modelo de desconto hiperbólico, entretanto, permite escolhas probabilísticas inconsistentes. Assim como um indivíduo pode escolher a alternativa maior e mais arriscada quando a probabilidade de receber ambas as recompensas é bem pequena, o mesmo indivíduo pode optar pela recompensa menor e mais certa quando as pro- 
babilidades de recebê-las aumentarem proporcionalmente. Esse tipo de reversão das preferências é similar ao paradoxo proposto por Allais em 1940 [63] e ao efeito certeza proposto por Kahneman e Tversky em 1979 [64], os quais serão explorados no próximo capítulo.

É importante notar que o conceito de impulsividade no domínio probabilístico difere do descrito para descontos temporais. A impulsividade em escolhas intertemporais é definida como a grande preferência por recompensas menores e imediatas a recompensas maiores e tardias. Essa definição determina que, no contexto do desconto temporal, um indivíduo A, que é mais impulsivo que um indivíduo $\mathrm{B}$, desconta recompensas tardias mais fortemente, de modo que a taxa de desconto temporal do indivíduo A é maior que a do indivíduo B. No contexto do desconto probabilístico, entretanto, indivíduos mais impulsivos são relacionados a menores taxas de desconto, ou seja, descontam recompensas probabilísticas de forma mais amena que indivíduos que apresentam auto-controle [65]. O comportamento impulsivo, neste caso, leva à propensão ao risco, até mesmo quando pequenas probabilidades são consideradas.

Assim como resultados experimentais [17, 19, 22, 32, 33, 34] mostram que o desconto do valor de uma recompensa em função do atraso é melhor descrito por uma função hiperbólica, Rachlin et al. [62] verificaram experimentalmente que o modelo hiperbólico também descreve o desconto de recompensas probabilísticas de forma mais precisa que o modelo exponencial. Este resultado foi replicado por Green et al. [65].

Alternativamente, em analogia ao modelo que Myerson e Green propuseram para o desconto temporal, Ostaszewski et al. [66] sugeriram que o desconto de recompensas probabilísticas pode ser melhor descrito por uma função semelhante à hipérbole, em que o denominador é elevado a uma potência dada $g$ :

$$
V_{p}(\Theta)=\frac{V_{0}}{\left(1+k_{1} \Theta\right)^{g}} .
$$

Este modelo foi ajustado a dados experimentais [66] e os resultados mostraram que a inclusão de um expoente na função de desconto probabilística melhora significativamente o ajuste destes dados. Green et al. [65] também reproduziram este resultado.

Semelhante à generalização proposta por Cajueiro [54] em relação ao desconto 
temporal [Eq. (2.12)], Takahashi [53] introduziu uma função generalizada para o desconto probabilístico, a partir da função q̃-exponencial [Eq. (2.10)]:

$$
V_{\tilde{q} n p}(\Theta)=\frac{V_{0}}{\exp _{\tilde{q}}\left(k_{\tilde{q}} \Theta\right)}=\frac{V_{0}}{\left(1+\tilde{q} k_{\tilde{q}} \Theta\right)^{1 / \tilde{q}}},
$$

sendo $V_{0}$ o valor objetivo da recompensa e $k_{\tilde{q}}$ um parâmetro de aversão ao risco em $\Theta=0$. Para $\tilde{q}=0$, a Eq. (3.6) é equivalente à função de desconto exponencial. Para $\tilde{q}=1$, ela é equivalente à função de desconto hiperbólica. Escrevendo $\tilde{q}=1 / g$ e $k_{\tilde{q}}=g k_{1}$, obtém-se o modelo comportamental de Ostaszewski et al. [66].

A descrição dos descontos temporal e probabilístico pela mesma forma matemática levantou questões sobre a possibilidade de ambos os descontos refletirem um único processo de tomada de decisão. Se um processo único fundamentar ambos os tipos de desconto, entretanto, a forma similar das funções de desconto temporal e probabilística não indica se um tipo de desconto é mais fundamental que o outro. Por exemplo, Rachlin et al. [33] argumentaram que o desconto temporal é o processo mais fundamental. O desconto probabilístico, neste caso, surge porque recompensas probabilísticas são experimentadas como jogadas repetidas nas quais quanto menor a probabilidade, maior o tempo, em média, para que a vitória ocorra e, assim, maior o tempo de espera para receber a recompensa. Em contrapartida, Myerson e Green [42] sugeriram que o desconto probabilístico deveria ser o processo mais fundamental. O desconto temporal surge, então, porque maiores atrasos representam um maior risco de que a recompensa não seja realmente recebida, como em um jogo probabilístico de uma única rodada.

Independentemente de qual tipo de desconto é assumido como fundamental, se o mesmo processo de desconto fundamenta ambos os tipos de decisão, então a mesma forma do modelo matemático deve descrever ambos. Entretanto, o inverso não é verdadeiro. Embora os descontos temporal e probabilístico possam ser descritos pela mesma forma da função matemática, não necessariamente ambos os tipos de desconto envolvem processos de tomada de decisão idênticos.

Evidências recentes têm mostrado que algumas variáveis apresentam efeitos distintos em descontos temporais e probabilísticos, o que sugere que processos distintos possam sustentar o desconto de recompensas que diferem em atraso e probabilidade. A evidência mais notável é o efeito oposto que a magnitude de uma recom- 
pensa tem sobre as taxas de desconto de recompensas probabilísticas e atrasadas. No domínio do desconto intertemporal, recompensas menores são descontadas de forma mais acentuada em função do atraso do que recompensas maiores. Esse efeito da magnitude de recompensas na taxa de desconto temporal tem sido demonstrada em vários estudos envolvendo recompensas reais e hipotéticas [17, 30, 42, 18, 67, 68]. Porém, em descontos envolvendo recompensas probabilísticas, o efeito da magnitude aparece na direção oposta à observada para o desconto temporal: recompensas probabilísticas maiores são descontadas mais fortemente que recompensas probabilísticas menores [65, 69, 70, 71]. Como mencionado anteriormente, maiores taxas de desconto para recompensas em função do atraso implicam em maior impulsividade, enquanto maiores taxas de desconto para recompensas probabilísticas implicam em maior auto-controle. Assim, os resultados encontrados para o efeito da magnitude mostram que o aumento do valor da recompensa leva a um maior auto-controle em ambos os contextos (temporal e probabilístico) [65]. Essas mudanças são difíceis de ser entendidas da perspectiva de um processo único para ambos os descontos, mas indicam que estes processos são pelo menos fundamentalmente similares.

Além da magnitude da recompensa, outras variáveis também influenciam os descontos intertemporal e probabilísticos de diferentes formas. Du et al. [71] avaliou o desconto de recompensas atrasadas e probabilísticas entre estudantes americanos, japoneses e chineses. Segundo a hipótese de processo único, indivíduos criados em uma cultura onde recompensas probabilísticas são descontadas mais (ou menos) fortemente, deveriam também descontar recompensas em função do atraso de forma mais (ou menos menos) acentuada, e vice-versa. Entretanto, embora os americanos tenham relativamente descontado ambos os tipos de recompensa de forma acentuada, os chineses descontaram recompensas tardias mais fortemente que os japoneses, enquanto o comportamento contrário foi observado no caso de recompensas probabilísticas. Este resultado mostrou que similaridades e diferenças culturais também são inconsistentes com a hipótese de processo único. Indivíduos que diferem em relação a traços de personalidade [72] e à dependência do álcool [72] também foram estudados e evidências de violação à hipótese de processo único foram novamente encontradas.

De forma geral, estudos mostram que o desconto de recompensas tardias e 
probabilísticas podem ser descritos pelas mesmas funções de desconto, mas algumas evidências não sustentam a hipótese de processo único como embasador de ambos os domínios. Novos trabalhos precisam ser conduzidos para uma melhor investigação da adequação da hipótese de processo único a descontos temporais e probabilísticos.

\subsection{Resultados}

A substituição do atraso $(t)$ por uma função da probabilidade $(p)$, representada por $\Theta$, nas funções de desconto intertemporais, resultou em funções de desconto probabilísticas capazes de descrever adequadamente os dados experimentais obtidos para o respectivo desconto. Entretanto, os modelos que foram explorados, até então, não associam os efeitos psicofísicos de percepção ao processo de tomada de decisão probabilístico.

Neste trabalho, de forma similar ao proposto para tomadas de decisão intertemporais, estendemos a teoria psicofísica de percepção ao domínio das probabilidades. Se o atraso médio para recebimento de uma recompensa está relacionado à probabilidade dessa recompensa pela Eq. (3.1), então, a partir das leis de WeberFechner e Stevens para a percepção temporal, obtemos, respectivamente:

$$
\Pi(\Theta)=a \ln (1+b \Theta)
$$

$\mathrm{e}$

$$
\Pi(\Theta)=c(1+b \Theta)^{s}-c
$$

sendo $\Pi$ a percepção subjetiva de $\Theta$, e as grandezas $a, b, c$ e $s$ parâmetros psicofísicos. Observe que as expressões acima representam as funções de percepção de $\Theta$ seguindo as leis da psicofísica de Weber-Fechner e Stevens, respectivamente. Essa extensão das leis da psicofísica à percepção de probabilidades é resultado de uma substituição de variáveis, baseada em resultados experimentais que mostraram uma relação entre atrasos e probabilidades. Entretanto, não podemos assegurar sobre a real validade dessa extensão; diferentemente do domínio temporal, as leis da psicofísica ainda não foram avaliadas no domínio das probabilidades. 
Podemos utilizar também a forma unificada das leis da psicofísica para descrição da percepção psicofísica de $\Theta$. A partir da Eq. (2.23), obtemos:

$$
\Pi(\Theta)=a \ln _{s}(1+b \Theta)
$$

onde para o caso particular $s=0$ obtém-se a lei de percepção de Weber-Fechner para probabilidades e, para os demais casos, obtém-se a forma da lei de Stevens.

Similarmente ao trabalho desenvolvido para escolhas intertemporais, podemos também associar os modelos de desconto probabilísticos sem efeitos psicofísicos de percepção (exponencial, hiperbólico e q̃-generalizado) e as funções de percepção para probabilidades (incluindo a forma unificada das leis proposta neste trabalho). A tabela 3.1 sumariza essas possíveis combinações.

Observe que a expressão:

$$
v_{\tilde{q} u p}=\frac{1}{\exp _{\tilde{q}}\left[k_{\tilde{q}} a \ln _{s}(1+b \Theta)\right]}
$$

é uma função de desconto generalizada para o processo de tomada de decisão probabilístico envolvendo a psicofísica da percepção de probabilidades, em função de $\Theta$. A Fig. 3.3 mostra algumas curvas de desconto obtidas a partir da variação dos parâmetros $\tilde{q}$ e $s$ na Eq. (3.10). 
Tabela 3.1 - Modelos de desconto em escolhas probabilísticas. Os subíndices 0,1 e $\tilde{q}$ representam os modelos de desconto exponencial, hiperbólico e $\tilde{q}$-generalizado, respectivamente. Os subíndices $f, s$ e $u$ representam as percepções de $\Theta$ seguindo as leis de Weber-Fechner, Stevens e a unificação destas, respectivamente.

\begin{tabular}{|c|c|c|c|c|}
\hline & \multicolumn{3}{|c|}{$\mathbb{H}(I)=-I^{2} ; \mathbb{F}(I)=-b I /(1+b \Theta)$} \\
\hline & & Desconto exponencial (0) & Desconto hiperbólico (1) & Desconto $\tilde{q}$-generalizado $(\tilde{q})$ \\
\hline \multirow{4}{*}{ 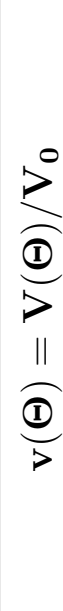 } & Sem percepção $(n)$ & $v_{0 n p}=\exp \left(-k_{0} \Theta\right)$ & $v_{1 n p}=\frac{1}{1+k_{1} \Theta}$ & $v_{\tilde{q} n p}=\frac{1}{\exp _{\tilde{q}}\left(k_{\tilde{q}} \Theta\right)}$ \\
\hline & Weber-Fechner $(f)$ & $v_{0 f p}=\frac{1}{(1+b \Theta)^{g}}$ & $v_{1 f p}=\frac{1}{1+k_{1} a \ln (1+b \Theta)}$ & $v_{\tilde{q} f p}=\frac{1}{\exp _{\tilde{q}}\left[k_{\tilde{q}} a \ln (1+b \Theta)\right]}$ \\
\hline & Stevens $(s)$ & $v_{0 s p}=\frac{1}{\exp \left[k_{0} a \ln _{s}(1+b \Theta)\right]}$ & $v_{1 s p}=\frac{1}{1+k_{1} a \ln _{s}(1+b \Theta)}$ & $v_{\tilde{q} s p}=\frac{1}{\exp _{\tilde{q}}\left[k_{\tilde{q}} a \ln _{s}(1+b \Theta)\right]}$ \\
\hline & Forma unificada $(u)$ & $v_{0 u p}=\frac{1}{\exp \left[k_{0} a \ln _{s}(1+b \theta)\right]}$ & $v_{1 u p}=\frac{1}{1+k_{1} a \ln _{s}(1+b \Theta)}$ & $v_{\tilde{q} u p}=\frac{1}{\exp _{\tilde{q}}\left[k_{\tilde{q}} a \ln _{s}(1+b \Theta)\right]}$ \\
\hline
\end{tabular}




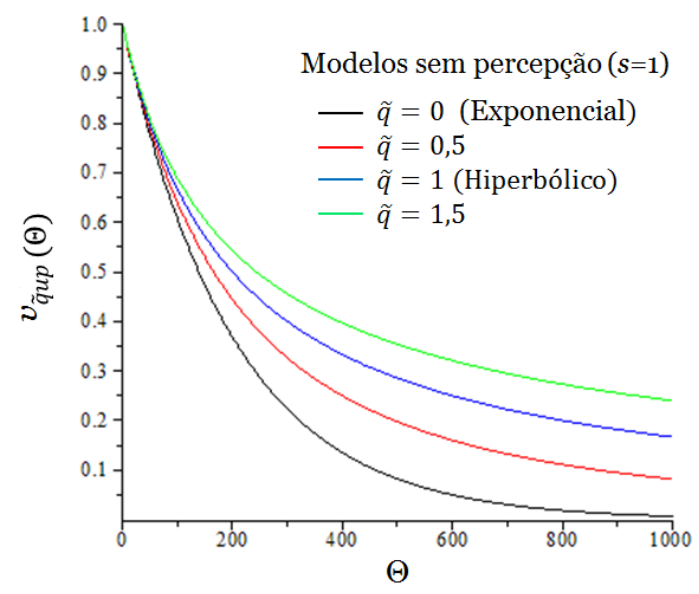

(a)

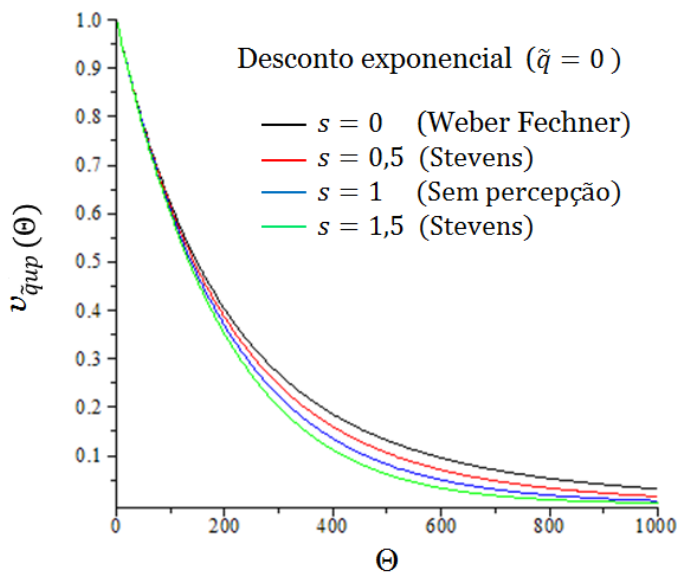

(b)

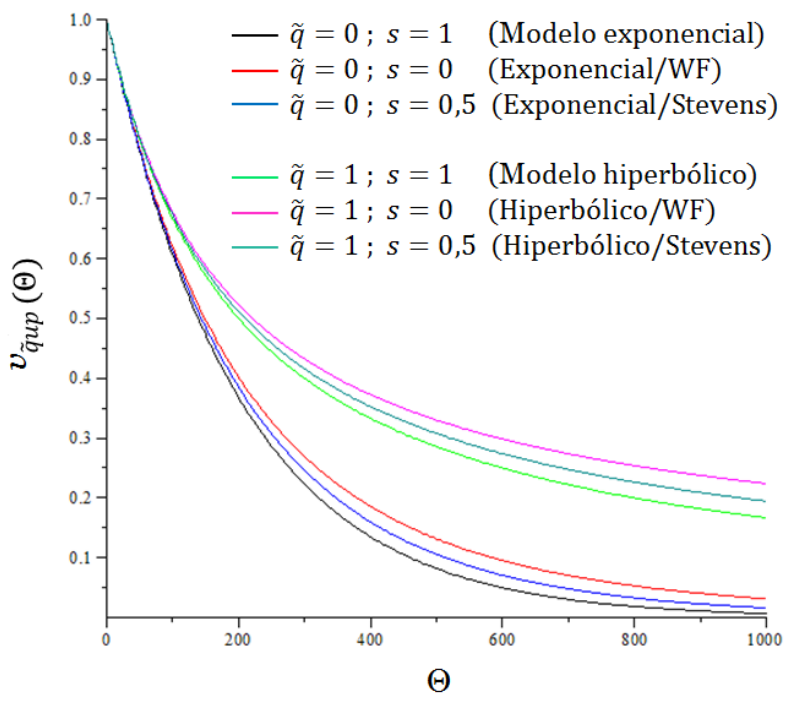

(c)

Figura 3.3 - Desconto generalizado em função de $\Theta$ para diferentes valores de $\tilde{q}$ e $s$ : (a) Modelos sem percepção psicofísica $(s=1)$; (b) Desconto exponencial $(\tilde{q}=0)$ associado a diferentes funções de percepção ( $s$ variável); (c) Descontos exponencial $(\tilde{q}=0)$ e hiperbólico $(\tilde{q}=1)$ associados a diferentes funções de percepção. Para todos os casos foram mantidos $k=1, a=5$ e $b=0,001$. 


\section{Capítulo}

\section{Teoria da utilidade esperada}

Nos capítulos a seguir, temos por objetivo verificar se a forma generalizada da função de desconto probabilística que propusemos [Eq. (3.10)] satisfaz às propriedades definidas para estas funções no domínio teórico. Desta forma, focamos na descrição dos modelos teóricos obtidos para escolhas probabilísticas (Fig. 4.1). Neste capítulo, exploramos a teoria da utilidade esperada (EUT). A EUT fornece um forma muito simples de combinar probabilidades e consequências em uma única medida de valor. Baseada em sólidos fundamentos axiomáticos, esta teoria predominou por um longo período como modelo normativo para descrição de tomadas de decisão sob incerteza. A seguir, apresentamos uma breve revisão sobre os primórdios da EUT, assim como sua proposição e posterior axiomatização.

\subsection{Primórdios e proposição}

Os primeiros passos da teoria da probabilidade, desenvolvidos no século XVII pelos matemáticos Blaise Pascal e Pierre de Fermat, permitiram o surgimento da primeira teoria sobre tomadas de decisão que se tem notícia. Segundo Pascal, apesar da razão não poder determinar a existência ou não de Deus, a decisão de seguir uma vida pia (como se Deus existisse) ou uma vida mundana (de acordo com a satisfação das paixões humanas) poderia ser racionalizada a partir da comparação entre seus valores esperados [73]. Esta comparação ficou conhecida como princípio da expectância matemática e foi amplamente utilizada como método de análise de decisões durante as últimas décadas do século XVII [73].

Formalmente, seja 


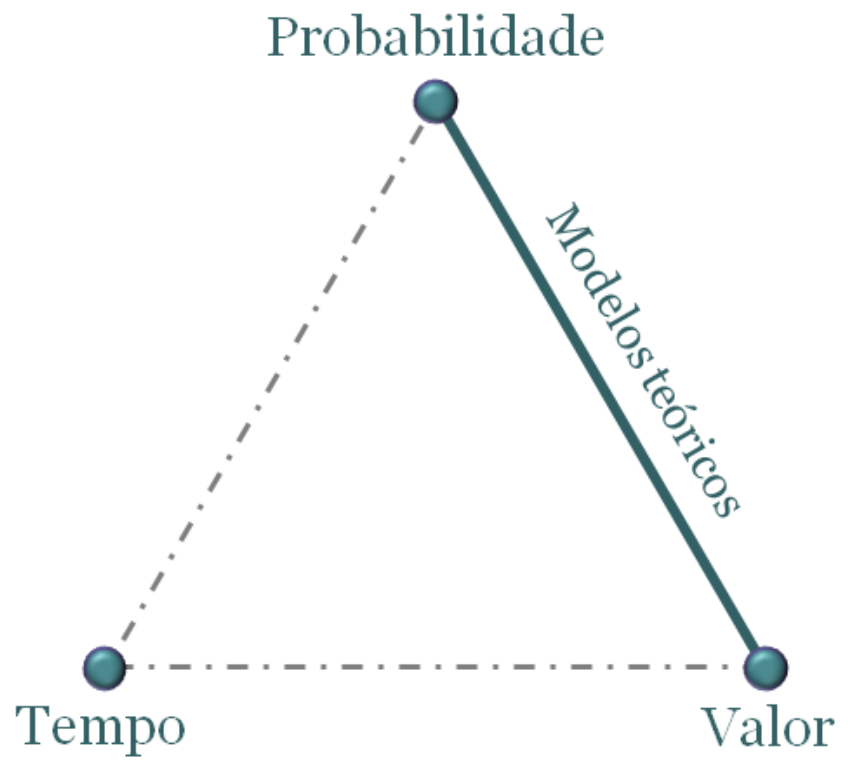

Figura 4.1 - Esquema ilustrando as interações entre as grandezas valor, tempo e probabilidade em tomadas de decisão. Exploramos modelos teóricos sobre tomadas de decisão envolvendo valor e probabilidade.

$$
\vec{X}=|X\rangle=\left[\begin{array}{c}
x_{1} \\
x_{2} \\
\vdots \\
x_{n}
\end{array}\right]
$$

um vetor de $n$ possíveis resultados de uma aposta. Considere um conjunto de $m$ apostas disponíveis para $\vec{X}$, representadas por vetores de probabilidades:

$$
\vec{L}_{k}=\left|L_{k}\right\rangle=\left[\begin{array}{c}
p_{1}^{(k)} \\
p_{2}^{(k)} \\
\vdots \\
p_{n}^{(k)}
\end{array}\right], k=1,2, \ldots, m
$$


O cálculo do valor esperado de uma loteria $\overrightarrow{L_{k}}$ é dado pelo produto escalar:

$$
E\left(\vec{X}, \vec{L}_{k}\right)=\vec{L}_{k}^{T} \cdot \vec{X}=\left\langle L_{k} \mid X\right\rangle=\sum_{i=1}^{n} x_{i} p_{i}^{(k)} .
$$

O princípio da expectância matemática afirma que a aposta $\overrightarrow{L_{e}}, 1 \leq e \leq m$, deve ser escolhida entre $m$ apostas de valores esperados distintos se, e somente se, o valor esperado da loteria $\vec{L}_{e}$ for maior ou igual ao valor esperado das demais loterias:

$$
E\left(\vec{X}, \vec{L}_{e}\right) \geq E\left(\vec{X}, \vec{L}_{k}\right), \text { para todo } k=1,2, \ldots, m
$$

Assim, a única medida importante para a tomada de decisão é o valor esperado. Este princípio consistiu no primeiro desenvolvimento intelectual capaz de lidar com decisões envolvendo escolhas probabilísticas.

Apesar da praticidade do princípio da expectância matemática, algumas limitações começaram a aparecer. Daniel Bernoulli, em 1738, citou o famoso Paradoxo de São Petersburgo. Suponha que uma moeda é jogada repetidamente até que a primeira "cara" apareça. O jogo paga $2^{n-1}$ dólares se a primeira cara aparecer na enésima jogada [73]. Se um indivíduo se baseasse no princípio da expectância matemática, ele estaria disposto a pagar qualquer preço para entrar nesse jogo, pois

$$
E(\vec{X}, \vec{L})=\sum_{i=1}^{\infty}(1 / 2)^{n} \cdot 2^{n-1}=\infty .
$$

Sabe-se, entretanto, que a maioria das pessoas não estaria disposta a pagar mais do que alguns reais para participar desse jogo. A solução de Bernoulli para o Paradoxo de São Petersburgo marcou o início da teoria da utilidade esperada (EUT) [3].

Segundo Bernoulli, o valor que uma pessoa atribui a sua riqueza não é o próprio valor monetário desta, mas sim seu valor moral ou utilidade [73]:

“ (...) a determinação do valor de um item não pode ser baseado em seu preço, mas sim na utilidade que ele fornece. O preço de um item depende somente do próprio item e é igual para todo mundo; a utilidade, contudo, depende das circunstâncias particulares do indivíduo que faz a estimativa." [3]

De acordo com essa proposição, tomadores de decisão não são mais vistos como 
maximizadores de valor esperado, mas como indivíduos que procuram maximizar a utilidade esperada dos resultados.

O cálculo da utilidade esperada de uma loteria $\vec{L}_{k}, U\left(\vec{L}_{k}\right)$, é semelhante ao cálculo do valor esperado, porém cada resultado, $x_{i}$, é substituído pela sua utilidade, $u\left(x_{i}\right)$. Sejam $\vec{X}$ e $\vec{L}_{k}, k=1,2, \ldots, m$, como definidos anteriormente. Para cada vetor $\vec{X}$ associamos um vetor de utilidades $\vec{u}$ dado por:

$$
\vec{u}=\mathcal{U}(\vec{X})=\left[\begin{array}{c}
u\left(x_{1}\right) \\
u\left(x_{2}\right) \\
\vdots \\
u\left(x_{n}\right)
\end{array}\right]=\mathcal{U}|X\rangle=|u\rangle,
$$

sendo $\mathcal{U}$ o operador que associa a cada resultado $x_{i}$ sua utilidade $u\left(x_{i}\right)$. A utilidade esperada de uma loteria é, então, definida por:

$$
U\left(\vec{X}, \vec{L}_{k}\right)=E\left(\mathcal{U}(\vec{X}), \vec{L}_{k}\right)=\vec{L}_{k}^{T} \cdot \mathcal{U}(\vec{X})=\left\langle L_{k}|\mathcal{U}| X\right\rangle=\sum_{i=1}^{n} u\left(x_{i}\right) p_{i}^{(k)}
$$

É importante ressaltar que a utilidade esperada $U$ é definida sobre loterias, enquanto a utilidade $u$ é definida sobre resultados.

A teoria da utilidade esperada afirma que a aposta $\vec{L}_{e}, 1 \leq e \leq m$ deve ser escolhida entre $m$ apostas de valores esperados distintos se, e somente se, a utilidade esperada da loteria $\overrightarrow{L_{e}}$ for maior ou igual à utilidade esperada das demais loterias:

$$
U\left(\vec{X}, \vec{L}_{e}\right) \geq U\left(\vec{X}, \vec{L}_{k}\right), \text { para todo } k=1,2, \ldots, m
$$

Com a teoria da utilidade esperada, a subjetividade foi definitivamente introduzida à teoria de decisão [73]. Os possíveis resultados e as probabilidades deixam de ser suficientes para determinar a decisão, pois a utilidade depende das características e das circunstâncias específicas do tomador de decisão.

Bernoulli postulou também a chamada lei da utilidade marginal decrescente: o aumento na utilidade resultante da aquisição de uma quantia monetária adicional diminui com o aumento da riqueza. Ele supôs ainda que a função utilidade é igual ao logaritmo do resultado, em qualquer base $b: u(x)=\log _{b}(x)$, sendo $b>0$ e 
$b \neq 1$. Observe que este não é o logaritmo generalizado $\ln _{\tilde{q}}(x)$ utilizado previamente [Eq.(2.11)].

\subsection{Bases axiomáticas}

Embora a teoria de Bernoulli tenha sido um passo importante na tentativa de modelar como indivíduos tomam suas decisões, as bases axiomáticas que fundamentaram a EUT somente foram fornecidas em 1944, por John Von Neumann e Oskar Morgenstern, em Theory of games and economic behavior [6]. Os autores mostraram que a hipótese da utilidade esperada poderia ser derivada de um conjunto de axiomas de preferência aparentemente atraentes. Na medida em que seus axiomas puderam ser justificados como princípios sólidos da escolha racional aos quais qualquer pessoa razoável aderiria, eles forneceram a base para interpretação da EUT como modelo normativo. Nesta obra, a forma matemática da utilidade esperada era a mesma que Bernoulli utilizou no século XVIII [Eq. (4.3)], fundamentada, porém, por um conjunto de axiomas [73].

Para facilitar a compreensão dos axiomas, cada par $\left(\vec{X}, \vec{L}_{k}\right)$ será simplificado e representado apenas por um vetor de probabilidades $\vec{L}_{k}$, sendo $\vec{X}$ omitido. As preferências de um tomador de decisão serão formalizadas pela relação $\succeq$, chamada relação de preferência fraca. A expressão $\vec{L}_{1} \succeq \vec{L}_{2}$ representa que $\vec{L}_{1}$ é fracamente preferível a $\vec{L}_{2}$.

A partir de $\succeq$, pode-se definir duas outras relações:

(a) Relação de preferência estrita $(\succ): \vec{L}_{1} \succ \vec{L}_{2} \Leftrightarrow \vec{L}_{1} \succeq \vec{L}_{2}$ mas não $\vec{L}_{2} \succeq \vec{L}_{1}\left(\vec{L}_{1}\right.$ é fortemente preferível a $\vec{L}_{2}$ );

(b) Relação de indiferença $(\sim): \vec{L}_{1} \sim \vec{L}_{2} \Leftrightarrow \vec{L}_{1} \succeq \vec{L}_{2}$ e $\vec{L}_{2} \succeq \vec{L}_{1}$.

A hipótese da utilidade esperada pode ser derivada a partir de três axiomas: ordenação, continuidade e independência [73]. Von Neumann e Morgenstern impuseram uma consistência sobre as preferências dos indivíduos através da suposição de racionalidade ou axioma da ordenação. Este axioma é baseado em duas propriedades: 
1. Completude: para quaisquer loterias $\vec{L}_{1}$ e $\vec{L}_{2}, \vec{L}_{1} \preceq \vec{L}_{2}$ ou $\vec{L}_{1} \succeq \vec{L}_{2}$ ou $\vec{L}_{1} \sim \vec{L}_{2}$. O tomador de decisão é capaz de comparar qualquer par de loterias.

2. Transitividade: Para quaisquer $\vec{L}_{1}, \vec{L}_{2}$ e $\vec{L}_{3}$, se $\vec{L}_{1} \succeq \vec{L}_{2}$ e $\vec{L}_{2} \succeq \vec{L}_{3}$, então $\vec{L}_{1} \succeq \vec{L}_{3}$. Não existem preferências circulares.

O segundo axioma que fundamenta a hipótese da utilidade esperada é chamado axioma da continuidade: para quaisquer loterias $\vec{L}_{1}, \vec{L}_{2}$ e $\vec{L}_{3}$, onde $\vec{L}_{1} \succeq \vec{L}_{2}$ e $\vec{L}_{2} \succeq \vec{L}_{3}$, existe alguma probabilidade $p$ tal que $\left(\vec{L}_{1}, p ; \vec{L}_{3}, 1-p\right) \sim \vec{L}_{2}$. Ou seja, mudanças marginais nas probabilidades não alteram o ordenamento entre prospectos.

Os axiomas da ordenação e da continuidade juntos implicam que as preferências sobre prospectos podem ser representadas por uma função $U($.$) que atribui um$ valor real a cada prospecto. Um indivíduo escolherá a loteria $\vec{L}_{1}$ à loteria $\vec{L}_{2}$ se, e somente se, o valor atribuído a $\vec{L}_{1}$ por $U($.) não for menor que o valor atribuído pela mesma função à loteria $\vec{L}_{2}$ :

$$
U\left(\vec{L}_{1}\right) \geq U\left(\vec{L}_{2}\right) \Leftrightarrow \vec{L}_{1} \succeq \vec{L}_{2} .
$$

Assumir a existência de tal função de preferência é o ponto inicial de qualquer teoria econômica de escolha. Isso equivale a assumir que indivíduos têm preferências bem definidas, enquanto impondo restrições mínimas à forma precisa destas preferências.

Além da ordenação e continuidade, a axiomatização de Von Neumann e Morgenstern inclui o axioma da independência. Este axioma desempenha papel fundamental na teoria da utilidade esperada, dado que ele impõe fortes restrições à forma precisa das preferências. É o axioma da independência que fornece à teoria padrão a maior parte do seu conteúdo empírico, sendo o axioma que a maioria dos modelos alternativos à EUT irão relaxar. Segundo o axioma da independência, para quaisquer loterias $\vec{L}_{1}, \vec{L}_{2}$ e $\vec{L}_{3}$ : se $\vec{L}_{1} \succeq \vec{L}_{2}$, então $\left(\vec{L}_{1}, p ; \vec{L}_{3}, 1-p\right) \succeq\left(\vec{L}_{2}, p ; \vec{L}_{3}, 1-p\right)$, para todo $p$.

Se os três axiomas - ordenação, continuidade e independência - forem válidos, as preferências podem, então, ser representadas pela função $U\left(\overrightarrow{L_{k}}\right)$, conforme descrito na Eq. (4.3), proposta por Bernoulli.

A EUT fornece um forma muito simples de combinar probabilidades e consequências em uma única medida de valor, a qual apresenta uma série de proprieda- 
des atraentes. Uma dessas propriedades é a monotonicidade: prospectos estocasticamente dominantes são preferíveis aos prospectos que eles dominam. A dominância estocástica pode ser definida como a seguir [74].

Considere $x_{1}, \ldots, x_{n}$ um conjunto de possíveis consequências ordenadas da pior $x_{1}$ até a melhor $x_{n}$. Uma loteria

domina estocasticamente outra loteria

$$
\vec{L}_{1}=\left[\begin{array}{c}
p_{1}^{(1)} \\
\vdots \\
p_{n}^{(1)}
\end{array}\right]
$$

se para todo $i=1, \ldots, n$ :

$$
\vec{L}_{2}=\left[\begin{array}{c}
p_{1}^{(2)} \\
\vdots \\
p_{n}^{(2)}
\end{array}\right]
$$

$$
\sum_{j=i}^{n} p_{j}^{(1)} \geq \sum_{j=i}^{n} p_{j}^{(2)},
$$

a qual deve obedecer a uma inequalidade estrita para pelo menos um $i$. Por exemplo, considere um par de loterias, descritas pelo percentual de bolinhas de gude de diferentes cores e pelo valor de perda ou ganho associado à cor da bolinha a ser sorteada aleatoriamente (Tabela. 4.1).

Tabela 4.1 - Exemplo de dominância estocástica. Um par de loterias é descrito pelo

\begin{tabular}{|c|c|c|c|c|}
\hline \multicolumn{5}{|c|}{ Opção A } \\
\hline 90\%branca & $6 \%$ vermelha & $1 \%$ verde & $1 \%$ azul & $2 \%$ amarela \\
\hline$R \$ 0$ & Ganha $R \$ 45$ & Ganha $R \$ 30$ & Perde $R \$ 15$ & Perde $R \$ 15$ \\
\hline \multicolumn{5}{|c|}{ Opção B } \\
\hline $90 \%$ branca & $6 \%$ vermelha & $1 \%$ verde & $1 \%$ azul & $2 \%$ amarela \\
\hline$R \$ 0$ & Ganha $R \$ 45$ & Ganha $R \$ 45$ & Perde $R \$ 10$ & Perde $R \$ 15$ \\
\hline
\end{tabular}
percentual de bolinhas de gude de diferentes cores e pelo valor de perda ou ganho associado à cor da bolinha a ser sorteada aleatoriamente [75]. 
Ordenando as consequências da pior pra a melhor tem-se o conjunto: ( $R \$ 15$, $-R \$ 10, R \$ 0, R \$ 30, R \$ 45)$. As loterias para as opções $\mathrm{A}$ e $\mathrm{B}$ podem ser escritas, respectivamente, como:

$$
\vec{L}_{A}=\left[\begin{array}{c}
3 \% \\
0 \% \\
90 \% \\
1 \% \\
6 \%
\end{array}\right] \text { e } \vec{L}_{B}=\left[\begin{array}{c}
2 \% \\
1 \% \\
90 \% \\
0 \% \\
7 \%
\end{array}\right] .
$$

Para $i=1, \ldots, 5$, as somas $\sum_{j=i}^{5} p_{j}^{(A)}$ e $\sum_{j=i}^{5} p_{j}^{(B)}$, estão mostradas na Tabela 4.2 .

Tabela 4.2 - Verificação da dominância estocástica da loteria $\vec{L}_{B}$ sobre a loteria $\vec{L}_{A}$.

\begin{tabular}{|c|c|c|}
\hline \hline$i$ & $\sum_{j=i}^{5} p_{j}^{(A)}$ & $\sum_{j=i}^{5} p_{j}^{(B)}$ \\
\hline 1 & $100 \%$ & $100 \%$ \\
\hline 2 & $97 \%$ & $98 \%$ \\
\hline 3 & $97 \%$ & $97 \%$ \\
\hline 4 & $7 \%$ & $7 \%$ \\
\hline 5 & $6 \%$ & $7 \%$ \\
\hline \hline
\end{tabular}

Neste caso, diz-se que a loteria $\vec{L}_{B}$ domina estocasticamente a loteria $\vec{L}_{A}$ pois, para todo $i=1, \ldots, 5, \sum_{j=i}^{5} p_{j}^{(B)} \geq \sum_{j=i}^{5} p_{j}^{(A)}$ e para os casos $i=2$ e $i=5$ essa desigualdade é estrita $(>)$. Portanto, pela propriedade da monotonicidade, segundo a EUT, a loteria $\vec{L}_{B}$ é preferível à loteria $\vec{L}_{A}$, pois prospectos estocasticamente dominantes são preferíveis aos prospectos que eles dominam. A monotonicidade é amplamente aceita como uma propriedade base que qualquer teoria - descritiva ou normativa - deveria assumir.

A EUT assume ainda o princípio de integração dos ativos. Os resultados de uma escolha são agregados à posição corrente dos ativos (ou riqueza corrente), de 
modo que os objetos finais de escolha são loterias sobre níveis de riqueza agregados. Assim, segundo a EUT, um tomador de decisão, com um nível de riqueza $w$, visualiza a opção $\vec{X}$ com probabilidades dadas por $\vec{L}$ como $\vec{X}+\vec{w}$, sendo

$$
\vec{w}=\left[\begin{array}{c}
w \\
w \\
\vdots \\
w
\end{array}\right],
$$

com probabilidades dadas por $\vec{L}$. O domínio da função utilidade não são ganhos ou perdas, mas sim estados finais que incluem o nível de riqueza do tomador de decisão.

Nas teorias que envolvem decisões sob incerteza, tomadores de decisão são classificados em três tipos básicos: avessos, neutros e propensos ao risco. Seja $\vec{L}$ uma loteria e $\vec{E}_{L}$ a loteria degenerada que fornece o valor esperado da loteria $\vec{L}$ com certeza. Um tomador de decisão é (estritamente) avesso ao risco se, para qualquer loteria $\vec{L}$, a loteria degenerada $\vec{E}_{L}$ é (estritamente) preferível a $\vec{L}$. Um tomador de decisão é neutro ao risco se, para qualquer $\vec{L}, \vec{E}_{L}$ é indiferente a $\vec{L}$. Por fim, um tomador de decisão é (estritamente) propenso ao risco se, para qualquer loteria, $\vec{L}$ é (estritamente) preferível a $\vec{E}_{L}$.

Na teoria da utilidade esperada, a aversão ao risco é uma propriedade estabelecida a partir da função utilidade $u$ [73]. Seguindo as definições acima descritas e dado um vetor de resultados $\vec{X}$, o tomador de decisão, segundo a EUT, é (estritamente) avesso ao risco se a utilidade esperada de uma loteria qualquer $\vec{L}$ é menor que utilidade do valor esperado dessa loteria:

$$
U(\vec{X}, \vec{L})<u[E(\vec{X}, \vec{L})] .
$$

Se essa desigualdade é satisfeita, a função utilidade $u$ é côncava. Portanto, sob a teoria da utilidade esperada, a aversão ao risco equivale à concavidade de $u$. $\mathrm{Na}$ Fig. 4.2 está representada uma função utilidade (estritamente) côncava, referente a um individuo (estritamente) avesso ao risco.

Por outro lado, a propensão ao risco equivale à convexidade de $u$. Na Fig. 4.3 está representada uma função utilidade (estritamente) convexa que representa as 


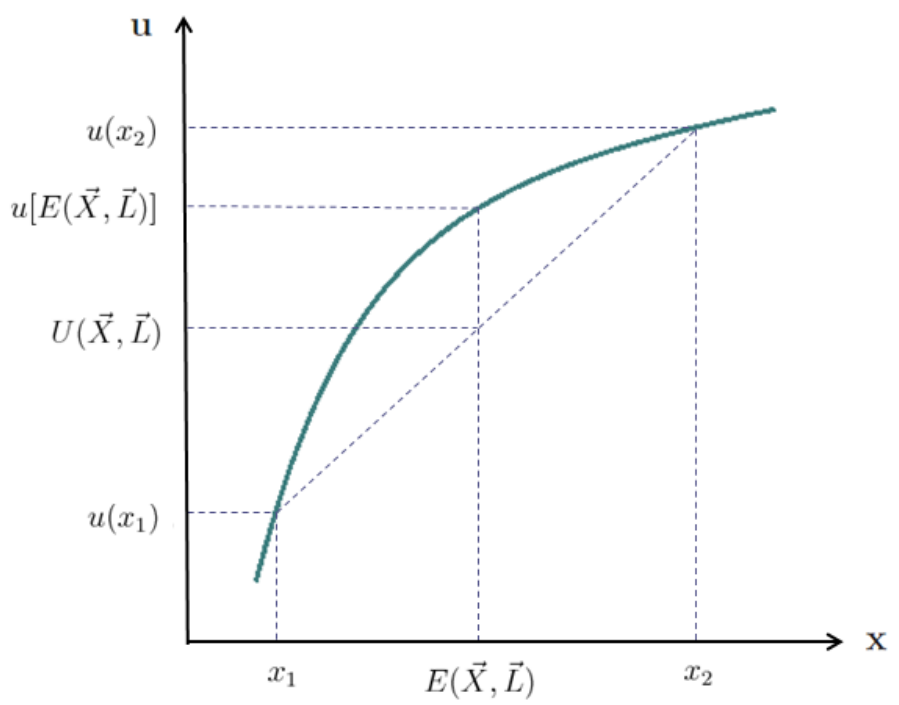

Figura 4.2 - Função utilidade hipotética para tomadores de decisão (estritamente) avessos ao risco [73].

preferências de um tomador de decisão (estritamente) propenso ao risco. Neste caso, a utilidade do valor esperado de uma loteria é inferior à utilidade esperada da loteria:

$$
u[E(\vec{X}, \vec{L})]<U(\vec{X}, \vec{L}) .
$$

Por fim, a neutralidade ao risco implica que a função utilidade $u$ é linear, como mostrado na Fig. 4.4. O indivíduo neutro ao risco é indiferente entre loterias de mesmo valor esperado:

$$
u[E(\vec{X}, \vec{L})]=U(\vec{X}, \vec{L}) .
$$

Assim, para tomadores de decisão neutros ao risco, a maximização da utilidade esperada $(U(\vec{X}, \vec{L}))$ equivale à maximização do valor esperado $(E(\vec{X}, \vec{L}))$, ou seja, estes indivíduos seguem o princípio da expectância matemática. O princípio da expectância matemática é, portanto, um caso particular da EUT.

A teoria da utilidade esperada, baseada em sólidos fundamentos axiomáticos, tornou-se popular entre os economistas. Ela passou a ser tradicionalmente aceita como um modelo normativo para descrição de tomadas de decisão sob incerteza, 


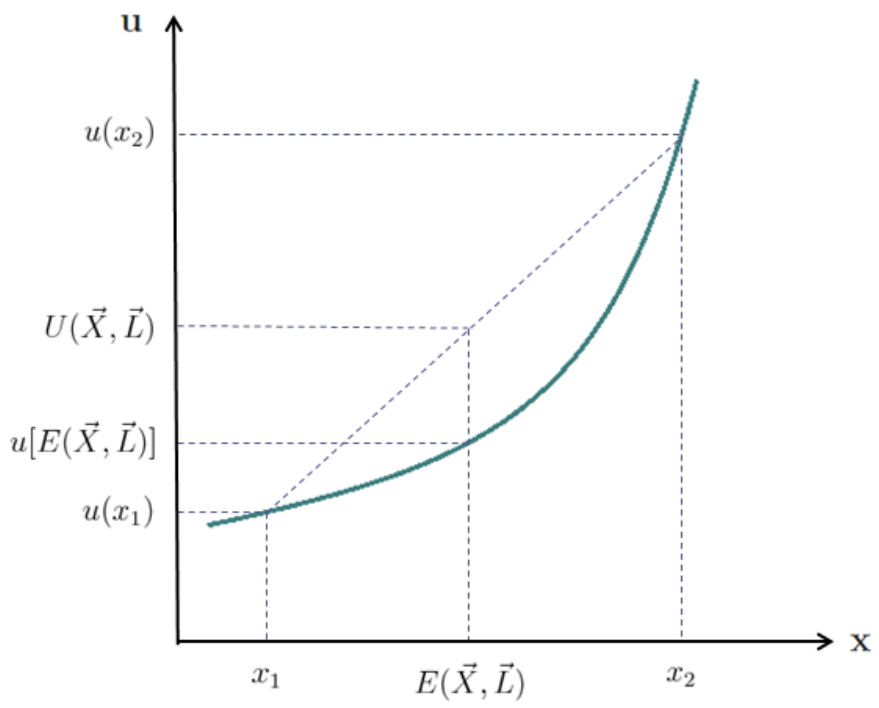

Figura 4.3 - Função utilidade hipotética para tomadores de decisão (estritamente) propensos ao risco [73].

admitindo tomadores de decisão racionais. Entretanto, em um trabalho publicado em 1953 [63], Allais propôs um problema de escolha que violou as hipóteses da utilidade esperada. Esse problema, que mais tarde ficou conhecido como paradoxo de Allais, foi seguido, então, por outras evidências experimentais que mostraram que a EUT é sistematicamente violada. Estas evidências levaram ao desenvolvimento de novas teorias que pudessem incorporar as anomalias apresentadas pela EUT. A seguir, descrevemos algumas destas teorias, destacando as violações da EUT que foram exploradas em cada uma delas. 


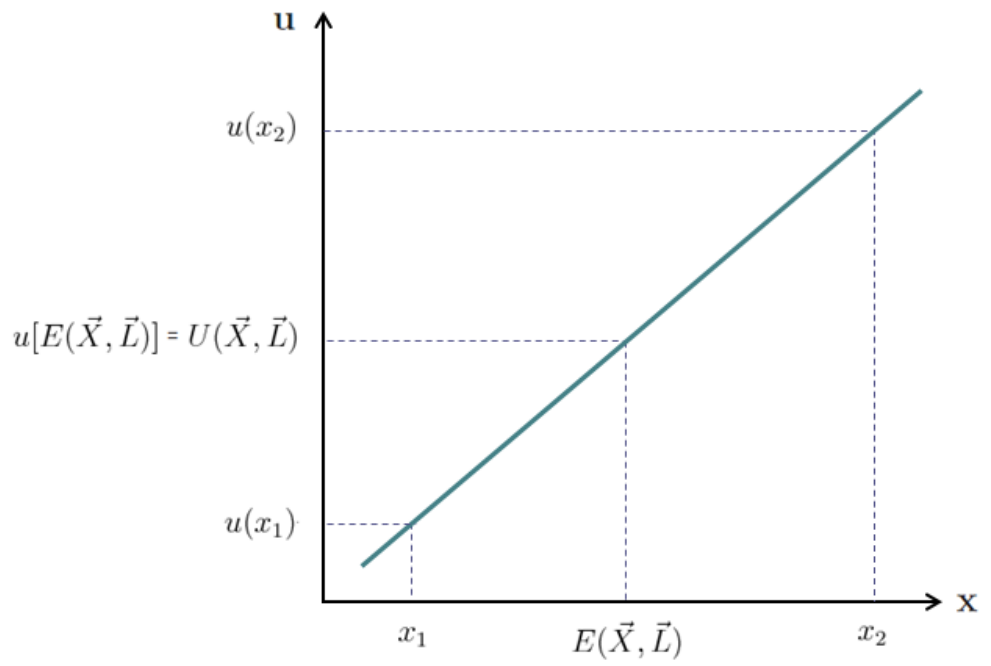

Figura 4.4 - Função utilidade hipotética para tomadores de decisão neutros ao risco [73]. 


\section{Capítulo}

\section{Teorias da utilidade não-esperada}

Estudos empíricos desde o início dos anos 50 tem revelado uma variedade de padrões no comportamento de indivíduos frente a escolhas que são inconsistentes com a EUT. Estas evidências levaram ao desenvolvimento de novas teorias envolvendo tomadas de decisão probabilísticas, chamadas teorias da utilidade não-esperada (NEUT), que pudessem incorporar as anomalias apresentadas pela EUT. A NEUT se divide em duas grandes categorias: as teorias que tem possíveis explicações em termos de alguma teoria convencional de preferências (teorias convencionais) e aquelas que aparentemente não (teorias não-convencionais). Ambas são descritas neste capítulo.

Para facilitar o entendimento destas teorias, cada par

$$
\vec{X}=\left[\begin{array}{c}
x_{1} \\
x_{2} \\
\vdots \\
x_{n}
\end{array}\right] \text { e } \vec{L}=\left[\begin{array}{c}
p_{1} \\
p_{2} \\
\vdots \\
p_{n}
\end{array}\right]
$$

será representado na forma de um prospecto:

$$
\vec{P}=\left[\begin{array}{c}
\left(x_{1}, p_{1}\right) \\
\left(x_{2}, p_{2}\right) \\
\vdots \\
\left(x_{n}, p_{n}\right)
\end{array}\right]
$$


que é um contrato que fornece o resultado $x_{i}$ com probabilidade $p_{i}$, onde $p_{1}+p_{2}+$ $\ldots+p_{n}=1$.

\subsection{Anomalias da utilidade esperada}

Um dos experimentos mais conhecidos que demonstraram a violação sistemática da EUT foi o paradoxo proposto por Allais [63]. Considere uma escolha hipotética entre os prospectos $\vec{P}_{1}$ e $\vec{P}_{2}$, dados por:

$$
\overrightarrow{P_{1}}=\left[(1 \text { milhão; 100\%) }] ; \quad \overrightarrow{P_{2}}=\left[\begin{array}{c}
(5 \text { milhões } ; 10 \%) \\
(1 \text { milhão } ; 89 \%) \\
(0 ; 1 \%)
\end{array}\right]\right. \text {. }
$$

Qual dos prospectos seria escolhido? Assim como esperado por Allais, indivíduos sujeitos a estas escolhas optaram pelo prospecto $\vec{P}_{1}$, incentivados pela certeza de se tornarem milionários. Segundo os princípios da teoria da utilidade esperada, a preferência por $\vec{P}_{1}$ a $\vec{P}_{2}$ indica que $U\left(\vec{P}_{1}\right)>U\left(\vec{P}_{2}\right)$. A partir da Eq. (4.3) tem-se:

$$
u(1 \text { milhão }) \times 0,11>u(5 \text { milhões }) \times 0,10+u(0) \times 0,01 .
$$

Considere agora um segundo caso de escolha entre os prospectos $\vec{P}_{3}$ e $\vec{P}_{4}$, dados por:

$$
\overrightarrow{P_{3}}=\left[\begin{array}{c}
(1 \text { milhão } ; 11 \%) \\
(0 ; 89 \%)
\end{array}\right] ; \quad \vec{P}_{4}=\left[\begin{array}{c}
(5 \text { milhões } ; 10 \%) \\
(0 ; 90 \%)
\end{array}\right] \text {. }
$$

Qual entre ambos os prospectos seria escolhido? A maioria dos indivíduos preferiu o prospecto $\vec{P}_{4}$, dado que as probabilidades de ambos são similares, mas o prêmio oferecido pelo prospecto $\vec{P}_{4}$ é significativamente maior que o oferecido por $\vec{P}_{3}$. Entretanto, segundo a EUT, a relação $\vec{P}_{4} \succ \vec{P}_{3}$ resulta em:

$$
u(5 \text { milhões }) \times 0,10+u(0) \times 0,01>u(1 \text { milhão }) \times 0,11,
$$

o que contradiz a desigualdade obtida no caso anterior para as loterias $\vec{P}_{1}$ e $\vec{P}_{2}$. Este famoso paradoxo desempenhou um papel importante no desenvolvimento das teorias que criticaram as hipóteses da utilidade esperada.

O paradoxo de Allais representou a primeira evidência de que o comportamento de escolha de indivíduos pode violar sistematicamente o axioma da independência que fundamenta a EUT. A partir do final de 1970, uma série de teorias, 
conhecidas como convencionais, exploraram esta evidência. Essa ramificação das NEUT apresenta três características em comum:

(i) As preferências são representadas por alguma função $U($.$) bem definida sobre$ prospectos;

(ii) A função $U($.$) satisfaz os axiomas de ordenação e continuidade;$

(iii) $U($.$) é projetada para permitir as violações observadas do axioma da indepen-$ dência, mas o princípio da monotonicidade é mantido.

Assim, a linha de desenvolvimento das teorias convencionais é baseada em funções bem definidas de preferência, consistentes com as violações observadas do axioma da independência. Duas suposições implícitas de qualquer teoria convencional são:

1. Invariância de procedimento: a preferência sobre prospectos é independente do método utilizado para descrevê-los;

2. Invariância de descrição: a preferência sobre prospectos é função puramente das distribuições de probabilidade das consequências e, portanto, não dependem de como estas distribuições são descritas.

Embora estas suposições assumidas pelas teorias convencionais pareçam naturais a qualquer teoria econômica de decisão, existe uma ampla evidência de que, na prática, ambas não são obedecidas.

Um experimento que permite verificar facilmente a violação da invariância de procedimento é composto por duas tarefas [74]. Na primeira tarefa, um indivíduo deve escolher entre dois prospectos: um que ofereça uma boa recompensa com probabilidade de recebimento pequena $\left(\vec{P}_{1}\right)$ e outro que ofereça uma recompensa de menor valor, porém com uma maior chance de ganho $\left(\vec{P}_{2}\right)$. Por exemplo, considere $\vec{P}_{1}=[(500 ; 10 \%)]$ e $\vec{P}_{2}=[(100 ; 90 \%)]$. Na segunda tarefa, o mesmo indivíduo deve atribuir valores monetários a ambos os prospectos. Estudos desenvolvidos por psicólogos mostraram uma forte tendência dos indivíduos a escolher $\vec{P}_{2}$ na primeira tarefa, mas atribuir maior valor monetário a $\vec{P}_{1}$ na segunda tarefa [75]. Esta violação não é naturalmente aceita pela teoria econômica padrão, pois, embora ambas as 
tarefas explorem a mesma questão sobre quais dos dois prospectos é preferido, uma inversão das preferências é observada de acordo com o procedimento utilizado.

Estudos evidenciam também que pequenas alterações na descrição dos prospectos podem alterar as escolhas dos tomadores de decisão, violando a invariância de descrição assumida pelas teorias convencionais. Considere, por exemplo, o experimento desenvolvido por Tversky e Kahneman em 1981 [76]. Dois grupos de indivíduos (I e II) foram apresentados ao seguinte problema: uma doença asiática incomum se disseminará em um país, a qual levará à morte de 600 pessoas. Foram, então, propostas a cada grupo dois possíveis programas para minimizar tal problema, conforme mostrado na Tabela 5.1. Para o grupo I, se o programa A fosse adotado, 200 pessoas seriam salvas; se o programa B fosse escolhido, haveria uma chance de $1 / 3$ de que 600 pessoas fossem salvas e de $2 / 3$ de que ninguém fosse salvo. Para o grupo II, se o programa C fosse selecionado, 400 pessoas iriam morrer; se o programa $\mathrm{D}$ fosse adotado, haveria $1 / 3$ de chance de não ocorrer mortes e $2 / 3$ de chance de 600 pessoas morrerem. Note que a informação é apresentada ao grupo I em termos de vidas salvas e ao grupo II em termos de vidas perdidas, embora os dois pares de opções sejam estocasticamente equivalentes. Os resultados experimentais mostraram, entretanto, que a maioria dos indivíduos no grupo I preferiu o programa $\mathrm{A}$ ao $\mathrm{B}$, enquanto que a maioria dos indivíduos no grupo II preferiu o programa D ao C.

Tabela 5.1 - Problema da doença asiática proposto por Tversky e Kahneman: para o grupo I, o cenário é apresentado em termos de vidas salvas; para o grupo II em termos de vidas perdidas [76].

\begin{tabular}{|c|c|c|c|}
\hline \multicolumn{3}{|c|}{ Doença asiática: $\sim 600$ pessoas morrerão } \\
\hline & Grupo I & \multicolumn{2}{c|}{ Grupo II } \\
\hline \multirow{2}{*}{ Programa A } & 200 vidas salvas $; p=1$ & Programa C & 400 mortes $; p=1$ \\
\hline \multirow{2}{*}{ Programa B } & $\begin{array}{c}600 \text { vidas salvas } ; p=1 / 3 \\
0 \text { vidas salvas } ; p=2 / 3\end{array}$ & Programa D & 0 mortes $; p=1 / 3$ \\
& 000 mortes $; p=2 / 3$ \\
\hline \hline
\end{tabular}


Violações da invariância de procedimento e da invariância de descrição não podem ser explicadas a partir de uma única função de preferência bem definida $(U()$.$) sobre prospectos, como assumido pela EUT e pelas teorias convencionais de$ utilidade não-esperada. Este aspecto tem sido fortemente explorado pelas chamadas teorias não-convencionais. Neste domínio, a preferência de indivíduos frente a tomadas de decisão é explorada a partir de conceitos mais familiares à psicologia que à economia.

Como mostrado na Fig. 5.1, o domínio convencional da NEUT consiste primariamente de críticas às violações do axioma da independência da EUT; o domínio não-convencional explora críticas à suposição da EUT de que escolhas podem ser representadas por funções de preferência bem definidas. Ambos os domínios são explorados nas seções a seguir.

\section{Limitações da EUT}

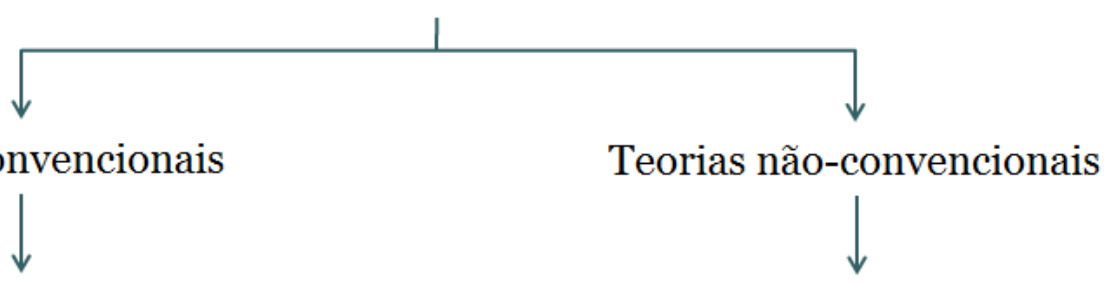

Crítica: Axioma da independência

Crítica: Função de preferência bem definida

Figura 5.1 - Domínios da teoria da utilidade não-esperada. O domínio convencional consiste primariamente de críticas ao axioma da independência. $\mathrm{O}$ domínio não-convencional explora críticas à suposição de que escolhas podem ser representadas por funções de preferência bem definidas.

\subsection{Teorias convencionais}

A principal motivação para o desenvolvimento do domínio convencional foi explorar quais propriedades uma teoria convencional de preferência deveria ter para explicar as violações observadas do axioma da independência. Como mencionado anteriormente, este axioma desempenha papel fundamental na teoria da utilidade esperada, dado que ele impõe fortes restrições à forma precisa da função de preferên- 
cias. Dois exemplos importantes da violação sistemática do axioma da independência são o efeito da consequência comum e o efeito da razão comum.

O paradoxo proposto por Allais descrito anteriormente é um exemplo do efeito da consequência comum. Esse efeito envolve escolhas entre par de prospectos da forma:

$$
\vec{P}_{1}=\left[\begin{array}{c}
(y ; p) \\
(c ; 1-p)
\end{array}\right] \text { e } \vec{P}_{2}=\left[\begin{array}{c}
\left(\vec{P}_{3} ; p\right) \\
(c ; 1-p)
\end{array}\right] \text {, sendo } \vec{P}_{3}=\left[\begin{array}{c}
(x ; \lambda) \\
(0 ; 1-\lambda)
\end{array}\right]
$$

e $0<\lambda<1$. As consequências $c, x$ e $y$ são não-negativas e $x>y$. Note que os prospectos $\vec{P}_{1}$ e $\vec{P}_{2}$ oferecem $c$ com probabilidade $1-p$, que é a consequência comum. Pelo axioma da independência da EUT, as escolhas entre ambos os prospectos deveria ser independente do valor de $c$. Vários estudos mostram, entretanto, que a escolha entre prospectos com essa estrutura é sistematicamente influenciada pelo valor de $c$. Em geral, se $c=y$, o prospecto $\vec{P}_{1}$ é escolhido; se $c=0$, o prospecto $\vec{P}_{2}$ é preferido.

O efeito da razão comum, também descoberto por Allais, é observado em escolhas entre prospectos da forma:

$$
\vec{P}_{1}=\left[\begin{array}{c}
(y ; p) \\
(0 ; 1-p)
\end{array}\right] \text { e } \vec{P}_{2}=\left[\begin{array}{c}
(x ; \lambda p) \\
(0 ; 1-\lambda p)
\end{array}\right]
$$

sendo $x>y$. O axioma da independência implica que preferências não deveriam ser influenciadas pelo valor de $p$. Diversos experimentos revelam, entretanto, uma tendência de indivíduos a mudar suas preferências de $\vec{P}_{1}$ para $\vec{P}_{2}$ conforme $p$ diminui.

Mark Machina, em 1982, propôs uma extensão da teoria da utilidade esperada a partir da concavidade da função utilidade $u($.$) [77]. Baseado na existência$ dos efeitos da consequência comum e da razão comum, ele propôs a chamada hipótese do "fanning-out": a função utilidade $u($.$) se torna mais côncava à medida$ que se passa de distribuições estocasticamente dominadas a distribuições estocasticamente dominantes. Em outras palavras, a hipótese do "fanning-out" assume que indivíduos se tornam mais avessos ao risco conforme os prospectos apresentados se tornam melhores, o que gera implicações consistentes com os efeitos observados da consequência comum e da razão comum. 
Diversos modelos convencionais adotaram a propriedade do "fanning-out", utilizando uma forma enfraquecida do axioma da independência. Dentre eles, destaca-se a teoria da utilidade ponderada (WUT), desenvolvida por Soo Hong Chew e MacCrimmon em 1979, na qual preferências sobre prospectos são representadas pela função [78]:

$$
U(\vec{P})=\frac{\Sigma p_{i} \cdot g\left(x_{i}\right) \cdot u\left(x_{i}\right)}{\Sigma p_{i} \cdot g\left(x_{i}\right)}
$$

sendo $u($.$) e g($.$) duas funções distintas que atribuem pesos não-nulos às consequên-$ cias. Este modelo incorpora a EUT para o caso específico em que $g($.$) é constante.$

Assim como a WUT, outros modelos convencionais atendem de diferentes formas à hipótese do "fanning-out", gerando funções de escolha capazes de explicar as primeiras violações da EUT. Uma similaridade estrutural entre estes modelos é que eles resultam da atribuição de pesos subjetivos (ou utilidades) às consequências. O valor atribuído a um dado prospecto é determinado pela combinação destas utilidades com probabilidades objetivas.

Um segundo ramo das teorias convencionais envolvem o uso de funções de escolha que transformam probabilidades objetivas em pesos de decisão subjetivos. Essas teorias são baseadas em fortes evidências experimentais de que indivíduos ponderam subjetivamente probabilidades objetivas. Em geral, elas podem ser entendidas como variantes de uma forma funcional de decisão ponderada, dada por:

$$
U(\vec{P})=\sum_{i} u\left(x_{i}\right) \cdot w_{i}
$$

onde os termos $w_{i}$ representam pesos de decisão. Teorias deste tipo foram inicialmente discutidas por Ward Edwards, em 1955 [79]. Em sua forma mais simples, chamada valor esperado subjetivo, as probabilidades são ponderadas por pesos de decisão, enquanto assume-se $u\left(x_{i}\right)=x_{i}$ para todo $i$. Na versão apresentada por Jagdishy Handa em 1977 [80], o peso de decisão atribuído a cada recompensa é determinado por uma função ponderada de probabilidade, $\pi\left(p_{i}\right)$, que transforma as probabilidades de cada recompensa diretamente em pesos. A maioria das teorias que incorporam essa função assumem que $\pi($.) é crescente, com $\pi(1)=1$ e $\pi(0)=0$. 
A forma do valor esperado subjetivo não foi amplamente utilizada, mas teorias que incorporaram transformações não-lineares de ambas, consequências e probabilidades, se destacaram. O modelo mais simples neste caso assume que a preferência de indivíduos pode ser representada pela função:

$$
U(\vec{P})=\sum u\left(x_{i}\right) \cdot \pi\left(p_{i}\right)
$$

Esta forma é conhecida como utilidade ponderada de decisão simples (SDWU). Devido à transformação direta das probabilidades individuais de cada consequência, a SDWU não satisfaz de forma geral a propriedade da monotonicidade. A única forma de garantir monotonicidade neste tipo de teoria é igualar os pesos de decisão às probabilidades objetivas de cada consequência, $w_{i}=\pi\left(p_{i}\right)=p_{i}$, o que reduz a Eq. (5.3) à forma funcional da EUT. Dado que a monotonicidade é amplamente aceita como uma propriedade base que qualquer teoria econômica de decisão deveria assumir, os esforços no domínio das teorias convencionais ao longo das duas décadas seguintes foram focados na determinação de uma forma para os pesos de decisão que satisfizesse esta propriedade.

A ideia central do desenvolvimento das teorias convencionais foi a proposta de modelos ponderados de decisão com transformações de probabilidades mais sofisticadas, garantindo a monotonicidade de $U($.$) [74]. Um modelo que se destacou$ nessa linha de desenvolvimento, proposto por John Quiggin em 1982 [81], foi a teoria da utilidade esperada dependente da ordenação (RDUT). Neste modelo, o peso associado a uma dada consequência de um prospecto depende não somente da probabilidade a ela associada, como também da sua ordenação em relação às demais recompensas do prospecto. Considere $x_{1}, \ldots, x_{n}$ um conjunto de possíveis consequências ordenadas da pior $x_{1}$ até a melhor $x_{n}$. A hipótese da RDUT assume que indivíduos maximizam a forma funcional de decisão ponderada [Eq. (5.2)] a partir de pesos dados por:

$$
\begin{gathered}
w_{i}=\pi\left(p_{i}+\ldots+p_{n}\right)-\pi\left(p_{i+1}+\ldots+p_{n}\right), \text { se } i=1, \ldots, n-1 \\
w_{i}=\pi\left(p_{i}\right), \text { se } i=n .
\end{gathered}
$$

Note que $\pi\left(p_{i}+\ldots+p_{n}\right)$ é um peso subjetivo atribuído à probabilidade de se obter uma consequência melhor ou igual a $x_{i}$, e $\pi\left(p_{i+1}+\ldots+p_{n}\right)$ é um peso atribuído à 
probabilidade de se obter uma consequência melhor que $x_{i}$. Portanto, $\pi($.$) é uma$ transformação sobre probabilidades acumuladas. Este procedimento garante que $U($.$) satisfaz monotonicidade. Além disso, o peso atribuído a uma consequência$ pode variar de acordo com o quão boa ou ruim ela é comparada às demais consequências do prospecto. Como descrito anteriormente, o axioma da independência da EUT determina que a preferência entre prospectos não é alterada pela substituição de consequências comuns. A RDUT, entretanto, baseada numa forma fraca do axioma da independência, determina que essa substituição somente não afetará as preferências se a mudança no valor da consequência comum não alterar a ordenação das recompensas.

Os pressupostos da RDUT dependem crucialmente da forma de $\pi($.$) . Quig-$ gin [81] propôs inicialmente para $\pi($.$) a forma de um "S" invertido, como mostrado$ na Fig. 5.2. $\pi(p)=p$ somente para o valor $p=p^{*}=0,5$, sendo côncava para probabilidades menores que $p^{*}\left(p<p^{*}\right)$ e convexa para $p>p^{*}$. Esta forma é capaz de explicar as primeiras violações da EUT. Trabalhos mais recentes têm avaliado possíveis formas analíticas que atendam às propriedades esperadas para a função $\pi($.$) , de forma a garantir que a RDUT possa incorporar violações observadas ex-$ perimentalmente para a EUT. Estes trabalhos serão melhor explorados no capítulo 6.

A Fig. 5.3 mostra um esquema das teorias da utilidade não-esperada convencionais, que foram descritas anteriormente. A seção a seguir apresenta o domínio das teorias que criticam a EUT sob uma aproximação não-convencional. Em particular, destacaremos o trabalho desenvolvido por Kahneman e Tversky, em 1979, que resultou no desenvolvimento da chamada teoria do prospecto.

\subsection{Teorias não-convencionais}

As teorias convencionais associam as decisões de indivíduos à maximização de uma função de preferência, sem pressupor que o modelo corresponda às atividades mentais realmente envolvidas numa tomada de decisão. Enquanto essa metodologia, em geral, domina a teoria econômica pela sua maior simplicidade, uma abordagem mais comum na psicologia procura modelar o processo que leva à escolha. As teo- 


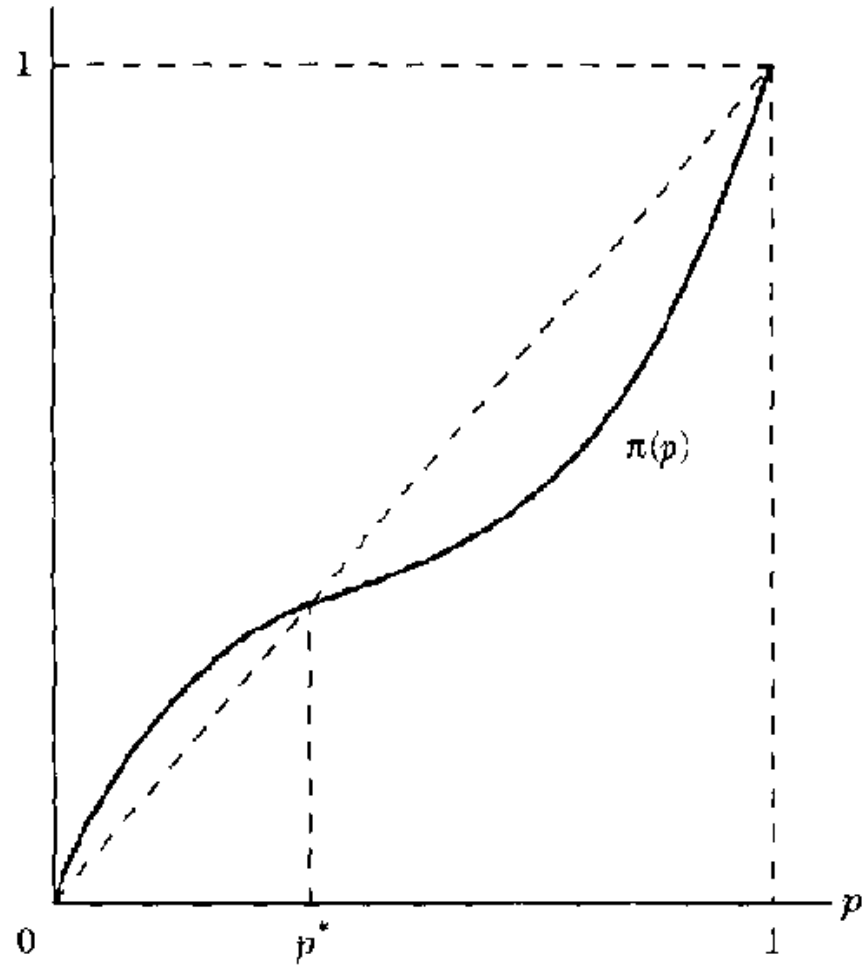

Figura 5.2 - Forma hipotética da função de ponderação de probabilidades. $\pi(p)=p$ somente para $p=p^{*}$, sendo côncava para $p<p^{*}$ e convexa para $p>p^{*}$. Quiggin [81] propôs $p^{*}=0,5$.

rias que seguem esta última abordagem são chamadas não-convencionais. Uma característica comum a estes modelos é assumir que indivíduos se baseiam em heurísticas (regras) de escolha que variam de acordo com o contexto em que a tomada de decisão está inserida. A dificuldade, neste casos, é determinar o conjunto de heurísticas que o tomador de decisão segue e em quais condições específicas elas serão utilizadas [74]. O contexto passa a ser relevante para a tomada de decisão.

No campo das críticas atribuídas à EUT como modelo padrão de tomada de decisão envolvendo risco, pode-se destacar um modelo não-convencional desenvolvido por Daniel Kahneman e Amos Tversky em 1979 [64]: a teoria do prospecto (PT). Neste trabalho, baseados nas respostas de estudantes a problemas hipotéticos envolvendo escolhas entre prospectos, os autores demonstraram vários fenômenos que violaram alguns princípios da EUT.

Inicialmente, baseados no paradoxo de Allais, Kahneman e Tversky mostraram que pessoas superponderam resultados que são considerados certos em relação 


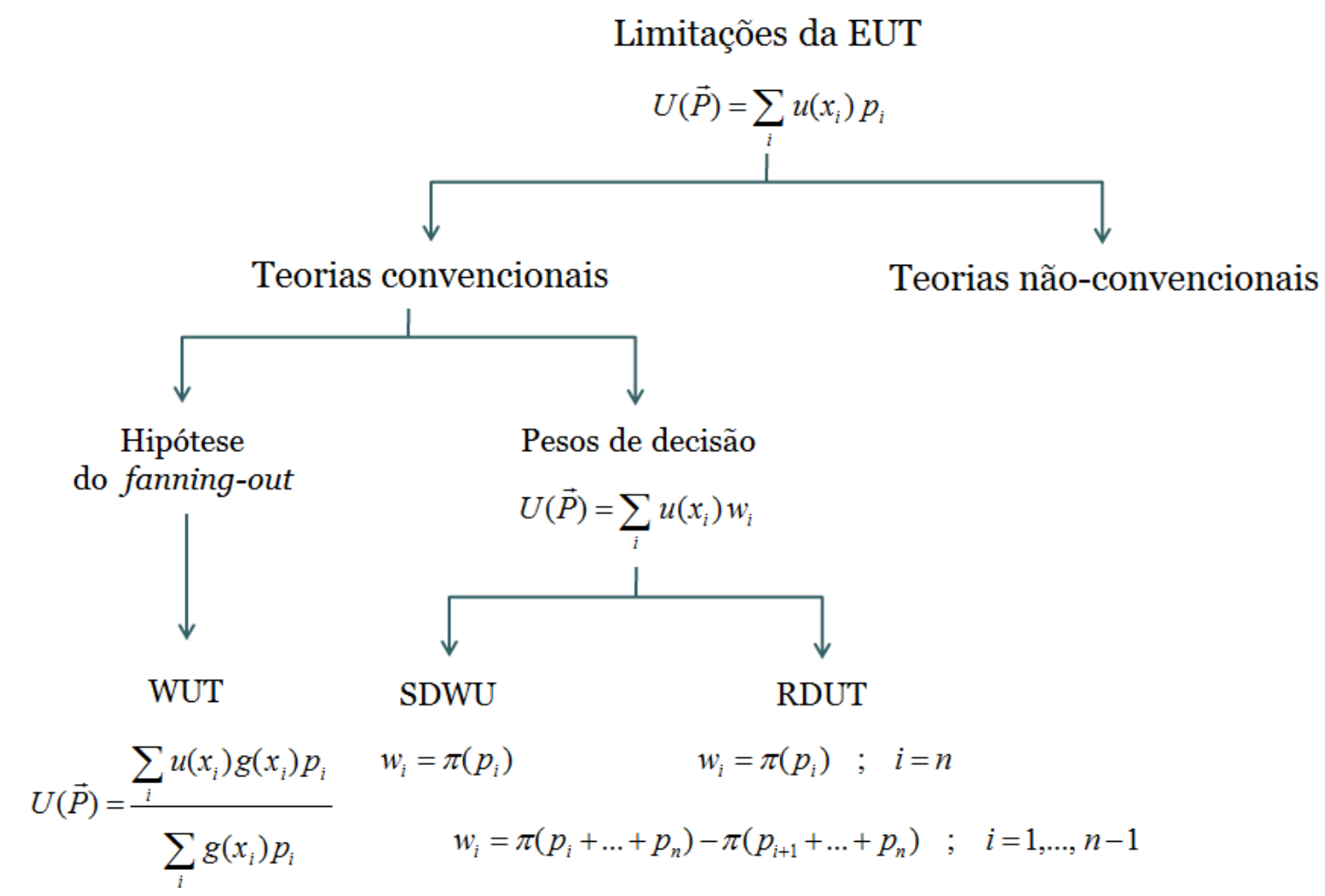

Figura 5.3 - Representação esquemática das teorias convencionais da NEUT, as quais consistem primariamente de críticas às violações do axioma da independência da EUT.

a resultados que são meramente prováveis - um fenômeno que chamaram de efeito certeza. Este efeito é um caso particular do efeito da razão comum.

Os autores exploraram também exemplos envolvendo prospectos em que o sinal das recompensas é negativo, ou seja, exemplos em que ganhos foram substituídos por perdas. Os resultados mostraram que a preferência entre prospectos negativos é a imagem refletida da preferência entre prospectos positivos, ou seja, a ordem de preferências é invertida quando recompensas positivas são substituídas por recompensas negativas. Este padrão foi chamado de efeito reflexão. O efeito reflexão implica que a aversão ao risco no domínio positivo é acompanhada pela propensão ao risco no domínio negativo. A propensão ao risco em escolhas entre prospectos negativos foi observada inicialmente por Markowitz [82]. Assim como no domínio positivo, Kahneman e Tversky mostraram que perdas certas são superponderadas em relação a perdas prováveis (efeito certeza). No domínio positivo, o efeito certeza 
contribui para a preferência (avessa ao risco) por um ganho certo em relação a um ganho maior meramente provável. No domínio negativo, o mesmo efeito leva a uma preferência (propensa ao risco) por uma perda meramente provável a uma perda menor, porém certa. O exemplo da doença asiática é consistente com o efeito reflexão: quando as consequências são descritas em termos de vidas salvas, tomadores de decisão são avessos ao risco e optam pelo ganho certo de 200 vidas; quando as opções são descritas como mortes (perdas), a maioria dos indivíduos rejeita a morte certa de 400 pessoas e assume a opção de maior risco.

Por fim, os autores propuseram escolhas entre pares de problemas idênticos em relação a recompensas e probabilidades finais, porém variando a forma de representação das probabilidades ou das recompensas. Os resultados mostraram que, de modo a simplificar escolhas entre alternativas, indivíduos, em geral, desconsideram componentes (probabilidades ou valores) que são comuns às alternativas e focam nas componentes que as diferem. O fenômeno foi chamado de efeito isolamento. Este tipo de aproximação pode resultar em preferências inconsistentes, pois um par de prospectos pode ser decomposto em componentes comuns e distintas de diferentes formas, e decomposições distintas, em alguns casos, levam a preferências distintas.

Considere, por exemplo, um jogo composto por duas etapas [64]. Na primeira etapa, existe uma probabilidade de $75 \%$ do participante terminar o jogo sem ganhar nada e $25 \%$ de chance de ir para a segunda etapa. Caso chegue à segunda etapa, o participante deve escolher entre dois prospectos:

$$
\vec{P}_{1}=[(R \$ 4000 ; 80 \%)] \quad \text { e } \quad \vec{P}_{2}=[(R \$ 3000 ; 100 \%)] .
$$

A escolha deve ser feita antes que o resultado da primeira etapa seja conhecido. Esta formulação do problema é chamada sequencial e está mostrada na Fig. 5.4(a). Em termos de recompensas e probabilidades finais, o jogo em questão pode ser visualizado em uma única etapa, onde os participantes devem escolher entre os prospectos

$$
\vec{P}_{1 f}=[(R \$ 4000 ; 20 \%)] \quad \text { e } \quad \vec{P}_{2 f}=[(R \$ 3000 ; 25 \%)] .
$$

Esta configuração final está mostrada na Fig. 5.4(b). Embora ambas as formulações, sequencial e final, representem o mesmo problema, Kahneman e Tversky mostraram que a escolha dos participantes se altera de acordo com a formulação escolhida. Isso ocorre porque quando indivíduos são submetidos à formulação sequencial, eles 
ignoram a primeira etapa do jogo, comum aos dois prospectos. Desta forma, as consequências e probabilidades finais avaliadas pelo participante não são equivalentes nas duas situações.

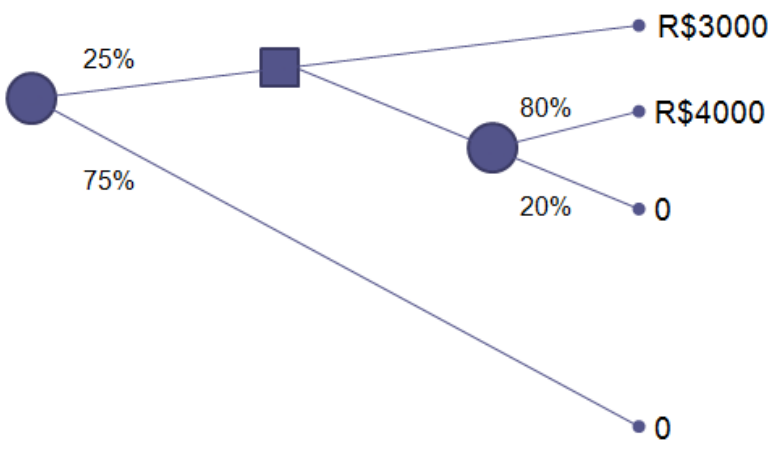

(a) Sequencial

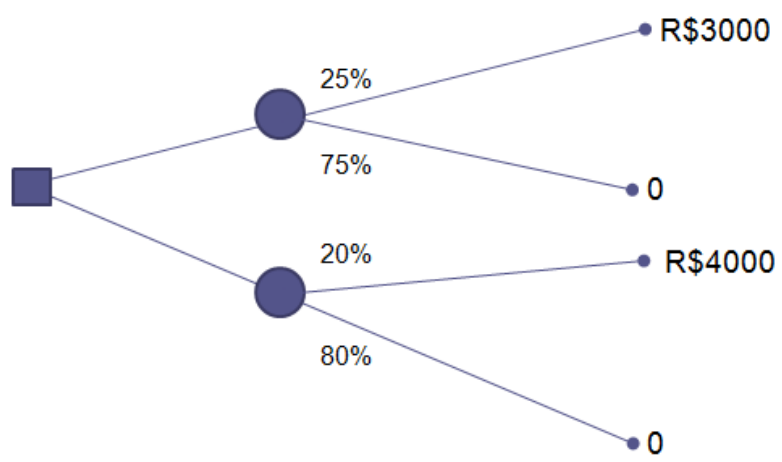

(b) Final

Figura 5.4 - Formulações (a) sequencial e (b) final de um jogo de duas etapas envolvendo prospectos.

O efeito isolamento leva a uma das principais críticas feitas à EUT: indivíduos percebem recompensas como ganhos e perdas em relação a um ponto de referência, e não como estados finais de riqueza ou bem-estar (como proposto pela EUT). Markowitz foi o primeiro a propor esta crítica [82]. Em um experimento, Kahneman e Tversky propuseram aos participantes dois problemas de escolha entre 
prospectos [64]:

- Problema 1: Suponha que você possui um bônus de $R \$ 1000$, independente da opção a ser escolhida. Quais dentre os prospectos você prefere?

$$
\vec{P}_{1}=[(R \$ 1000 ; 50 \%)] \quad ; \quad \vec{P}_{2}=[(R \$ 500 ; 100 \%)]
$$

- Problema 2: Suponha que você possui um bônus de $R \$ 2000$, independente da opção a ser escolhida. Quais dentre os prospectos você prefere?

$$
\vec{P}_{3}=[(-R \$ 1000 ; 50 \%)] \quad ; \quad \vec{P}_{4}=[(-R \$ 500 ; 100 \%)]
$$

Note que ambos os problemas, considerando valores e probabilidades finais, representam a mesma escolha entre os prospectos

$$
\vec{P}_{1}=\vec{P}_{3}=\left[\begin{array}{c}
(R \$ 2000 ; 50 \%) \\
(R \$ 1000 ; 50 \%)
\end{array}\right] \text { e } \vec{P}_{2}=\vec{P}_{4}=[(R \$ 1500 ; 100 \%)] .
$$

Entretanto, verificou-se que a maioria dos indivíduos preferiu o prospecto $\vec{P}_{2}$ no primeiro problema e o prospecto $\vec{P}_{3}$ no segundo. Isso ocorre porque indivíduos não incorporam o bônus ao avaliarem os prospectos; eles avaliam apenas ganhos e perdas em relação ao ponto de referência (bônus) imposto inicialmente.

A partir das anomalias observadas, Kahneman e Tversky formularam os princípios da PT. Essa teoria distingue duas fases no processo de escolha: uma fase inicial de edição e uma fase subsequente de avaliação. A fase de edição consiste em uma análise preliminar dos prospectos oferecidos, em que as heurísticas de decisão são utilizadas para simplificar esses prospectos. Várias anomalias de preferência resultam da edição dos prospectos. Por exemplo, as inconsistências associadas ao efeito isolamento resultam do cancelamento de componentes comuns aos prospectos. $\mathrm{Na}$ segunda fase, a fase de avaliação, os prospectos editados são avaliados e o prospecto de maior valor é escolhido. O valor total de um prospecto editado, denotado por $V$, é expresso em termos de duas escalas, $v$ e $\pi$.

A primeira escala, $v$, associa a cada resultado $x$ um número $v(x)$, o qual reflete o valor subjetivo da respectiva recompensa. Entretanto, as recompensas 
nessa teoria são definidas em relação a um ponto de referência, o qual serve como o ponto zero da escala de valor. Assim, ao contrário da EUT, $v$ mede o valor que representa desvios em relação a um dado ponto de referência, ou seja, ganhos e perdas. O ponto de referência, na maioria dos problemas de escolha, é tomado como a posição corrente dos ativos (ou riqueza corrente) de um indivíduo. Porém existem algumas situações nas quais ganhos e perdas podem ser codificados em relação a um nível diferente de riqueza, de acordo com a forma de apresentação das loterias ou ainda pelas expectativas dos tomadores de decisão. Além disso, Kahneman e Tversky assumiram que a função $v$ deve ser côncava acima do ponto de referência $\left(v^{\prime \prime}(x)<0\right.$, para $\left.x>0\right)$ e convexa abaixo dele $\left(v^{\prime \prime}(x)>0\right.$, para $\left.x<0\right)$. Ou seja, o valor marginal de ambos, ganhos e perdas, geralmente decresce com sua magnitude. Os autores também consideraram uma característica saliente de atitudes frente a perdas e ganhos: a frustração de se perder uma soma em dinheiro parece ser maior que o prazer associado ao ganho de uma mesma quantia. Assim, a PT assume que a função de valor para perdas é mais acentuada que a função de valor para ganhos, ou seja, $v^{\prime}(x)<-v^{\prime}(-x)$, para todo $x$. Uma função de valor que satisfaça estas propriedades é uma função em forma de S, como mostrada na Fig. 5.5. O ponto de referência é a origem do gráfico.

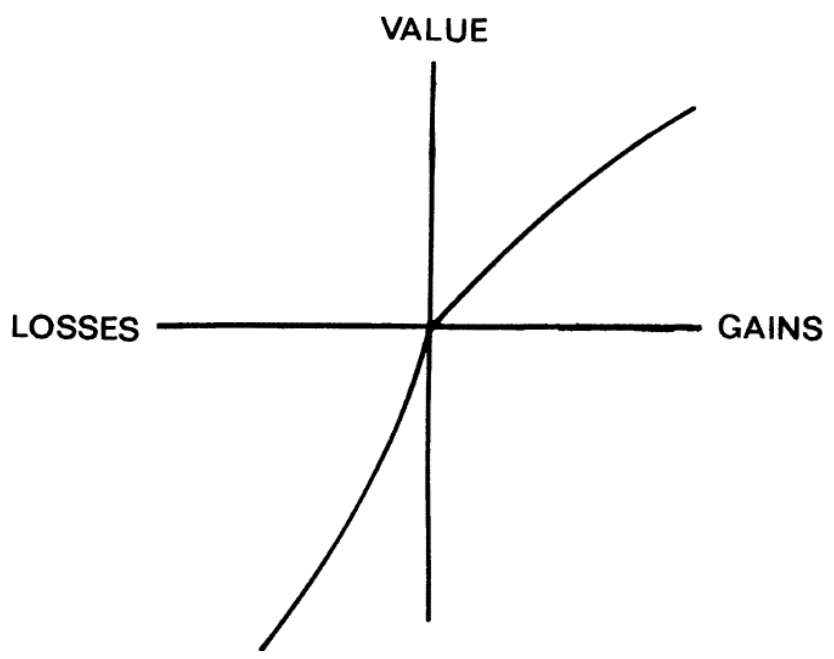

Figura 5.5 - Função de valor hipotética proposta por Kahneman e Tversk [64].

A segunda escala, $\pi$, associa diretamente a cada probabilidade $p$ um peso de decisão $\pi(p)$, que reflete o impacto de $p$ no valor total do prospecto. A função peso 
para pequenos valores de $p$ é subaditiva, ou seja, $\pi(r p)>r \pi(p)$ para $0<r<1$. Além disso, pequenas probabilidades são geralmente superponderadas, de modo que $\pi(p)>p$, para pequenos valores de $p$. Embora $\pi(p)>p$ para pequenas probabilidades, evidências experimentais sugeriram que, pra todo $0<p<1, \pi(p)+\pi(1-p)<1$. Essa propriedade é chamada de subcerteza. Uma análise do problema proposto originalmente por Allais [63] confirma essa propriedade descrita por Kahneman e Tversky. A inclinação de $\pi$, no intervalo $(0,1)$, pode ser vista como uma medida da sensibilidade das preferências a mudanças na probabilidade. A subcerteza implica que $\pi$ é regressiva em relação a $p$, ou seja, as preferências são geralmente menos sensíveis a variações de probabilidade que o princípio da expectância poderia predizer. Assim, a subcerteza captura um elemento essencial da atitude das pessoas frente a eventos incertos, ou seja, a soma dos pesos associados a eventos complementares é tipicamente menor que o peso associado ao evento certo. Kahneman e Tversky observaram ainda que para uma razão fixa de probabilidades, a razão dos pesos de decisão correspondentes está mais próximo da unidade quando as probabilidades são pequenas do que quando são grandes. Essa propriedade de $\pi$ é chamada subproporcionalidade.

A Fig 5.6 apresenta a função peso hipotética, proposta por Kahneman e Tversky, que satisfaz a superponderação e subaditividade para pequenos valores de $p$, assim como as propriedades de subcerteza e subproporcionalidade. De acordo com estas propriedades, $\pi$ é relativamente suave no intervalo aberto, e muda abruptamente próximo aos extremos, onde $\pi(0)=0$ e $\pi(1)=1$. A descontinuidade de $\pi$ nas extremidades são consistentes com a noção de que pessoas são limitadas na sua habilidade de compreender e avaliar probabilidades extremas. Eventos altamente improváveis são ignorados ou superponderados, e a diferença entre grande probabilidade e certeza é negligenciada ou exagerada.

A equação básica da PT descreve como $\pi$ e $v$ são combinados para determinar o valor total de um prospecto regular:

$$
V(\vec{P})=\sum v\left(x_{i}\right) \cdot \pi\left(p_{i}\right)
$$

sendo, $v(0)=0, \pi(0)=0$ e $\pi(1)=1$. Assim como na EUT, $V($.$) é definida sobre$ prospectos, enquanto $v($.$) é definida sobre resultados. As duas escalas coincidem$ 


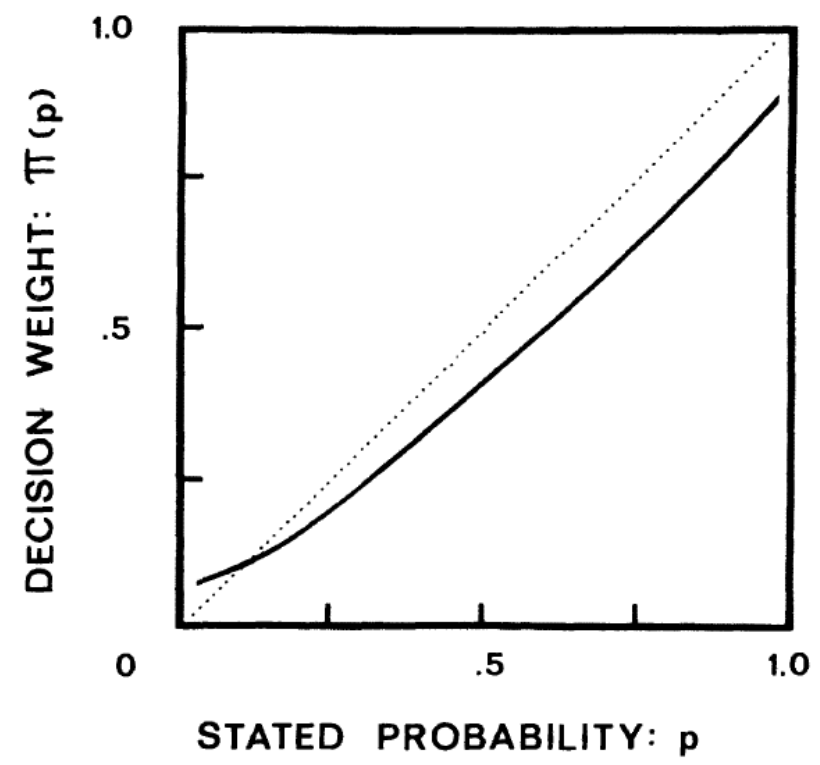

Figura 5.6 - Função peso hipotética proposta por Kahneman e Tversky [64].

para prospectos certos.

A equação da PT mantém a forma geral bilinear em que é baseada a EUT. Entretanto, valores são atribuídos a mudanças (ganhos e perdas) e não a estados finais, enquanto os pesos de probabilidades não coincidem com as probabilidades propostas. Devido à transformação direta das probabilidades individuais de cada consequência em pesos de decisão, a função de escolha da PT não satisfaz, de forma geral, à propriedade da monotonicidade. Este problema foi parcialmente solucionado pela suposição de outra regra de decisão chamada heurística de dominância: indivíduos eliminam prospectos dominados estocasticamente durante a fase de edição. É importante ressaltar que esta suposição feita por Kahneman e Tversky foi assumida apenas para prospectos cuja dominância estocástica pudesse ser detectada pelo tomador de decisão (dominância transparente). Por exemplo, no problema das bolinhas de gude apresentado anteriormente, é fácil verificar que a opção B domina a opção A, pois, para toda cor, o resultado oferecido por B é sempre ao menos tão bom quanto o oferecido por A. Entretanto, existem configurações de prospectos em que a dominância estocástica não é facilmente identificada pelo tomador de decisão (dominância opaca). Nestes casos, as violações de monotonicidade não podem ser captadas pelo modelo. Esta questão foi uma das fortes motivações que levaram Quiggin a desenvolver a RDUT [Eq. (5.4)], no contexto das teorias convencionais. 
A Fig. 5.7 apresenta uma síntese dos modelos que foram descritos até o momento. No ramo não-convencional, embora a PT seja fundamentada nos processos mentais realmente envolvidos nas tomadas de decisão, trabalhar com uma série de regras de decisão (fase de edição) dificulta a aplicação do modelo. O conjunto de heurísticas assumidas por um tomador de de decisão, assim como especificação das condições em que cada uma será aplicada, ou até mesmo a ordem desta aplicação, podem não ser tão claros. O princípio de de maximização de funções de escolha, adotado pelo ramo das teorias convencionais, facilita sua manipulação e as torna mais atraentes no contexto da teoria econômica.

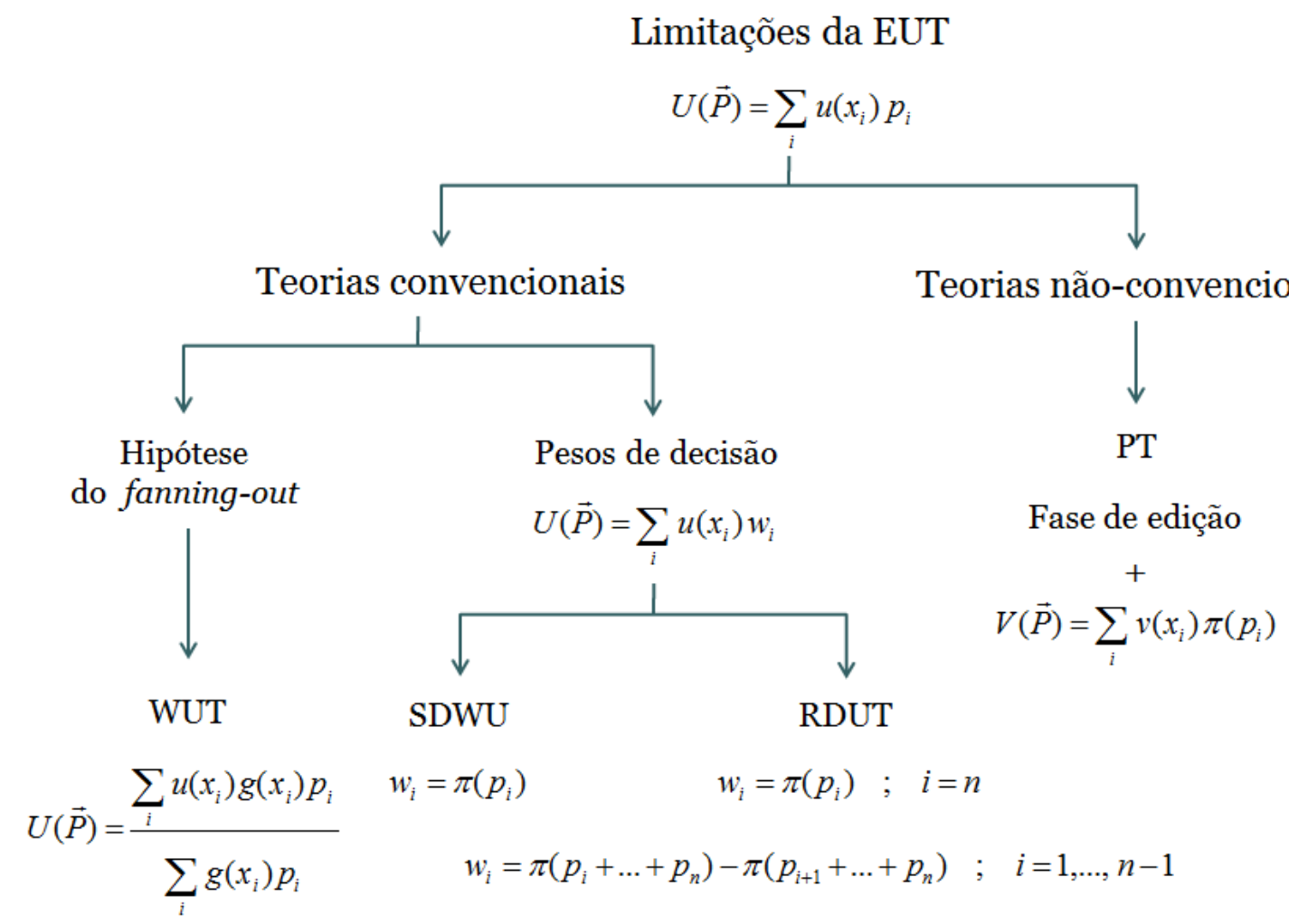

Figura 5.7 - Representação esquemática dos domínios convencionais e nãoconvencionais da NEUT.

\subsection{Teoria do prospecto acumulado}

Alguns modelos de escolha buscaram incorporar ao domínio convencional os princípios fundamentais de tomadas de decisão que emergiram com o desenvolvi- 
mento da PT. Em um trabalho desenvolvido em 1992 [83], Tversky e Kahneman mostraram que a forma funcional da teoria da utilidade esperada dependente da ordenação [Eq. (5.4)] poderia ser estendida para incorporar um elemento chave da teoria do prospecto: indivíduos percebem recompensas como ganhos e perdas em relação a pontos de referência. O modelo proposto, conhecido como teoria do prospecto acumulada (CPT), abandona a fase de edição que fundamenta a PT, mas mantém a avaliação de preferências em relação a um ponto de referência.

Na CPT, qualquer prospecto $\vec{P}$ é avaliado pela função:

$$
V(\vec{P})=V\left(\overrightarrow{P^{+}}\right)+V\left(\overrightarrow{P^{-}}\right)
$$

O termo $V\left(\overrightarrow{P^{+}}\right)$é a utilidade esperada do prospecto transformado $\overrightarrow{P^{+}}$, que corresponde ao prospecto $\vec{P}$ onde todas as recompensas negativas são substituídas por zero. De modo equivalente, $V\left(\overrightarrow{P^{-}}\right)$é a utilidade esperada do prospecto transformado $\overrightarrow{P^{-}}$, que corresponde ao prospecto $\vec{P}$ onde todas as recompensas positivas são substituídas por zero.

Considere, por exemplo, um jogo que envolve lançamentos de um dado. Neste jogo, se a face resultante for par, o jogador recebe $R \$ x$; se for ímpar, ele paga $R \$ x$. Assim, os possíveis resultados são $(-5,-3,-1,2,4,6)$, cada um com probabilidade de $1 / 6$. Neste caso,

$$
\vec{P}=\left[\begin{array}{c}
(-5 ; 1 / 6) \\
(-3 ; 1 / 6) \\
(-1 ; 1 / 6) \\
(2 ; 1 / 6) \\
(4 ; 1 / 6) \\
(6 ; 1 / 6)
\end{array}\right] \quad \overrightarrow{P^{+}}=\left[\begin{array}{c}
(0 ; 1 / 2) \\
(2 ; 1 / 6) \\
(4 ; 1 / 6) \\
(6 ; 1 / 6)
\end{array}\right] \text { e } \overrightarrow{P^{-}}=\left[\begin{array}{c}
(-5 ; 1 / 6) \\
(-3 ; 1 / 6) \\
(-1 ; 1 / 6) \\
(0 ; 1 / 2)
\end{array}\right] \text {. }
$$

Além disso, na CPT, os pesos de decisão atribuídos às probabilidades também são diferentes para componentes positivas e negativas. Para $-m \leq i \leq n$, em que os índices positivos e negativos correspondem, respectivamente, a ganhos e perdas, 
tem-se:

$$
V(\vec{P})=\sum_{i=0}^{n} v\left(x_{i}\right) \cdot w_{i}^{+}+\sum_{i=-m}^{0} v\left(x_{i}\right) \cdot w_{i}^{-}
$$

sendo

$$
\begin{gathered}
w_{i}^{+}=\pi^{+}\left(p_{i}+\ldots+p_{n}\right)-\pi^{+}\left(p_{i+1}+\ldots+p_{n}\right), \text { se } i=1, \ldots, n-1 \text { e } w_{n}^{+}=\pi^{+}\left(p_{n}\right) \\
w_{i}^{-}=\pi^{-}\left(p_{-m}+\ldots+p_{i}\right)-\pi^{-}\left(p_{-m}+\ldots+p_{i-1}\right), \text { se } i=1-m, \ldots, 0 \text { e } w_{-m}^{-}=\pi^{-}\left(p_{-m}\right) .
\end{gathered}
$$

Baseados nos padrões de escolhas observados experimentalmente, Kahneman e Tversky defenderam que o comportamento de indivíduos frente ao risco segue o que eles chamaram de padrão quádruplo de atitudes frente ao risco:

(i) Propensão ao risco para ganhos e aversão ao risco para perdas de pequena probabilidade;

(ii) Aversão ao risco para ganhos e propensão ao risco para perdas de alta probabilidade.

Este padrão sugere uma transformação não linear da escala de probabilidades, no formato de um "S" invertido, como mostrado na Fig. 5.8.

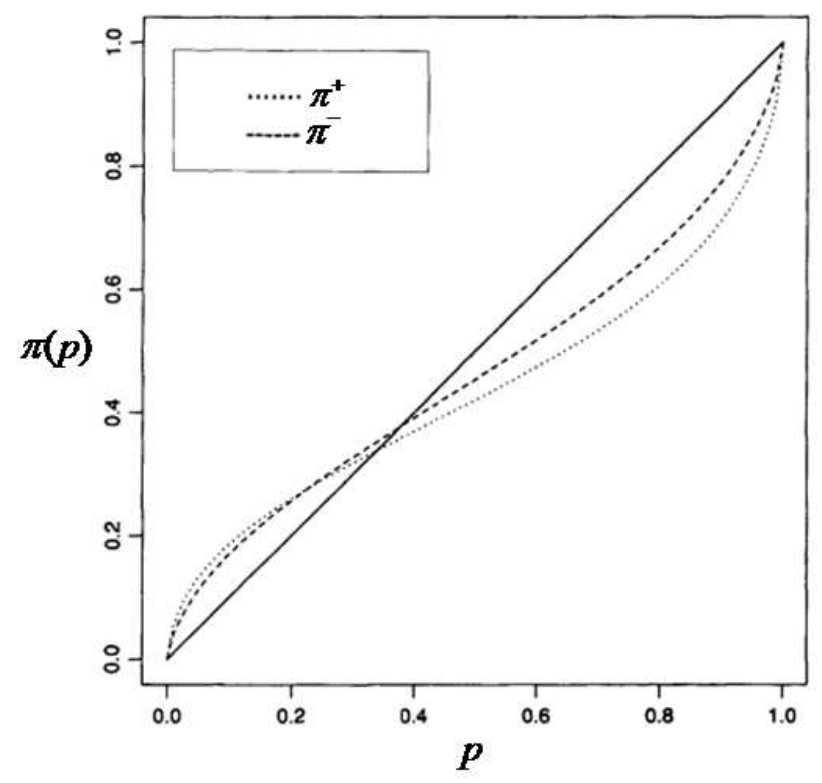

Figura 5.8 - Funções peso para ganhos $\left(\pi^{+}\right)$e perdas $\left(\pi^{-}\right)$obtidas por Kahneman e Tversky no desenvolvimento da CPT [83] 
No capítulo a seguir apresentamos alguns trabalhos que têm buscado formas analíticas que satisfaçam às propriedades definidas para a função peso na RDUT e na CPT. Descrevemos também alguns resultados que mostram que a forma generalizada da função de desconto probabilística [Eq. (3.10)] que propusemos pode satisfazer a estas propriedades. 


\section{Capítulo}

\section{Formas funcionais da função peso: uma nova proposta}

Conforme descrito nos capítulos anteriores, a teoria da utilidade esperada não é válida como modelo descritivo de escolhas envolvendo risco. As principais anomalias apresentadas pela EUT são resultado da linearidade nas probabilidades assumida pelo modelo. Em resposta a estas violações, uma série de teorias da utilidade nãoesperada tem sido propostas. Dentre elas, destaca-se a teoria da utilidade esperada dependente da ordenação (RDEU) e a teoria do prospecto acumulado (CPT). Uma característica essencial da função de preferência de ambas é que as probabilidades são transformadas por pesos de decisão através de uma função peso de probabilidades acumuladas. A não linearidade das preferências em relação às probabilidades permite a descrição de padrões de escolha não previstos pela EUT.

Uma variedade de métodos é utilizada para determinar a forma da função peso proposta na RDEU e na CPT [84]. A abordagem predominante especifica inicialmente uma forma paramétrica para esta função e, então, a estima a partir de experimentos e técnicas padrões. Esta estimativa por métodos paramétricos depende criticamente da forma paramétrica proposta inicialmente. No trabalho em que propuseram a CPT [83], Tversky e Kahneman estimaram uma forma paramétrica especificada por um único parâmetro $(\gamma)$ :

$$
\pi(p)=\frac{p^{\gamma}}{\left[p^{\gamma}+(1-p)^{\gamma}\right]^{1 / \gamma}}
$$

onde $\gamma$ controla a curvatura da função peso, isto é, a extensão à qual indivíduos são capazes de discriminar entre diferentes probabilidades, e a elevação da função peso, 
extensão à qual indivíduos acham atrativo o domínio arriscado. Wu e Gonzalez [85] sugeriram uma especificação de dois parâmetros para o formato " $\mathrm{S}$ " invertido da função peso:

$$
\pi(p)=\frac{\delta p^{\gamma}}{\delta p^{\gamma}+(1-p)^{\gamma}}
$$

Nesta equação, o parâmetro $\gamma$ controla a curvatura da função e o parâmetro $\delta$ controla a elevação. Prelec [86], em 1999, axiomatizou especificações alternativas para o formato "S" invertido de $\pi(p)$, a partir de um parâmetro,

$$
\pi(p)=\exp \left[-(-\ln p)^{\alpha}\right]
$$

e de dois parâmetros,

$$
\pi(p)=\exp \left[-\beta(-\ln p)^{\alpha}\right]
$$

A interpretação dos parâmetros $\alpha$ e $\beta$ é similar à Eq. (6.2): $\alpha$ controla a curvatura e $\beta$ controla a elevação de $\pi(p)$. A Eq. (6.3) é um caso particular da Eq. (6.4) em que $\beta=1$.

A Tabela 6.1 sumariza os resultados de alguns estudos empíricos que estimaram os parâmetros nas formas descritas acima. A CPT permite que os parâmetros sejam diferentes para ganhos e perdas. Todas as estimativas são consistentes com a função peso na forma de "S-invertido", como mostrado na Fig. 6.1. Apesar da estimação empírica de parâmetros, as formas paramétricas acima especificadas a princípio não são resultados de qualquer avaliação das atitudes de indivíduos frente ao risco. Elas são ferramentas matemáticas que permitem descrever as propriedades inferidas para a função peso a partir dos modelos teóricos.

No Capítulo 3, mostramos que o atraso médio $(t)$ para recebimento de uma recompensa pode ser relacionado à sua probabilidade de recebimento $(p)$ através da grandeza $\Theta=(1 / p)-1$. A avaliação do processo de desconto em função de $\Theta$ permitiu a interpretação das tomadas de decisão probabilísticas como combinação dos efeitos de desconto do valor e de percepção psicofísica de probabilidades. De modo semelhante, as formas funcionais de $\pi(p)$ propostas por Wu e Gonzalez e Prelec, quando escritas em função de $\Theta$, permitem uma interpretação simples de 
Tabela 6.1 - Formas funcionais e parâmetros empiricamente estimados para a função peso de probabilidades [84].

\begin{tabular}{|c|c|}
\hline \hline Forma funcional & Parâmetros estimados \\
\hline$\pi(p)=\frac{p^{\gamma}}{\left(p^{\gamma}+(1-p)^{\gamma}\right)^{1 / \gamma}}$ & Tversky e Kahneman [83]: $\gamma=0,61$ (ganhos) $\gamma=0,69$ (perdas) \\
& Camerer e Ho [87]: $\gamma=0,56$ (ganhos) \\
Wu e Gonzalez [88]: $\gamma=0,71$ (ganhos) \\
\hline$\pi(p)=\frac{\text { Abdellaoui [89]: } \gamma=0,60 \text { (ganhos) } ; \gamma=0,70 \text { (perdas) }}{\delta p^{\gamma}+(1-p)^{\gamma}}$ & Wu e Gonzalez [88]: $\delta=0,84, \gamma=0,68$ (ganhos) \\
& Gonzalez e Wu [85]: $\delta=0,77, \gamma=0,44$ (ganhos) \\
& Tversky e Fox [90]: $\delta=0,77, \gamma=0,69$ (ganhos) \\
\hline$\pi(p)=\exp \left(-(-\ln p)^{\alpha}\right)$ & Abdellaoui [89]: $\delta=0,65, \gamma=0,60$ (ganhos) $; \delta=0,84, \gamma=0,65$ (perdas) \\
\hline \hline
\end{tabular}

suas formas em termos destes processos. O mesmo não é verificado para a forma proposta por Kahneman e Tversky, como mostrado a seguir.

Reescrevendo as Eqs. (6.1), (6.2) e (6.4) tem-se, respectivamente:

- Kahneman e Teversky:

$$
\pi(\Theta)=\frac{(\Theta+1)^{1-\gamma}}{\left(\Theta^{\gamma}+1\right)^{1 / \gamma}}
$$

- Wu e Gonzalez:

$$
\pi(\Theta)=\frac{1}{1+\Theta^{\gamma} / \delta}
$$

- Prelec:

$$
\pi(\Theta)=\frac{1}{\exp \left\{\beta[\ln (1+\Theta)]^{\alpha}\right\}}
$$

A forma de Wu e Gonzalez [Eq. (6.6)] pode ser escrita como composição de duas funções: $f(x)=x^{b}$ e $g(y)=1 /\left(1+k_{1} y\right)$. A função $f$, quando aplicada em $\Theta$, pode ser interpretada como uma percepção psicofísica de $\Theta$ seguindo uma lei de 


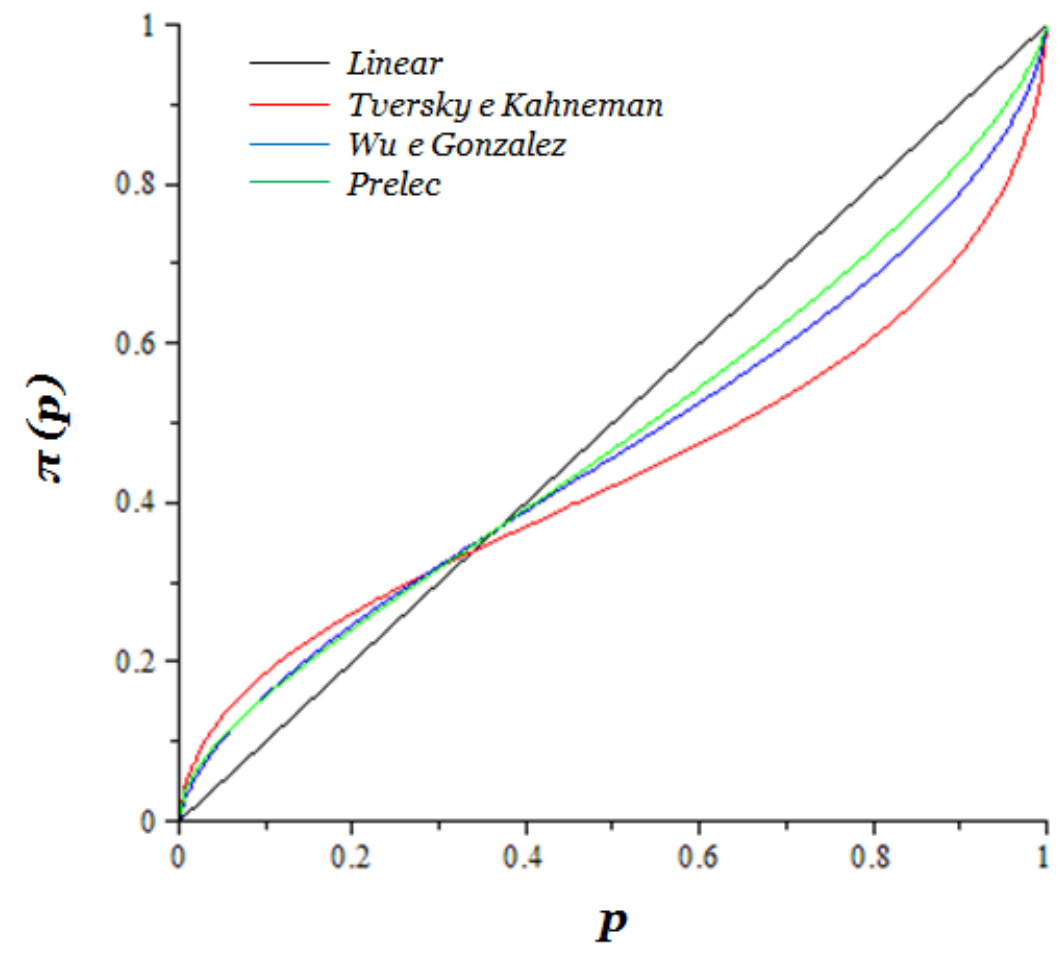

Figura 6.1 - Formas paramétricas para a função peso: Linear: $\pi(p)=p$; Tversky e Kahneman [Eq. (6.1)]: $\gamma=0,61$; Wu e Gonzalez [Eq. 6.2]: $\delta=0,84$ e $\gamma=0,68$; Prelec [Eq. 6.3]: $\alpha=0,74$.

potência (lei de Stevens): $f(\Theta)=\Theta^{b}$. A função $g$ apresenta a forma funcional do desconto hiperbólico e, quando aplicada na percepção de $\Theta, g[f(\Theta)]$, resulta em:

$$
\pi(\Theta)=\frac{1}{1+k_{1} \Theta^{b}}
$$

Observe que para $k_{1}=1 / \delta$ e $b=\gamma$ obtém-se a forma da função peso proposta por Wu e Gonzalez. Assim, pode-se interpretar a Eq. (6.6) como um processo que combina o efeito de percepção de $\Theta$ segundo uma lei de potência e o efeito de desconto hiperbólico.

Utilizando a função exponencial $\tilde{q}$-generalizada [Eq. (2.10)], pode-se genera- 
lizar o processo de desconto para a Eq. (6.6):

$$
\pi(\Theta)=\frac{1}{\exp _{\tilde{q}}\left(k_{\tilde{q}} \Theta^{b}\right)} .
$$

Para $\tilde{q}=0$, tem-se a função de desconto exponencial associada à lei de potência de $\Theta$, conhecida como exponencial estendida [50]. Para $\tilde{q}=1$, obtem-se a função proposta por Wu e Gonzalez. A Fig. 6.2 mostra a forma desta função para diferentes valores de $\tilde{q}$. Note que a forma "S-invertido" proposta para função peso é obtida apenas para $\tilde{q} \geq 1$.

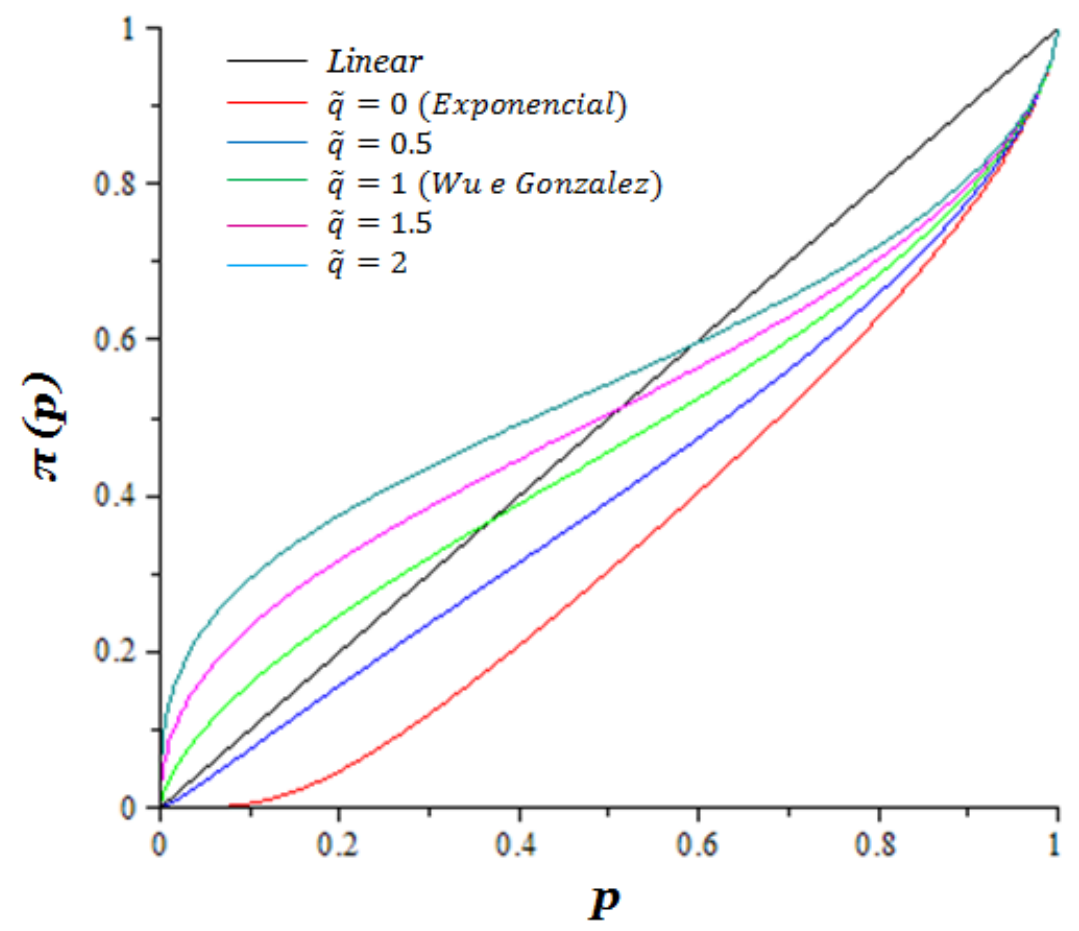

Figura 6.2 - Função generalizada da forma de $\pi(p)$ proposta por Wu e Gonzalez [Eq. (6.9)]: $k_{\tilde{q}}=1,19$ e $b=0,68$, para $\tilde{q}$ variando de 0 a 2 .

Assim como descrito para a Eq. (6.6), a forma proposta por Prelec também pode ser escrita como uma composição de duas funções: $v(x)=a[\ln (1+x)]^{b} \mathrm{e}$ $w(y)=\exp \left(-k_{0} y\right)$. A função $v$, aplicada em $\Theta$, pode ser interpretada como uma 
percepção psicofísica segundo uma lei de potência do logaritmo natural de $(1+$ $\Theta): v(\Theta)=a[\ln (1+\Theta)]^{b}$. A função $w$ representa a forma funcional do desconto exponencial. A composição $w[v(\Theta)]$ resulta em:

$$
\pi(\Theta)=\exp \left\{-k_{0} a[\ln (1+\Theta)]^{b}\right\}
$$

A equação acima representa a forma da função peso de dois parâmetros proposta por Prelec, sendo $k_{0} a=\beta$ e $b=\alpha$. A Eq. (6.7) pode ser interpretada como um processo que combina o efeito de percepção segundo uma lei de potência de $\ln (1+\Theta)$ e o efeito de desconto exponencial.

De forma semelhante ao descrito anteriormente, a partir da função exponencial $\tilde{q}$-generalizada tem-se:

$$
\pi(\Theta)=\frac{1}{\exp _{\tilde{q}}\left\{k_{\tilde{q}} a[\ln (1+\Theta)]^{b}\right\}},
$$

Para $\tilde{q}=0$ obtém-se a forma funcional proposta por Prelec [Eq. (6.4)]. A Fig. 6.3 mostra a forma desta função para diferentes valores de $\tilde{q}$. A forma "S-invertido" proposta para função peso se mantém para $\tilde{q} \geq 0$. Entretanto, para $\tilde{q}>0$, a Eq. (6.11) superestima pequenos valores de $p$.

Considere ainda a Eq. (6.11). A partir da função q̃-logaritmo [Eq. (2.11)] obtém-se a forma geral:

$$
\pi(\Theta)=\frac{1}{\exp _{\tilde{q}}\left\{k_{\tilde{q}} a\left[\ln _{s}(1+b \Theta)\right]^{n}\right\}} .
$$

Observe que, ajustando-se as constantes, a equação acima corresponde à forma funcional proposta por Prelec [Eq. (6.7)] para os parâmetros $\tilde{q}=0, s=0$ e $n=\alpha$. Como descrito anteriormente, este caso particular representa a associação entre o efeito de percepção segundo uma lei de potência em $\ln (1+\Theta)$ e o efeito de desconto exponencial. Para $\tilde{q}=1, s=1$ e $n=\gamma$ obtém-se a forma proposta por Wu e Gonzalez [Eq. (6.6)], a qual reflete uma combinação entre o efeito de percepção segundo uma lei de potência em $\Theta$ e o efeito de desconto hiperbólico.

Para $n=1$, a Eq. (6.12) representa a forma generalizada da função de des- 


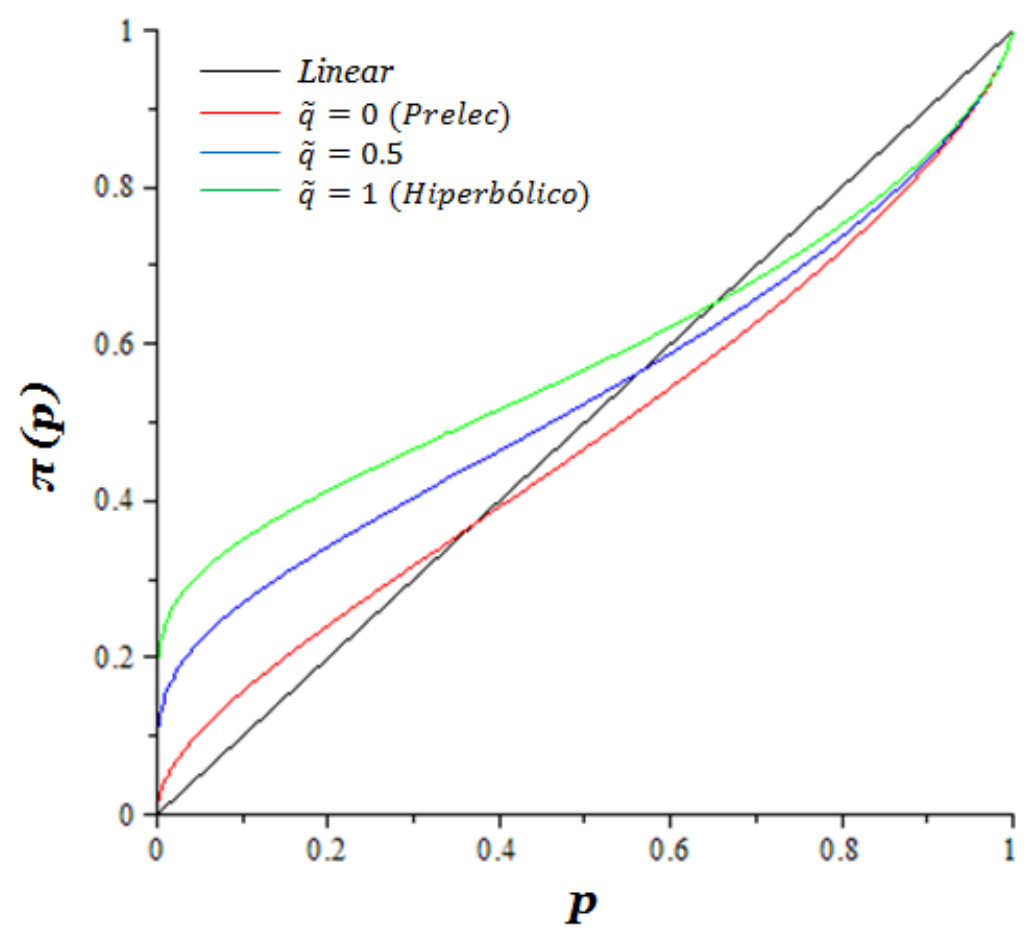

Figura 6.3 - Função generalizada da forma proposta por Prelec [Eq. (6.11)]: $k_{\tilde{q}} a=1$ e $b=0,74$, para $\tilde{q}$ variando de 0 a 1 .

conto probabilístico envolvendo a percepção psicofísica que obtivemos no Capítulo 3 :

$$
\pi(\Theta)=\frac{1}{\exp _{\tilde{q}}\left[k_{\tilde{q}} a \ln _{s}(1+b \Theta)\right]}
$$

Assim como as funções descritas na Tabela 6.1, propomos esta função generalizada para a forma funcional de $\pi(p)$. Diferentemente das formas propostas na literatura, esta função é amparada por modelos comportamentais de tomada de decisão. Como mostrado anteriormente, a substituição do atraso $(t)$ por uma função de probabilidade $[\Theta(p)]$ resultou em funções de desconto probabilísticas capazes de descrever adequadamente os dados experimentais neste domínio. Variando-se os parâmetros $\tilde{q}$ e $s$, pode-se obter modelos particulares da combinação entre os modelos de desconto sem percepção (exponencial, hiperbólico e $\tilde{q}$-generalizado) e as leis da psicofísica 
(Weber-Fechner e Stevens). A Fig. 6.4 mostra o comportamento da função de desconto probabilística generalizada em comparação com as formas funcionais propostas para descrição de $\pi(p)$. Os parâmetros para a função generalizada não foram estimados experimentalmente como no caso das demais curvas apresentadas no gráfico. Experimentos precisam ser conduzidos para avaliação dos parâmetros desta função no domínio das probabilidades.

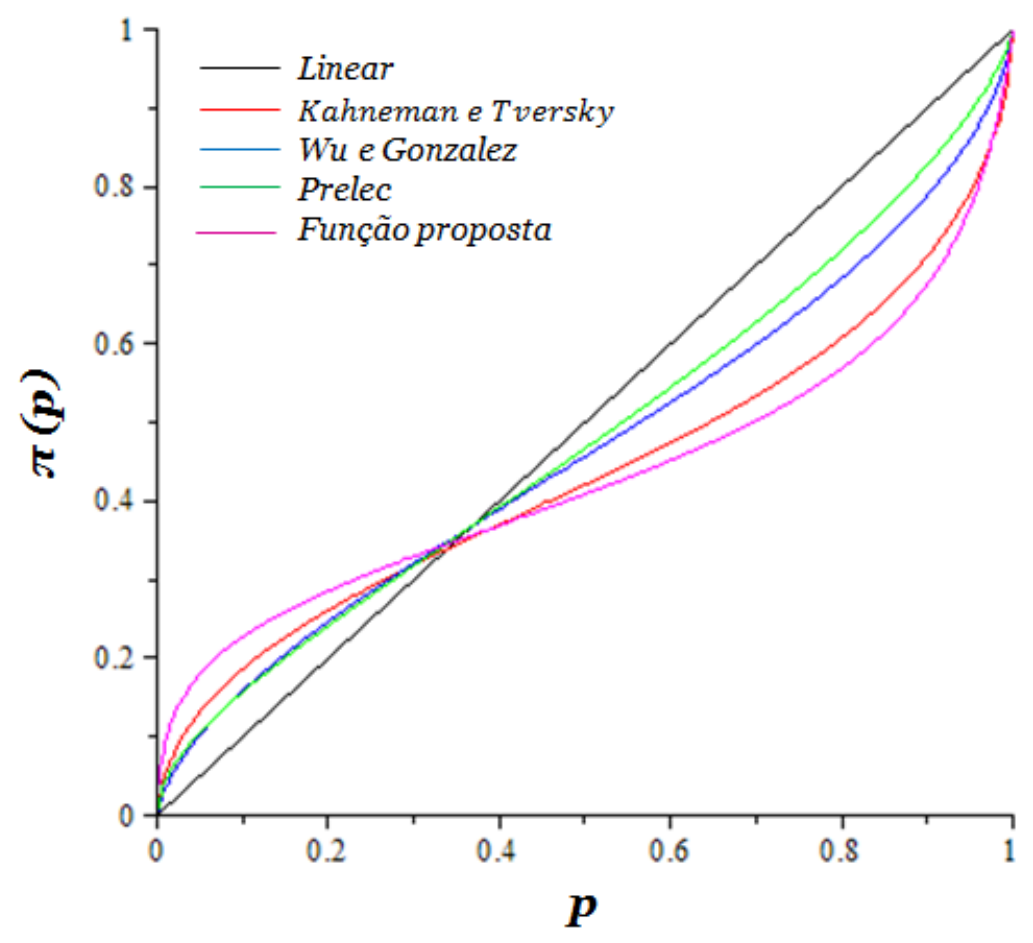

Figura 6.4 - Formas paramétricas para a função peso: Linear: $\pi(p)=p$; Tversky e Kahneman [Eq. (6.1)]: $\gamma=0,61$; Wu e Gonzalez [Eq. (6.2)]: $\delta=0,84$ e $\gamma=0,68$; Prelec [Eq. (6.3)]: $\alpha=0,74$; Forma proposta [Eq. (6.13)]: $s=2, \tilde{q}=4, k_{\tilde{q}}=100, a=1.7$ e $b=0.05$. 


\section{Capítulo}

\section{Conclusões}

Neste trabalho, foram explorados modelos de tomada de decisão envolvendo interações entre as grandezas valor, tempo e probabilidade. As preferências de indivíduos em relação a estas escolhas multidimensionais, em geral, não são facilmente predizíveis. Em áreas como a neuroeconomia, a econofísica e a sociofísica, um dos problemas centrais a serem explorados é entender como indivíduos tomam suas decisões frente a estes problemas multidimensionais.

Escolhas intertemporais, que exploram as grandezas valor e tempo, são influenciadas não somente pelo efeito de desconto de valor em diferentes instantes, como também pelo efeito de percepção temporal, avaliado em função do atraso na entrega de uma recompensa. Estes efeitos agem simultaneamente no processo de tomada de decisão. A associação das funções de percepção do atraso aos modelos de desconto de valor mostram que a medida total do grau de inconsistência á aditiva nestes efeitos. Esta grandeza, portanto, permite avaliar separadamente os fatores que estão envolvidos no processo de desconto intertemporal e suas respectivas contribuições. A determinação direta do grau de inconsistência é que favorecerá o entendimento do processo que fundamenta estas escolhas.

Em jogos de repetição, o atraso médio para recebimento de uma recompensa pode ser relacionado à sua probabilidade de recebimento através do número médio de perdas esperadas antes que uma vitória ocorra $(\Theta)$. Experimentos mostram que as mesmas formas matemáticas descrevem adequadamente os descontos do atraso em escolhas intertemporais e de $\Theta$ em tomas de decisão probabilísticas. A extensão das leis da psicofísica à percepção de probabilidades permite a obtenção de uma função generalizada para o desconto probabilístico. Esta função descreve o processo 
de tomada de decisão como uma combinação entre o efeitos de desconto de valor e de percepção de probabilidades (avaliada em função de $\Theta$ ). Experimentos envolvendo escolhas probabilísticas precisam ser explorados para avaliar o modelo proposto.

No domínio dos modelos teóricos, a teoria da utilidade esperada (EUT), baseada em sólidos fundamentos axiomáticos, predominou por um longo período como modelo normativo para descrição de tomadas de decisão probabilísticas. Entretanto, experimentos mostram que esta teoria não é válida como modelo descritivo destas escolhas. As principais anomalias apresentadas pela EUT são resultado da linearidade nas probabilidades assumida pelo modelo. As teorias da utilidade não-esperada (NEUT), convencionais ou não, transformam as probabilidades em pesos de decisão através de uma função peso $\pi(p)$. A não-linearidade das preferências em relação às probabilidades permite a descrição de padrões de escolha não previstos pela EUT.

Dentre os métodos utilizados para determinar a forma da função peso, a abordagem predominante especifica inicialmente uma forma paramétrica para esta função e, então, a estima a partir de experimentos e técnicas padrões. Apesar da estimação empírica de parâmetros, as formas paramétricas especificadas, a princípio, não são derivadas de qualquer avaliação das atitudes de indivíduos frente ao risco. Entretanto, a análise destas em função de $\Theta$ permite uma interpretação simples de suas formas em termos dos efeitos de desconto do valor e de percepção psicofísica de probabilidades. A partir das funções $\tilde{q}$-exponencial e $\tilde{q}$-logarítmica, pode-se obter uma nova função generalizada para $\pi(p)$. Os casos limites desta função englobam algumas formas paramétricas já propostas na literatura e, em particular, a função de desconto probabilística proposta neste trabalho. Diferentemente das demais, esta última é amparada por modelos comportamentais de decisão e deriva da suposição de que indivíduos se comportam de forma similar frente a probabilidades e atrasos. Novos experimentos precisam ser conduzidos para que seus parâmetros sejam estimados empiricamente.

Além de conectar as formas empíricas de desconto intertemporal e probabilístico às leis básicas da psicofísica em um contexto único, este trabalho propõe a elaboração de novos experimentos no domínio da econofísica e neuroeconomia que possam ampliar o conhecimento sobre o comportamento humano frente ao tempo e às incertezas. 


\section{Referências}

[1] J.-P. Bouchaud, "Economics needs a scientific revolution", Nature, vol. 455, p. 1181, 2008.

[2] L. Green e J. Myerson, "A discounting framework for choice with delayed and probabilistic rewards", Psychological Bulletin, vol. 130, no. 5, pp. 769-792, 2004.

[3] D. Bernoulli, "Specimen theoriae novae de mensura sortis", Commentarii Academiae Scientiarum Imperialis Petropolitanae, vol. 5, pp. 175-192, 1738. Versão traduzida: "Exposition of a New Theory on the Measurement of Risk", Econometrica, vol. 22, no. 1, pp. 23-36, 1954.

[4] P. A. Samuelson, "A note on measurement of utility", The Review of Economic Studies, vol. 4, pp. 155-161, 1937.

[5] D. Prelec e G. Loewenstein, "Decision making over time and under uncertainty: A common approach", Management Science, vol. 37, no. 7, pp. 770-786, 1991.

[6] J. V. Neumann e O. Morgenstern, Theory of games and economic behavior. New Jersey: Princeton University Press, 1944.

[7] T. C. Koopmans, "Stationary ordinal utility and impatience", Econometrica, vol. 28, pp. 287-309, 1960.

[8] N. Destefano e A. S. Martinez, "The additive property of the inconsistency degree in intertemporal decision making through the generalization of psychophysical laws", Physica A, vol. 390, pp. 1763-1772, 2011.

[9] D. Read, "Is time discounting hyperbolic or subadditive?", Journal of Risk and Uncertainty, vol. 23, no. 1, pp. 5-32, 2001. 
[10] T. Takahashi, H. Oono e M. H. B. Radford, "Psychophysics of time perception and intertemporal choice models", Physica A, vol. 387, pp. 2066-2074, 2008.

[11] T. Takahashi, H. Oono e M. H. B. Radford, "Empirical estimation of consistency parameter in intertemporal choicebased on Tsallis' statistics", Physica A, vol. 381, pp. 338-342, 2007.

[12] G. Ainslie, "Impulse control in pigeons", Jounal of the Experimental Analysis of Behavior, vol. 21, pp. 485-489, 1974.

[13] B. Reynolds, H. de Wit e J. B. Richards, "Delay of gratification and delay discounting in rats", Behavioural Processes, vol. 59, pp. 157-168, 2002.

[14] J. E. Mazur e D. R. Biondi, "Delay-amount tradeoffs in choices by pigeons and rats: hyperbolic versus exponential discounting", Journal of the Experimental Analysis of Behavior, vol. 91, no. 2, pp. 197-211, 2009.

[15] L. Green, A. F. Fry e J. Myerson, "Discounting of delayed rewards: a life-span comparison", Psychological Science, vol. 5, pp. 33-36, 1994.

[16] W. K. Bickel, A. L. Odum e G. J. Madden, "Impulsivity and cigarette smoking: delay discounting in current, never, and ex-smokers", Psychopharmacology, vol. 146, pp. 447-454, 1999.

[17] K. N. Kirby, "Bidding on the future: Evidence against normative discounting of delayed rewards", Journal of Experimental Psychology: General, vol. 126, no. 1, pp. 54-70, 1997.

[18] M. W. Johnson e W. K. Bickel, "Within-subject comparison of real and hypothetical money rewards in delay discounting", Journal of the Experimental Analysis of behavior 2002, vol. 77, no. 2, pp. 129-146, 2002.

[19] G. J. Madden, A. M. Begotka, B. R. Raiff e L. L. Kastern, "Delay discounting of real and hypothetical rewards", Experimental and Clinical Psychopharmacology, vol. 11, no. 2, pp. 139-145, 2003.

[20] J. M. Kirk e A. W. Logue, "Effects of deprivation level on humans self-control for food reinforcers", Appetite, vol. 28, pp. 215-226, 1997. 
[21] S. D. Lane, D. R. Cherek, C. J. Pietras e O. V. Tcheremissine, "Measurement of delay discounting using trial-by-trial consequences", Behavioural Processes, vol. 64, pp. 287-303, 2003.

[22] B. Reynolds e R. Schiffbauer, "Measuring state changes in human delay discounting: An experiential discounting task", Behavioural Processes, vol. 67, pp. 343-356, 2004.

[23] B. Reynolds, "A review of delay-discounting research with humans: relations to drug use and gambling", Behavioural Pharmacology, vol. 17, no. 8, pp. 651-667, 2006.

[24] J. McDonald, L. Schleifer, J. B. Richards e H. de Wit, "Effects of THC on behavioral measures of impulsivity in humans", Neuropsychopharmacology, vol. 28, pp. 1356-1365, 2003.

[25] B. Reynolds, J. B. Richards, M. Dassingera e H. de Wita, "Therapeutic doses of diazepam do not alter impulsive behavior in humans", Pharmacology, Biochemistry and Behavior, vol. 79, pp. 17-24, 2004.

[26] B. Reynolds, J. B. Richards e H. de Wit, "Acute-alcohol effects on the experiential discounting task (EDT) and a question-based measure of delay discounting", Pharmacology, Biochemistry and Behavior, vol. 83, pp. 194-202, 2006.

[27] E. Roblesa, P. A. Vargas e R. Bejarano, "Within-subject differences in degree of delay discounting as a function of order of presentation of hypothetical cash rewards", Behavioural Processes, vol. 81, pp. 260-263, 2009.

[28] G. F. Loewenstein, "Frames of mind in intertemporal choice", Management Science, vol. 34, pp. 200-214, 1988.

[29] J. G. Murphy, R. E. Vuchinich e C. A. Simpson, "Delayed reward and cost discounting", The Psychological Record, vol. 51, no. 4, pp. 571-588, 2001.

[30] R. H. Thaler, "Some empirical evidence on dynamic inconsistency", Economics Letters, 1981, vol. 8, issue 3, pages 201-20\%, vol. 8, no. 3, pp. 201-207, 1981. 
[31] M. Patak e B. Reynolds, "Question-based assessments of delay discounting: do respondents spontaneously incorporate uncertainty into their valuations for delayed rewards?", Addictive Behaviors 32 (2007) 351357, vol. 32, pp. 351-357, 2007.

[32] M. L. Rodriguez e A. W. Logue, "Adjusting delay to reinforcement: comparing choice in pigeons and humans", Journal of Experimental Psychology: Animal Behavior Processes, vol. 14, no. 1, pp. 105-117, 1988.

[33] H. Rachlin, A. Raineri e D. Cross, "Subjective probability and delay", Journal of the Experimental Analysis of Behavior, vol. 55, no. 2, pp. 233-244, 1991.

[34] T. L. McKerchar, L. Green, J. Myerson, T. S. Pickford, J. C. Hill e S. C. Stout, "A comparison of four models of delay discounting in humans", Behavioural Processes, vol. 81, pp. 256-259, 2009.

[35] L. Green e S. J. Estle, "Preference reversals with food and water reinforcers in rats", Journal of the Experimental Analysis of Behavior, vol. 79, no. 2, pp. 233$242,2003$.

[36] J. Baron, "Can we use human judgments to determine the discount rate?", Risk Analysis, vol. 20, no. 6, pp. 861-868, 2000.

[37] L. Green, N. Fristoe e J. Myerson, "Temporal discounting and preference reversals in choice between delayed outcomes", Psychonomic Bulletin 89 Review, vol. 1, no. 3, pp. 383-389, 1994.

[38] L. Green, E. B. Fisher, S. Perlow e L. Sherman, "Preference reversal and self control: Choice as a function of reward amount and delay", Behaviour Analysis Letters, vol. 1, no. 1, pp. 43-51, 1981.

[39] K. N. Kirby e R. J. Herrnstein, "Preference reversals due to myopic discounting of delayed reward", Psychological Science, vol. 6, no. 2, pp. 83-89, 1995.

[40] D. Prelec, "Decreasing impatience: a criterion for non-stationary time preference and "hyperbolic" discounting", Scandinavian Journal of Economics, vol. 106, no. 3, pp. 511-532, 2004. 
[41] H. Rachlin, "Notes on discounting", Journal of the Experimental Analysis of Behavior, vol. 85, no. 3, pp. 425-435, 2006.

[42] J. Myerson e L. Green, "Discounting of delayed rewards: models of individual choice", Journal of the Experimental Analysis of Behavior, vol. 64, no. 3, pp. 263-276, 1995.

[43] C. Tsallis, "Possible generalization of Boltzmann-Gibbs statistics", Journal of Statistical Physics, vol. 52, no. 1-2, pp. 479-487, 1988.

[44] C. Tsallis, "What are the numbers that experiments provide?", Química Nova, vol. 17 , no. 6, pp. 468-471, 1994.

[45] T. J. Arruda, R. S. González, C. A. S. Terçariol e A. S. Martinez, "Arithmetical and geometrical means of generalized logarithmic and exponential functions: generalized sum and product operators", Physics Letters A, vol. 372, pp. 2578$2582,2008$.

[46] A. S. Martinez, R. S. González e A. L. Espíndola, "Generalized exponential function and discrete growth models", Physica A, vol. 388, pp. 2922-2930, 2009.

[47] A. S. Martinez, R. S. González e C. A. S. Terçariol, "Continuous growth models in terms of generalized logarithm and exponential functions", Physica A, vol. 387, pp. 5679-5687, 2008.

[48] A. S. Martinez, B. C. T. Cabella e F. Ribeiro, "Data collapse, scaling functions, and analytical solutions of generalized growth models", Physical Review E, vol. 83, p. 061902, out. 2011.

[49] C. Anteneodo, C. Tsallis e A. S. Martinez, "Risk aversion in economic transactions", Europhysics Letters, vol. 59, no. 5, pp. 635-641, 2002.

[50] A. S. Martinez, R. S. González e C. A. S. Terçariol, "Generalized probability functions", Advances in Mathematical Physics, vol. 2009, p. 206176, 2009.

[51] T. Takahashi, "A comparison between Tsalliss statistics-based and generalized quasi-hyperbolic discount models in humans", Physica A, vol. 387, pp. 551-556, 2008. 
[52] T. Takahashi, "A comparison of intertemporal choices for oneself versus someone else based on Tsallis statistics", Physica A, vol. 385, no. 2, pp. 637-644, 2007.

[53] T. Takahashi, "A probabilistic choice model based on Tsallis statistics", Physica $A$, vol. 386, no. 1, pp. 335-338, 2007.

[54] D. O. Cajueiro, "A note on the relevance of the $q$-exponential function in the contextof intertemporal choices", Physica A, vol. 364, pp. 385-388, 2006.

[55] T. Takahashi, "Loss of self-control in intertemporal choice may be attributable to logarithmic time-perception", Medical Hypotheses, vol. 65, no. 4, pp. 691-693, 2005.

[56] T. Takahashi, "Time-estimation error following WeberFechner law may explain subadditive time-discounting", Medical Hypotheses, vol. 67, pp. 1372-1374, 2006.

[57] B. J. West e P. Grigolini, "A psychophysical model of decision making", Physica A, vol. 389, pp. 3580-3587, 2010.

[58] G. Zauberman, B. K. Kim, S. A. Malkoc e J. R. Bettman, "Discounting time and time discounting: Subjective time perception and intertemporal preferences", Journal of Marketing Research, vol. XLVI, pp. 543-556, 2009.

[59] K. M. M. R. de Carvalho, Da discriminação à magnitude da sensação: um ensaio formal. Tese de Doutorado, Universidade de São Paulo, 2007.

[60] S. S. Stevens, "On the psychophysical law", The Psychological Review, vol. 64, no. 3, pp. 153-181, 1957.

[61] K. H. Norwich e W. Wong, "Unification of psychophysical phenomena:the complete form of Fechners law", Perception \& Psychophysics, vol. 59, no. 6, pp. 929940, 1997.

[62] H. Rachlin, A. W. Logue, J. Gibbon e M. Frankel, "Cognition and behavior in studies of choice", Psychological Review, vol. 93, no. 1, pp. 33-45, 1986. 
[63] M. Allais, "Le comportement de l'homme rationnel devant le risque: critique des postulats et axiomes de l'école américaine", Econometrica, vol. 21, pp. 503-546, 1953.

[64] D. Kahneman e A. Tversky, "Prospect theory: An analysis of decision under risk", Econometrica, vol. 47, no. 2, pp. 263-292, 1979.

[65] L. Green, J. Myerson e P. Ostaszewski, "Amount of reward has opposite effects on the discounting of delayed and probabilistic outcomes", Journal of Experimental Psychology: Learning, Memory, and Cognition, vol. 25, no. 2, pp. 418-427, 1999.

[66] P. Ostaszewski, L. Green e J. Myerson, "Effects of inflation on the subjective value of delayed and probabilistics rewards", Psychonomic Bulletin Es Review, vol. 5, pp. 324-333, 1998.

[67] L. Green, J. Myerson e E. McFadden, "Rate of temporal discounting decreases with amount of reward", Memory and Cognition, vol. 25, no. 5, pp. 715-723, 1997.

[68] F. Baker, M. W. Johnson e W. K. Bickel, "Delay discounting in current and never-before cigarette smokers: Similarities and differences across commodity, sign, and magnitude", Journal of Abnormal Psychology, vol. 112, no. 3, pp. 382392, 2003.

[69] J. Myerson, L. Green, J. S. Hanson, D. D. Holt e S. J. Estle, "Discounting delayed and probabilistic rewards: processes and traits", Journal of Economic Psychology, vol. 24, pp. 619-635, 2003.

[70] J. Christensen, S. Parker, A. Silberberg e S. Hursh, "Trade-offs in choice between risk and delay depend on monetary amounts", Journal of the Experimental Analysis of Behavior, vol. 69, no. 2, pp. 123-139, 1998.

[71] W. Du, L. Green e J. Myerson, "Cross-cultural comparisons of discounting delayed and probabilistic rewards", Psychological Record, vol. 52, pp. 479-492, 2002. 
[72] P. Ostaszewski, "Temperament and the discounting of delayed and probabilistic rewards: Conjoining european and american psychological traditions", European Psychologist, vol. 2, pp. 35-43, 1997.

[73] R. T. Cusinato, "Teoria da decisão sob incerteza e a hipótese da utilidade esperada: conceitos analíticos e paradoxos", Dissertação de Mestrado, Universidade Federal do Rio Grande do Sul, 2003.

[74] C. Starmer, "Developments in non-expected utility theory: the hunt for a descriptive theory of choice under risk", Journal of Economic Literature, vol. XXXVIII, pp. 332-382, 2000.

[75] A. Tversky e R. H. Thaler, "Anomalies: Preference reversals", The Journal of Economic Perspectives, vol. 4, no. 2, pp. 201-211, 1990.

[76] A. Tversky e D. Kahneman, "The framing of decisions and the psychology of choice", Science, vol. 211, no. 4481, pp. 453-458, 1981.

[77] M. J. Machina, "Expected utility theory without the independence axiom", Econometrica, vol. 50, pp. 277-323, 1982.

[78] S. H. Chew e K. MacCrimmon, "Alpha-nu choice theory: An axiomatization of expected utility", Working paper 669, University of British Columbia, 1979.

[79] W. Edwards, "The prediction of decisions among bets", Journal of Experimental Psychology, vol. 50, no. 3, pp. 201-214, 1955.

[80] J. Handa, "Risk, probabilities, and a new theory of cardinal utility", Journal of Political Economy, vol. 85, no. 1, pp. 97-122, 1977.

[81] J. Quiggin, "A theory of anticipated utility", Journal of Economic Behavior and Organization, vol. 3, no. 4, pp. 323-343, 1982.

[82] H. Markowitz, "The utility of wealth", The Journal of Political Economy, vol. 60, pp. 151-158, 1952.

[83] A. Tversky e D. Kahneman, "Advances in prospect theory: Cumulative representation of uncertainty", Journal of Risk and Uncertainty, vol. 5, pp. 297-323, 1992. 
[84] H. Bleichrodt e J. L. Pinto, "A parameter-free elicitation of the probability weighting function in medical decision analysis", Managment Science, vol. 46, no. 11, pp. 1485-1496, 2000.

[85] R. Gonzalez e G. Wu, "On the shape of the probability weighting function", Cognitive Psychology, vol. 38, pp. 129-166, 1999.

[86] D. Prelec, "The probability weighting function", Econometrica, vol. 66, no. 3, pp. 497-527, 1998.

[87] C. F. Camerer e T.-H. Ho, "Nonlinear weighting of probailities and violations of the betweenness axiom", Risk and Uncertainty, vol. 8, pp. 167-196, 1994.

[88] G. Wu e R. Gonzalez, "Curvature of the probability weighthing function", $M a$ nagement Science, vol. 42, pp. 1676-1690, 1996.

[89] M. Abdellaoui, "Parameter-free elicitation of utility and probability weighting functions", Management Science, vol. 46, pp. 1497-1512, 2000.

[90] A. Tversky e C. R. Fox, "Weighing risk and uncertainty", Psychological Review, vol. 102, pp. 269-283, 1995. 